\title{
SB 235
}

.U59

Copy 1

L E T T E R

OF THE

\section{COMVISSIONER OF AGRICOLTURE}

TO THE

\section{HON. JNO. W. JOHNSTON,}

CHAIRMAN OF THE COMMITTEE ON AGRICULTURE, U. S. SENATE,

on

\section{SORGHUM SUGAR.}

WASHINGTON:

GัOVERNMENT PRINTING OFFIOE。

1880 . 

[U.S. Iept of agriculture. Report no, 16. ]

\title{
L E T T E R
}

OF THE

\section{COMMISSIONER OF AGRICULTURE}

TO THE

\author{
HON. JNO. W. JOHNSTON,
}

CHATRMAN OF THE COMMITTEE ON AGRICULTURE, U. S. SENATE,

oN

\section{SORGHUM SUGAR.}

WASHINGTON :

GOVERNMENT PRINTING OFFICE。

1880 .

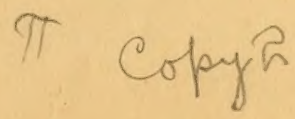


$S B^{23^{5}}$

159 
Department of Agriculture,

Washington, D. C., April 8, 1880.

Hon. JNo. W. JoHNSTON,

United States Senate:

SIR : I have the honor to acknowledge the receipt of your communieation of the 24th ultimo, inclosing Senate bill No.1514, and also the resolution introduced by Hon. A. S. Paddock, and adopted in committee, requesting the Commissioner of Agriculture "to furnish a written report giving all the information in his power in regard to the manufacture of sugar from sorghum and Chinese sugar-cane, its cost, the character and cost of the machinery necessary, \&c., together with statistics of the consumption and production of sugar in the United States and all matters bearing on the subject."

Replying seriatim to these inquiries, I submit the following, in some respects hastily-prepared, statement, which, while it is not as complete an answer to the resolution as I would desire to make, yet is as full as can be prepared in the limited time at my command.

The introduction and widespread distribution by the department of the variety of sorghum called Minnesota Early Amber (the juice of which is supposed to granulate more readily than that of many other varieties) has given a great impetus within the past two years to the cultivation of the sorghum cane and to the manufacture of sugar therefrom. It is earlier than any other known variety, ripening its seed in from ninety to one hundred days, and (as appears from reports made to the department, and in which are given the results obtained in almost every State in the Union) yields bountifully an excellent quality of sirup, besides, in many cases, good sugar, although all the operations reported, except the operation of F. A. Waidner \& Co. at Crystal Lake, Ill., were earried on with open-pan evaporation. It should also be remarked that these reports show that the farmers who have raised this variety of eane during the past year believe it to be better, from the quality of juice obtained, as well as from the quantity per acre, than any other variety previously cultivated. These opinions, however, are the opinions of farmers who have not had the opportunity to make comparative tests, and who compare the results with those obtained from former cultivation and manipulation, from their recollection rather than from note-books in which experiments have been carefully recorded.

We have now in the department some thirty-two varieties of sugarproducing sorghums and millets, all of which are valuable to a greater or less degree, according to the varying soil, climate, cultivation, seasons, and process of manufacture. That other valuable varieties of sorghum are to be obtained is altogether probable. The so-called Honduras sorghum is only one of the varieties native to the country of Honduras; and I have information that leads me to believe that there are several $1 \mathrm{AG}$ 
varieties growing in Central America and also at the mouth of Rio de la Plata, in South America. It is not impossible that varieties superior to any we now have may, in a few years, be common amongst us. It is of $\mathrm{h}$ e highest importance to the country at large that all obtainable varieties of cane should be carefully and scientifically examined; and, if possible, they should be grown in various soils and climates, that we may know which is best adapted to particular localities, which will give the best results for the least expense, and which, in the hands of the least intelligent, can be most easily manipulated.

For the northern part of the United States there is probably no cane so suitable as the Early Amber; and, perhaps, it might be said that no other variety would ripen sufficiently to yield sugar with certainty (although it might give good sirup) abore the latitude of Chicago. Below this latitude the Liberian might be planted as auxiliary to the Early Amber, while in the latitude of Saint Louis and to the south of it, Honduras sorghum should bo added to the other two varieties; thus extending the season for working the cane into sugar many weeks beyond the period that could be utilized in this way if but one kind of cane were planted-the Early Amber ripening in about ninety to one hundred days, the Chinese two weeks later, and the Honduras some five weeks after the Chinese, all being planted at the same time.

Illustrations of the seed-bearing tops of these different varities have been prepared for the forthcoming annual report of this department and are included in this reply, in inclosure marked $\mathrm{A}$.

At a meeting of the Northwestern Cane Growers' Association held in Minnesota last season, the subject of planting, cultivating, and harvesting Early Amber cane and of its manufacture into sugar was so thoroughly discussed that a résumé of the proceedings of that convention will probably give as much practical information on the question as can be condensed into the same space. The convention decided that as to the kind of seed to be planted in Minnesota there was no room for debate, the Early Amber being the only sort that would ripen in that high latitude; but the discussion of the characteristics of soil best adapted to the cane showed some difference of opinion as to the availability of new land. But for fuller information touching. these matters I would respectfully refer you to inclosure marked $B$.

The experimental work done at the department during the past two years in examining different sorghums has shown that old ideas in relation to the habit of the different varieties of this plant need to be corrected in many respects. The chemist of the department has demonstrated that there is practically but little if any difference in the juice of different varieties; that all varieties produce sugar that can be easily granulated, if the cane be taken at the proper period of growth; and that the only important question yet to be determined is as to the variety that will yield the largest amount in a given soil and climate. The Early Amber, the Liberian, the Chinese, and the Honduras, planted the past year within the corporate limits of this city, all yielded excellent results, as will be seen from the following report of the chemist of the department, prepared for our annual report for 1879 not yet published:

Hon. W. G. LE DuC,

Commissioner of Agriculture:

SIR: I have the honor to "Ibmit the following results of our recent experiments in the manufacture of sugar from the stalks of corn, sorghum, and pearl millet, made at the Agricultural Department during the year 1879.

During the past season there have been made several series of investigations for the 
purpose of determining the development of sugar in the juices of several varieties of sorghum and of pearl millet, and the results are such as to warrant their being given to the people at the earliest opportunity.

These investigations appear to demonstrate that there exists little difference betwe en the various kinds of sorghum as. sugar-producing plants; and, what is quite a surprising result, each of them is, at a certain period of its development, nearly if not quite as rich in sugar as the very best of sugar-cane. It is a matter, also, of extreme practical importance that this maximum content of sugar is maintained for a long period, and affords sufficient time to work up a large crop. Another result of these investigations has been to satisfactorily explain the cause of repeated failure in the production of sugar during the past quarter of a century, and to give the assurance that in the future such failure need not attend this industry. For the purpose of making clear the above points, the results obtained in the laboratory and in out-ofdoor experiments are appended.

The varieties of sorghum grown and subjected to continuous investigation during the season were Early Amber, White Liberian, Chinese, and Honduras, and Pearl Millet. Besides the above there were made very many examinations of other specimens of sorghums and corn-stalks; all the results of which only confirmed the general principle above stated, viz, the practical equality and great value of every variety of this plant.

In the following table are given the results of the analysis of each of the plants in the successive stages of development. It will be observed that the amount of glucose (or uncrystallizable sugar) diminishes, and the amount of sucrose (or true cane-sugar) increases. It will also be observed that the plants differ widely in the date when the sucrose is at its maximum, but are alike in this, that this maximum is attained at about the same degree of rlevelopment of the plant, viz, at full maturity, as indicated by the hard, dry seed, and the appearance of off-shoots from the upper joints of the stalk. It is also to be observed that the heary frost of October 24, which was sufficient to produce one-half inch of ice, did not cause any marked diminution of sugar.

For purpose of comparison, analyses are also appended of three varieties of sugarcane received from Louisiana, which arrived in excellent condition, and doubtless fairly represented the average character of this famous sugar-plant.

It will be understood that the results of these tables are to be taken as a whole, since it was practically impossible to secure in each case specimen stalks for examination in the laboratory, the development of which in every case corresponded to the date when the plant was eut, and, therefore, it doubtless happened that plants taken from the same row upon September 15, for example, were in reality no further developed than those selected a week earlier, but taken as a whole the several series of analyses are convincing as showing the rate and progress of development of saccharine matter in the plant.

By reference to the tables it will be seen that the analyses made of the several sorghums under date of October 29 , were, after they had been subjected to a very hard frost, sufficient to have formed ice one-half inch in thickness, and this cold weather continued for four days before this examination was made.' As will be seen, there appears no diminution of sucrose in either of the stalks examined and no increase of glucose as the result of this freezing and continued exposure to a low temperature. The examination of November 8 was made after a few days of warm weather had followed this cold spell, and the influenee of this subsequent thaw is noticeable in the diminution of sucrose and the increase of glucose in each specimen examined.

From this it would appear that the effeet of cold, even protracted, is not injurious to the quality of the canes, but that they should be speedily worked up after freezing and before they have again thawed out. This is a matter of such practical importance that some experiments should be made to learn whether the sirup prepared from the juice of frozen cane differs from that prepared from cane not frozen but in other respects of like quality.

The Early Amber, Chinese, Liberian, and Honduras sorghnms and the Pearl Millet examined, mentioned as having been grown upon the department grounds, were all planted the same day, May 15, 1879.

The relative weights of the different kinds of sorghum experimented upon are as follows:

Pounds.

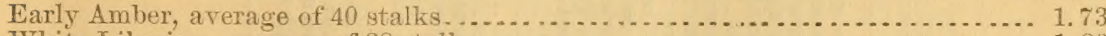

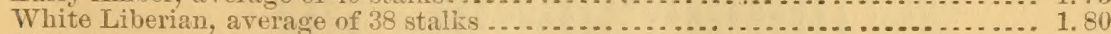

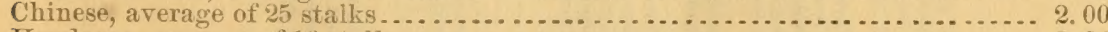

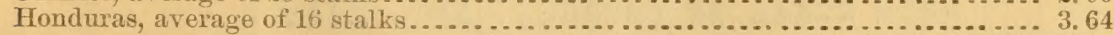

Since these were all grown side by side and upon land presumabiy of equal fertility, it will afford the data for calculating the relative amount of each variety to be grow $n$ per acre. 


\begin{tabular}{|c|c|c|}
\hline 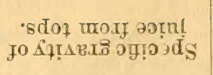 & - & \\
\hline 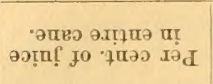 & 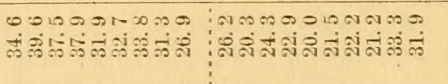 & 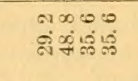 \\
\hline 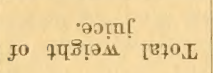 & 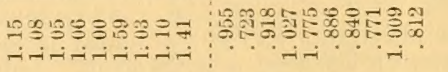 & 글 \\
\hline 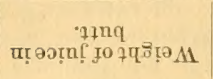 & 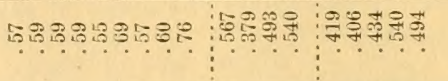 & : \\
\hline 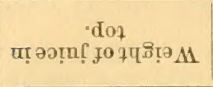 & 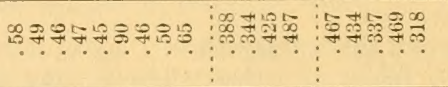 & : \\
\hline 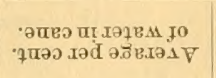 & 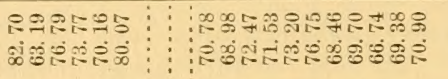 & 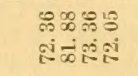 \\
\hline 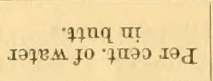 & 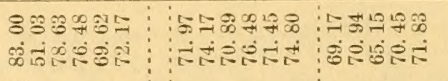 & 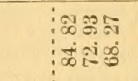 \\
\hline 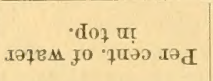 & 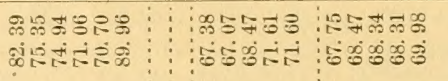 & 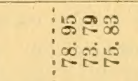 \\
\hline 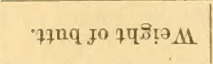 & : & : \\
\hline 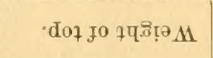 & 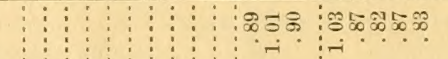 & : \\
\hline 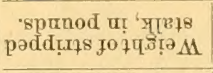 & 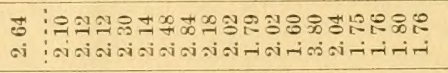 & 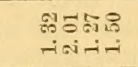 \\
\hline 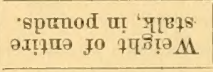 & 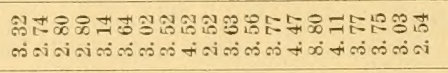 & 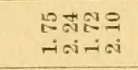 \\
\hline 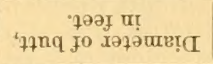 & 19.898 & 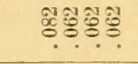 \\
\hline 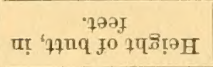 & 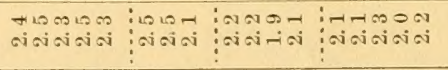 & 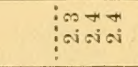 \\
\hline 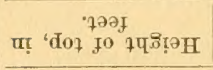 & 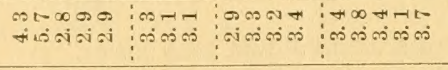 & $\begin{array}{lll}1 & \infty \\
\cos \infty & \infty\end{array}$ \\
\hline 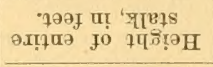 & 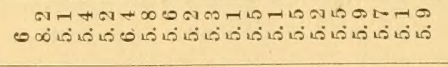 & 0000 \\
\hline 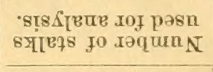 & 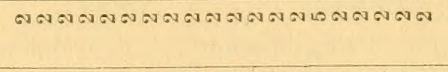 & \\
\hline 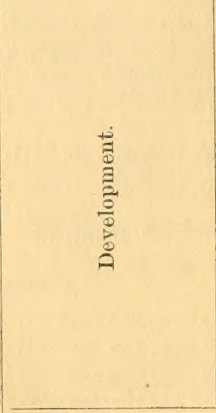 & $\begin{array}{l}0 \\
0 \\
0\end{array}$ & 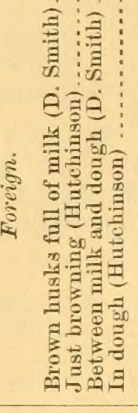 \\
\hline$\stackrel{0}{\stackrel{0}{\tilde{m}}}$ & 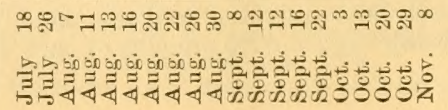 & ニッニッ \\
\hline
\end{tabular}




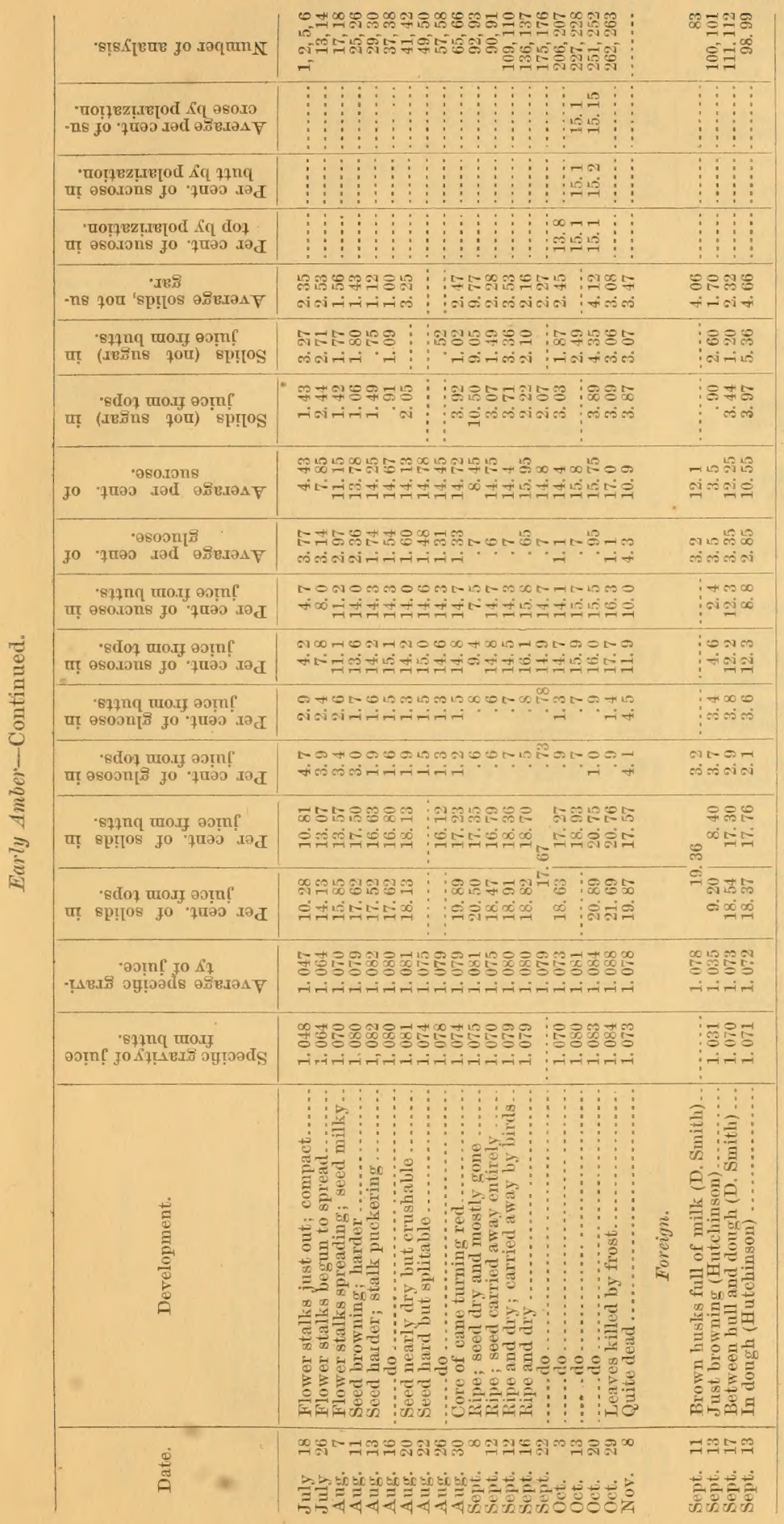




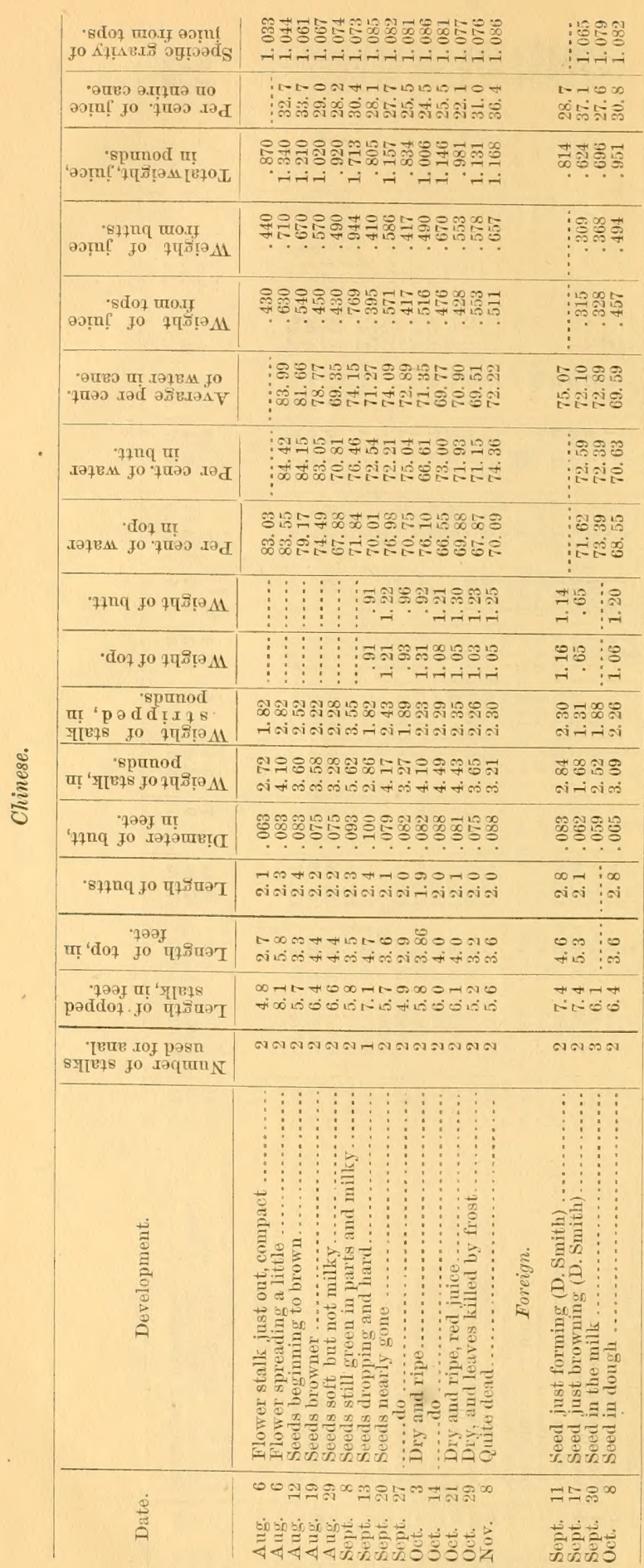




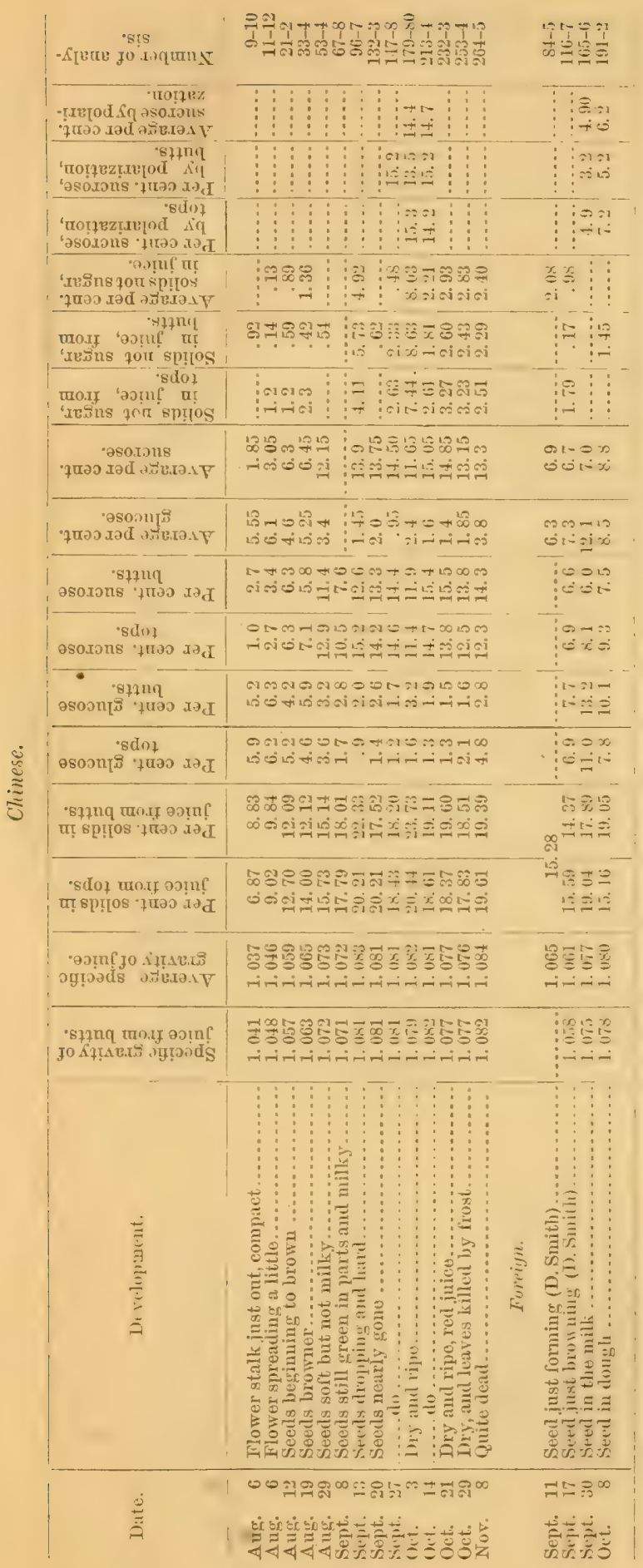




\begin{tabular}{|c|c|c|c|}
\hline 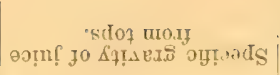 & 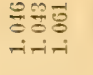 & 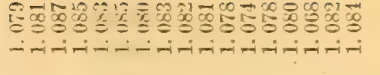 & 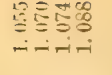 \\
\hline 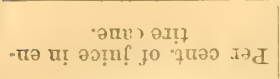 & $\begin{array}{l}+1 ? \\
\ddot{\leftrightarrow}: 0\end{array}$ & 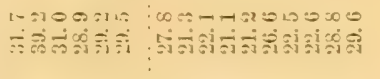 & 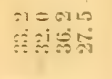 \\
\hline 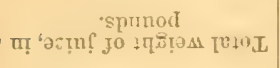 & $\begin{array}{l}9 \rho 0 \\
\text { rifi-i }\end{array}$ & 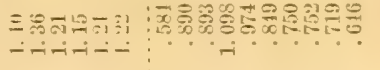 & 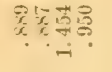 \\
\hline 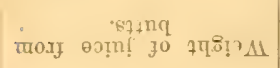 & $83 \pi$ & ㅇํ은 & \\
\hline 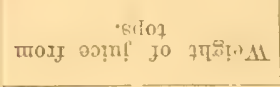 & 8919 & 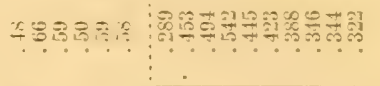 & $\equiv$ \\
\hline 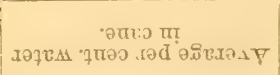 & 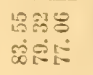 & 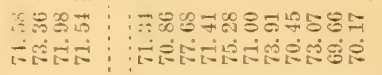 & 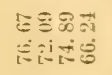 \\
\hline 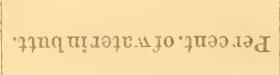 & 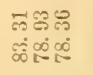 & 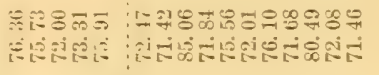 & 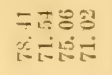 \\
\hline 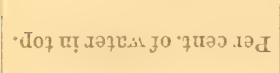 & 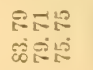 & 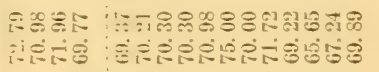 & 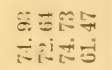 \\
\hline 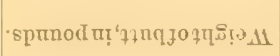 & & 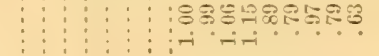 & 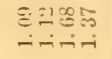 \\
\hline 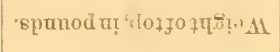 & & & $\begin{array}{l}\Xi ニ \\
\vdots\end{array}$ \\
\hline 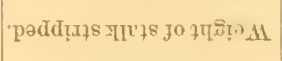 & 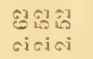 & 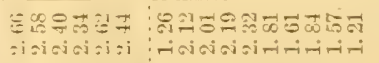 & 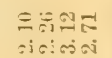 \\
\hline " & 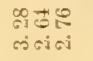 & 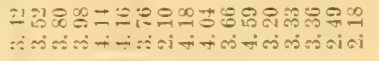 & 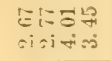 \\
\hline 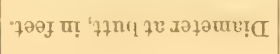 & 的 & 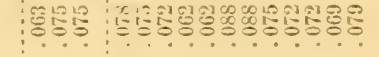 & \\
\hline 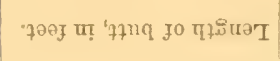 & $\begin{array}{l}\infty 100 \\
\operatorname{cici}=j\end{array}$ & 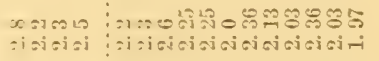 & $\begin{array}{l}\vdots \fallingdotseq 980 \\
\text { si=isici }\end{array}$ \\
\hline 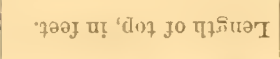 & $\begin{array}{l}\cos 250 \\
\cos 201\end{array}$ & 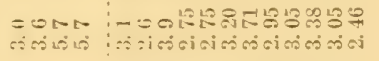 & $\begin{array}{l}=128 \\
-\because+7\end{array}$ \\
\hline 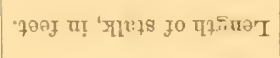 & 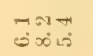 & 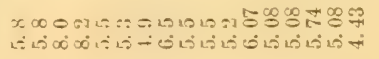 & 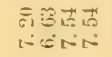 \\
\hline 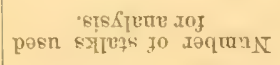 & 010301 & 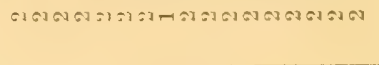 & $-\tau$ \\
\hline 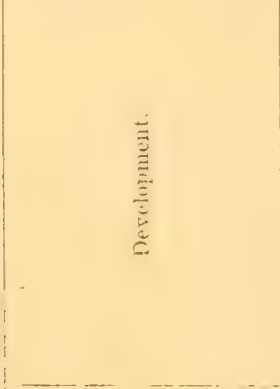 & 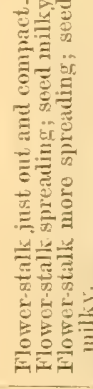 & 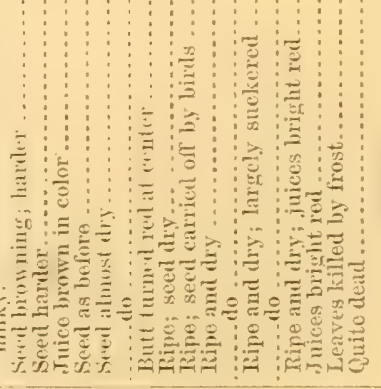 & 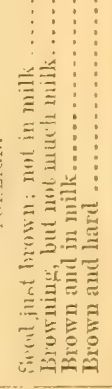 \\
\hline 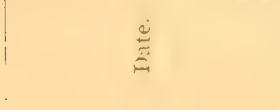 & 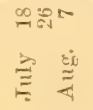 & 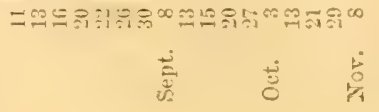 & 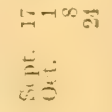 \\
\hline
\end{tabular}




\begin{tabular}{|c|c|c|c|}
\hline 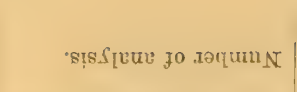 & \multicolumn{2}{|c|}{ 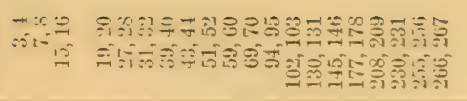 } & 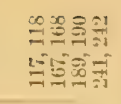 \\
\hline 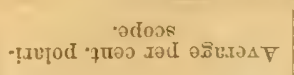 & & & \\
\hline 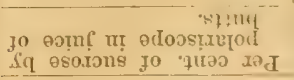 & & & \\
\hline 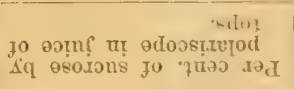 & & & \\
\hline 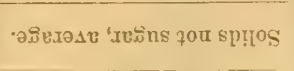 & $\because$ & 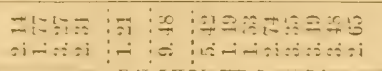 & $\vec{t}$ \\
\hline 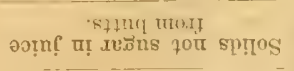 & 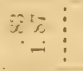 & 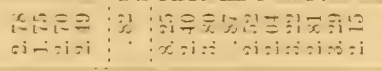 & $\overrightarrow{0}$ \\
\hline 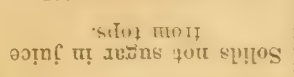 & $\equiv$ & 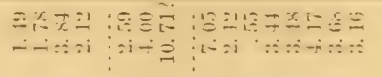 & 3 \\
\hline 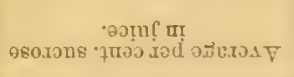 & $\begin{array}{ll}\because r O \\
\therefore-O\end{array}$ & 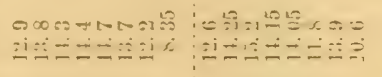 & 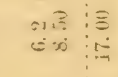 \\
\hline 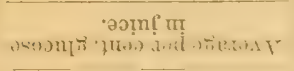 & $\therefore$ & 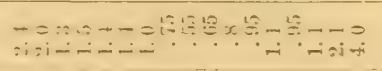 & 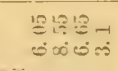 \\
\hline 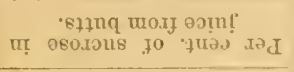 & $\begin{array}{l}n= \\
\therefore=\end{array}$ & 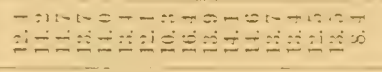 & \begin{tabular}{ll}
$\because 1$ \\
\hdashline$: 1$
\end{tabular} \\
\hline 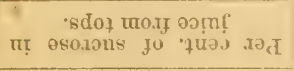 & $\begin{array}{l}0=0 \\
\dot{r} \rightarrow \vec{i}\end{array}$ & 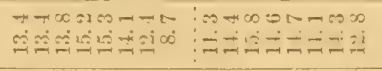 & 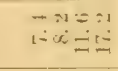 \\
\hline 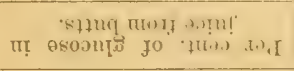 & $\begin{array}{l}=\approx x \\
\therefore \in i \leq i\end{array}$ & 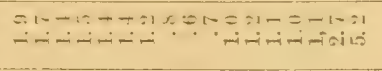 & $\because 8$ \\
\hline 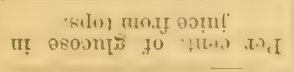 & $\begin{array}{l}01510 \\
15+\infty\end{array}$ & 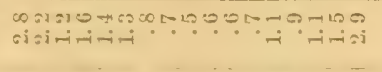 & \\
\hline 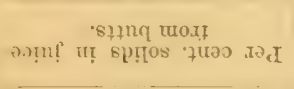 & 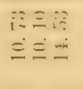 & 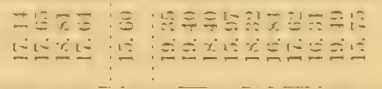 & 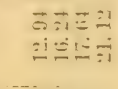 \\
\hline 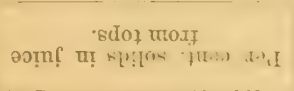 & 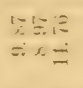 & 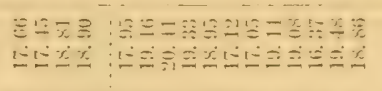 & 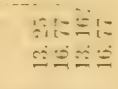 \\
\hline 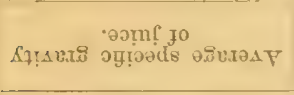 & 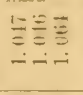 & $\begin{array}{l}6-1 \\
-1-2-1\end{array}$ & 等垔要 \\
\hline 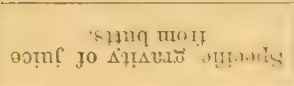 & $\begin{array}{l}x+x \\
=\end{array}$ & 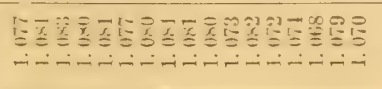 & 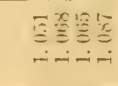 \\
\hline 竞 & 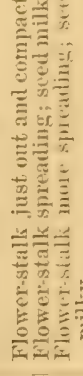 & 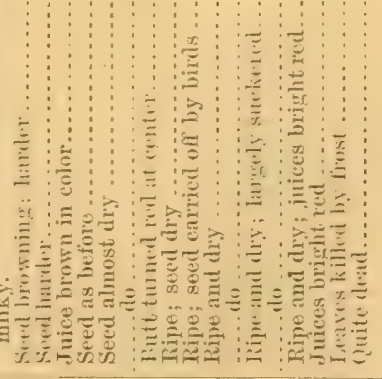 & 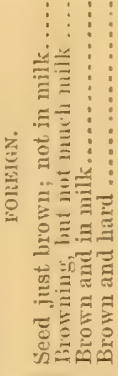 \\
\hline 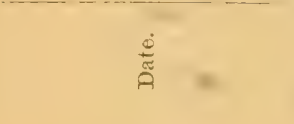 & 里言保 & 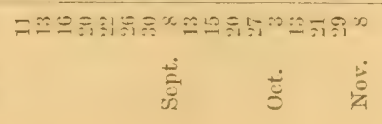 & 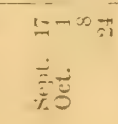 \\
\hline
\end{tabular}




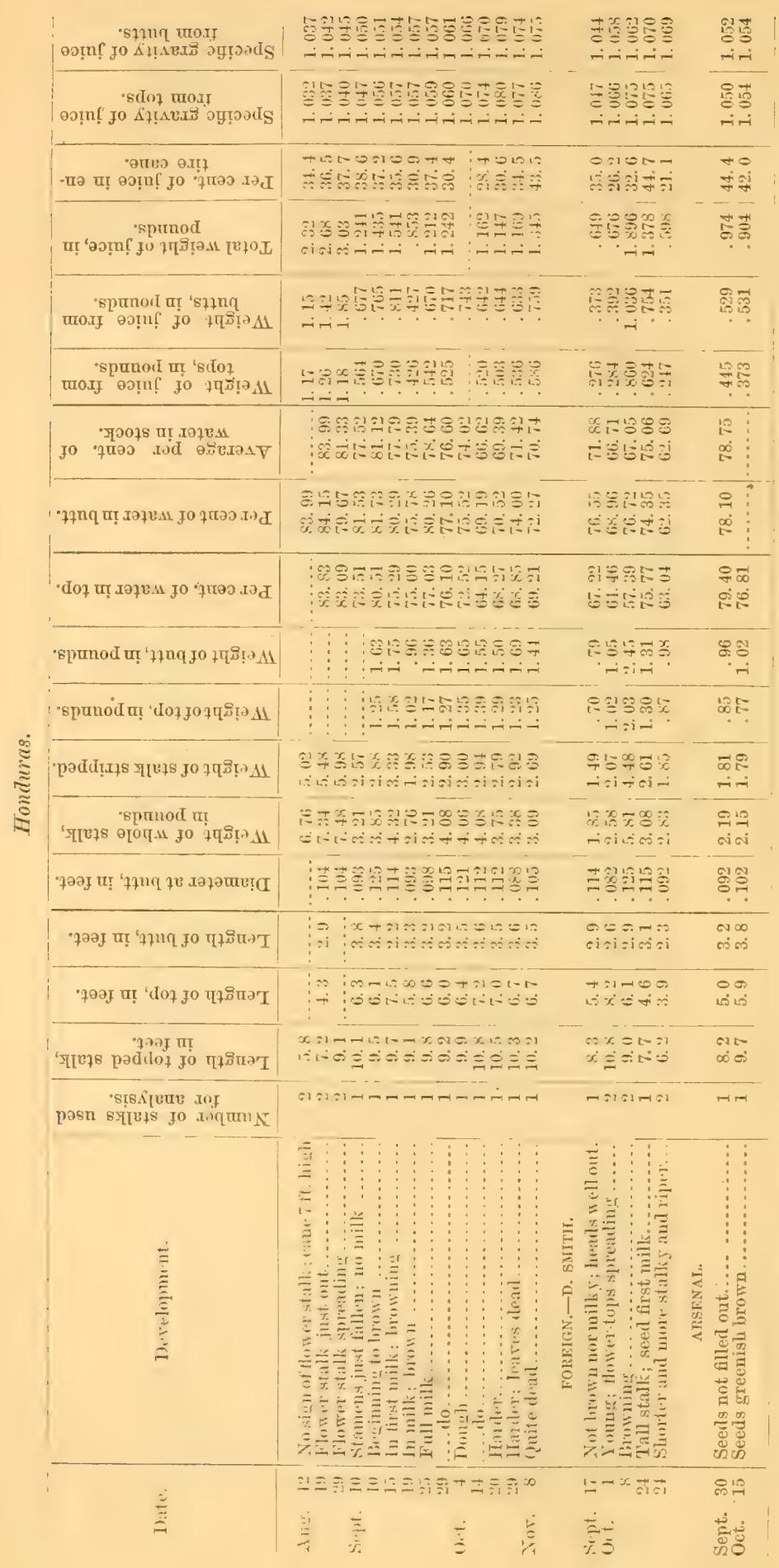




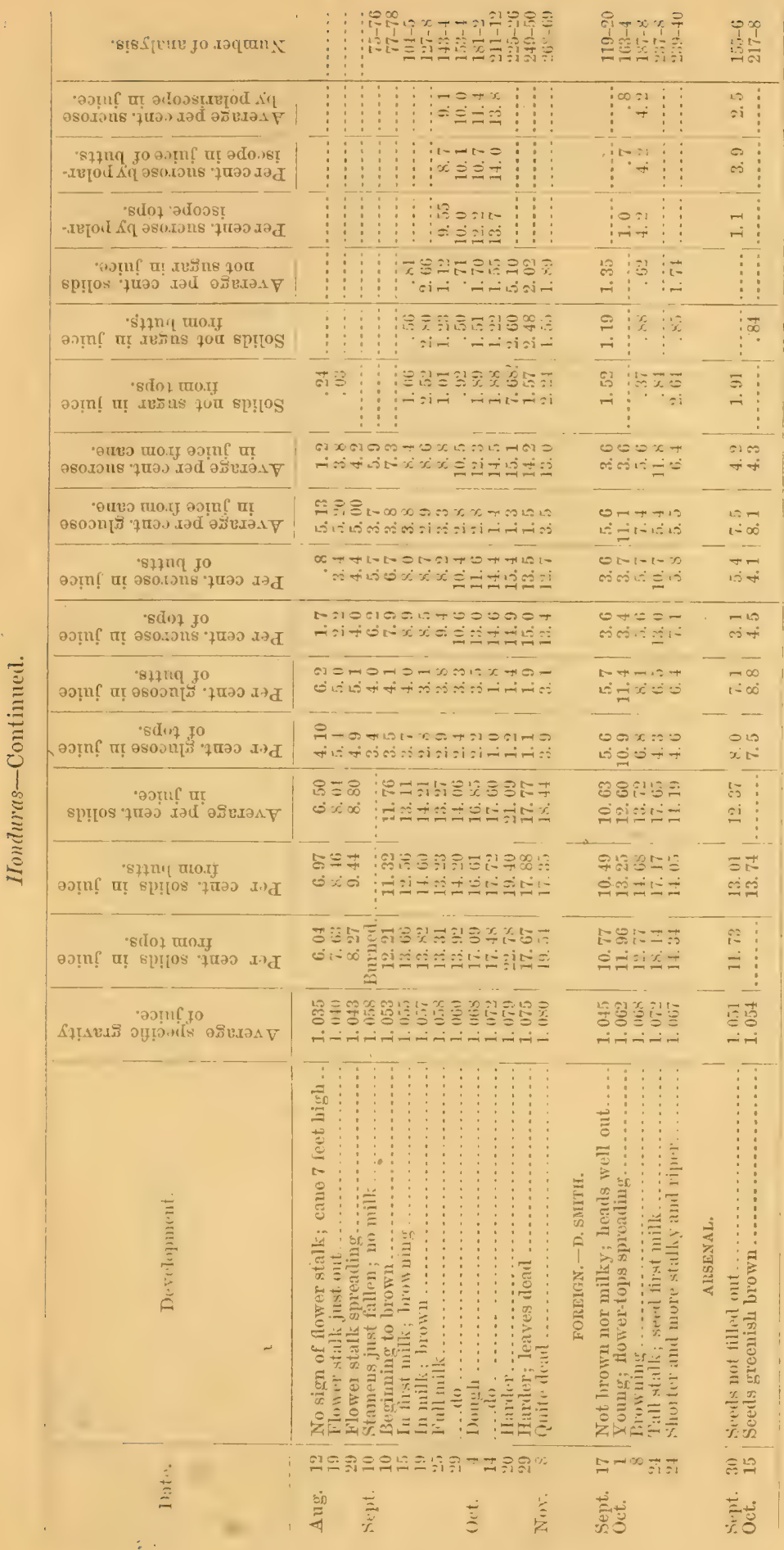




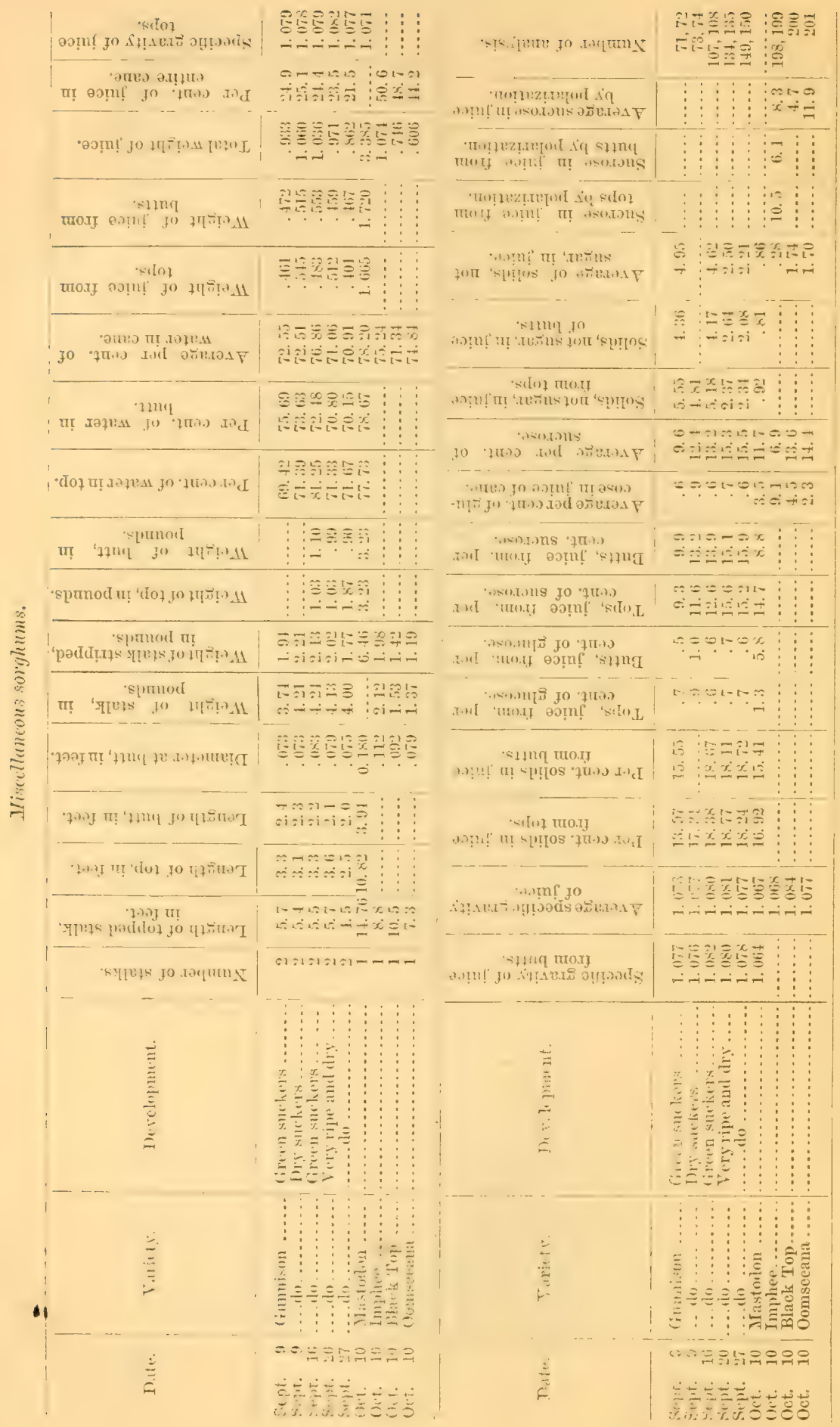




\section{3}

A

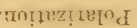

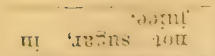

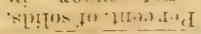

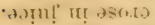

-ns jo mina and

क.

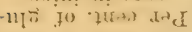

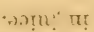

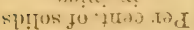

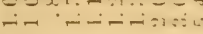

ㄴ..…

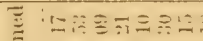

吅

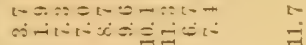
$0.0 \times 1:-91: 2==\rightarrow \quad$ L?

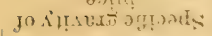

- क

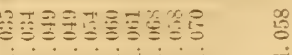

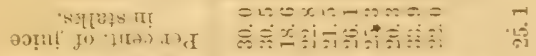

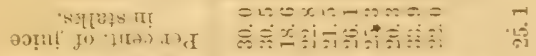

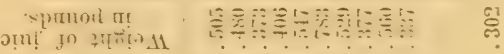

ताrm

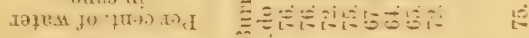

\begin{tabular}{|c|c|c|}
\hline 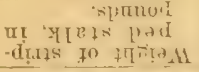 & 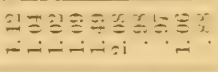 & 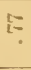 \\
\hline 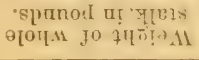 & 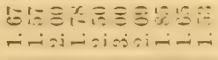 & \&i \\
\hline 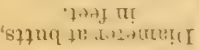 & 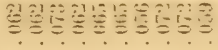 & 8 \\
\hline 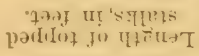 & 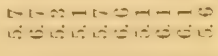 & เo \\
\hline 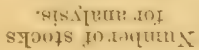 & 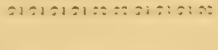 & 01 \\
\hline
\end{tabular}

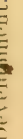




\section{4}

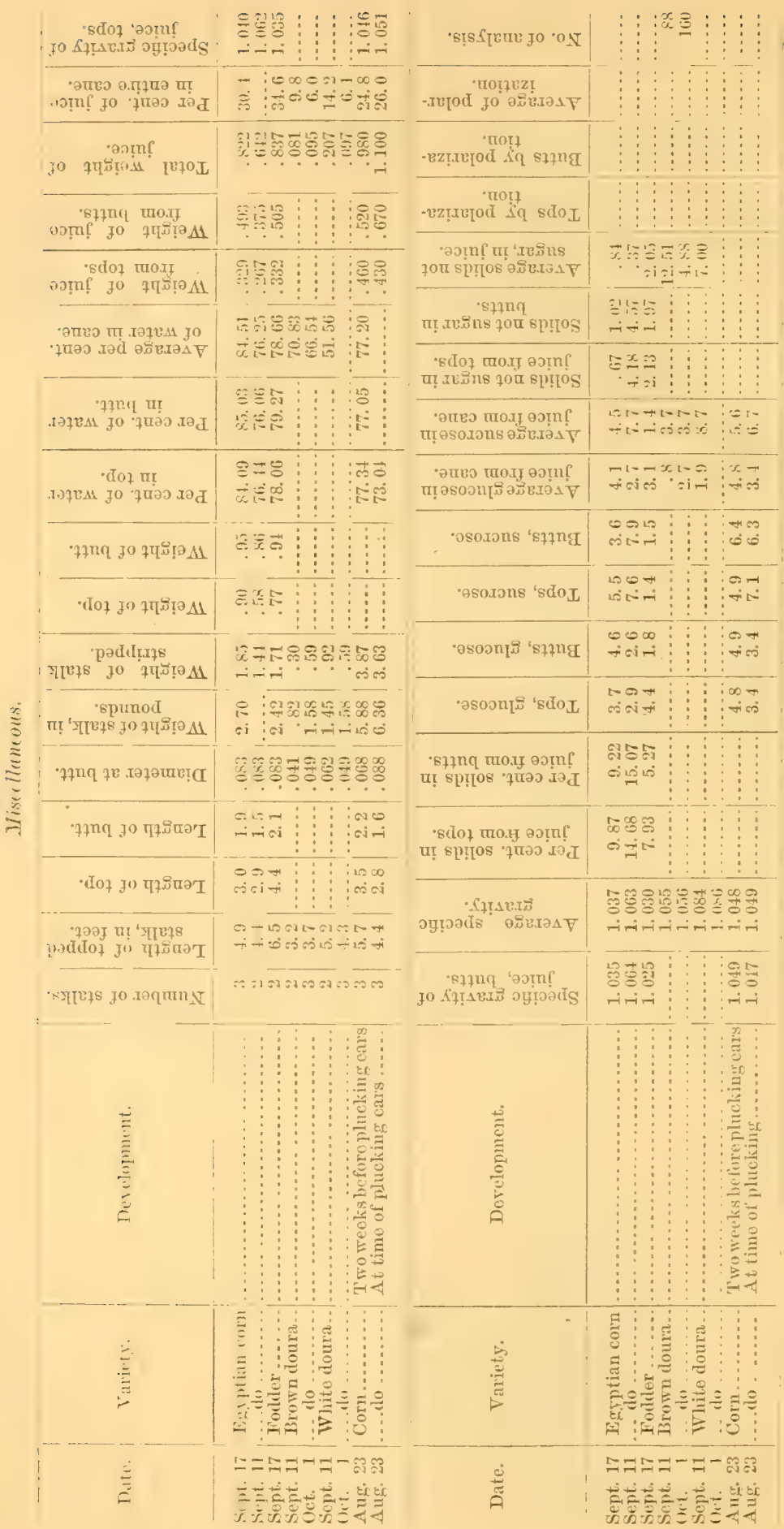


ณ๖ร: :

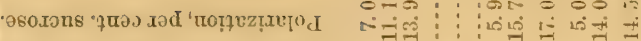

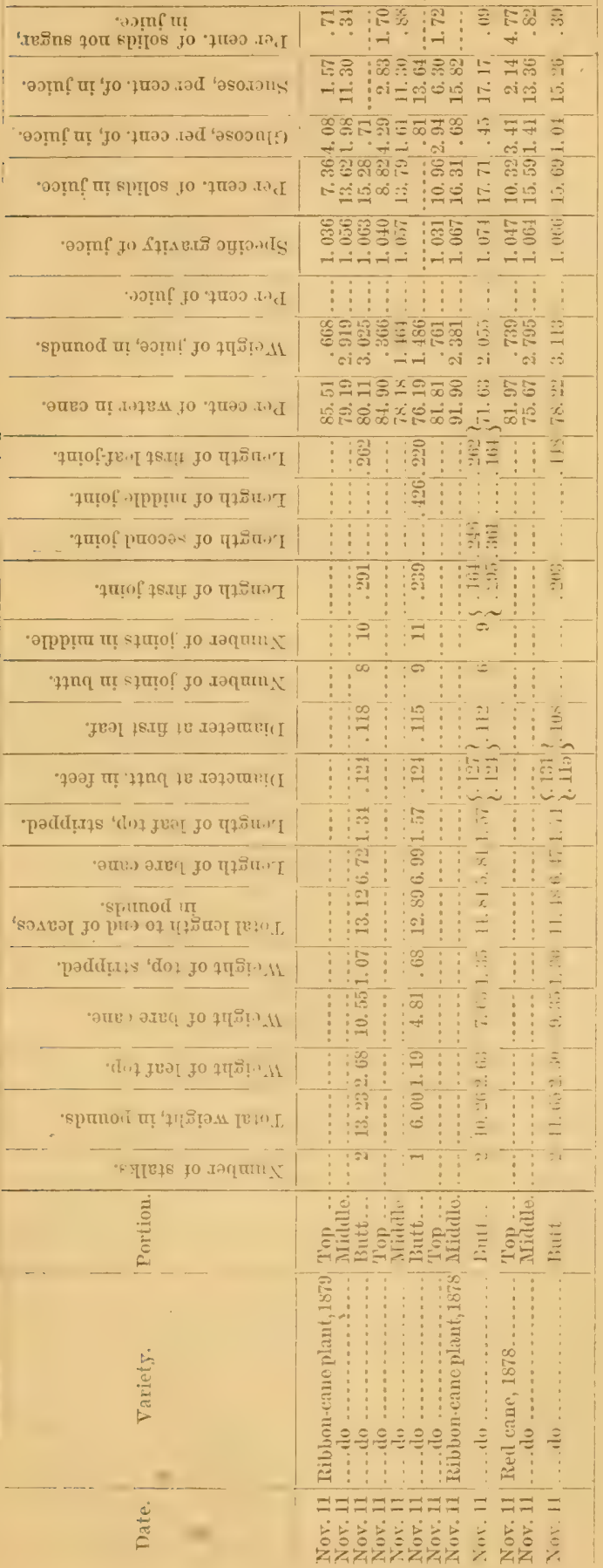


For purpose of further comparison the following analyses of sugar-canes and juice of the sugar-cane grown in Madras, India, are given below. The canes were divided into upper, middle, and lower thirds, each third being 2 feet in length, except tho lower thirds of the selected canes, which were 3 feet in length.

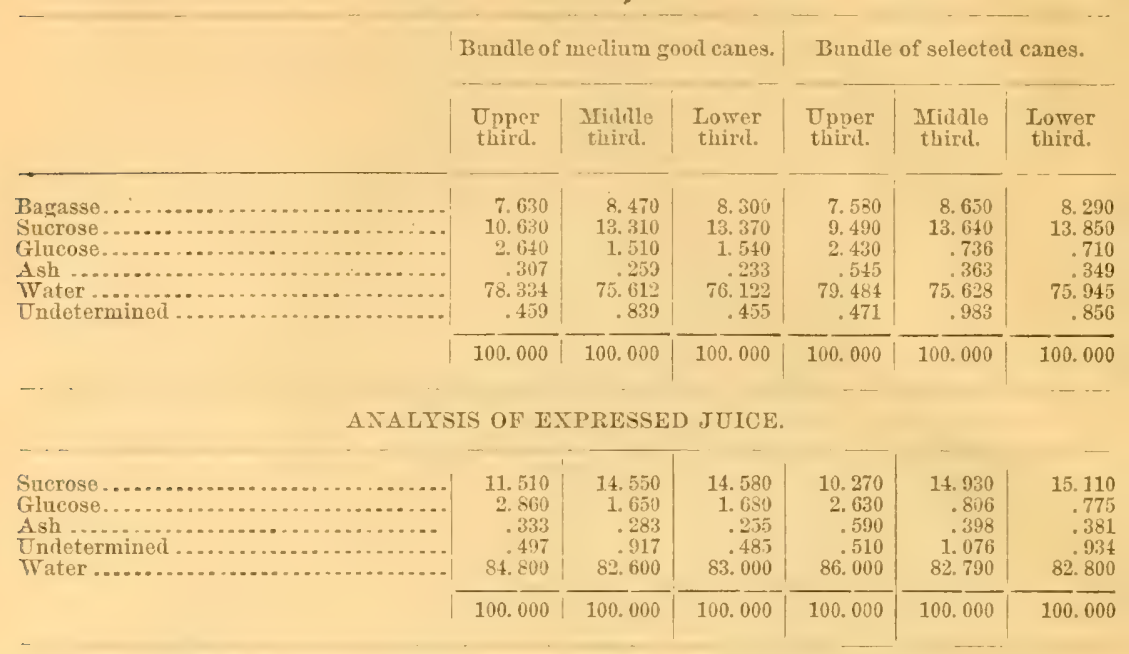

Cherr. Cent. Buatr., February, 1880.

For more clearly presenting the facts developed by the examinations of the four kinds of sorghmm, the following chart represents graphically the foregoing results:

It will be observed how closely the Early Amber and Liberian correspond in their development, being almost identical, and yet being clearly distinct varieties. It will also be seen that while these two varieties attain a content of sugar in their juices equal to the average content in the juice of sugar-eane by the middle of August, the Chinese does not reach this condition until the last of September, while the Honduras does not reach this noint until the middle of October.

It will be seen also that after having attained approximately the maximum content of sugar, this condition is maintained for a loug period, affording ample time to work in the crop.

It is doubless true that had the season been longer it would have been found that the Chinese and Honduras having once attained this full development of sugar would also have retained it; but, as is seen by the cliart, the heary frosts and subsequent warm weather which happened about Novenber 24 , caused a rapid diminution of sucrose in each variety, aud a corresponding increase in glucose.

'The converse of what is found true of the sucrose is elearly shown as to the devel. opment of the glucose, and it is seen that a minimum quantity once attained is continued a long time, and that this minimum is quite as low as the average amount foutd present in the sugar-canes.

It is obvious that the results depicted upon the chart are not to be taken as ontirely exact, but the general fact represented is without doubt true, and with a still larger number of observations the approach to true curves would be found nearer than here represented.

The line representing the arerage per cont. of sucrose in sugrar-beets is from the results of analysis of thirteen specimens of sugar-beets grown upon the Agricultural College farm, Amherst, Mass., and analszed by Professor Groessminn (vide Mass. Agric. Rept., 1870-'71).

An average of all the examinations made of these four sorghums during these periods when they were suitable for cutting gives the following results:

Early Amber, from August 13 to Oetobor 29 inelusive, 15 analyses oxtending over 78 days, 14.6 per cent. sucrose.

Liberian, from August 13 to October 23 inclusive, 13 aualyses, extending over 78 days, 13.8 per cent. suerose.

Chinese, from September 13 to October 29 inclusive, 7 analyses, extending ovor 46 days, 13.8 per cent. sucrose.

Honduras, from October 14 to October 29 inclusive, 3 analyses, extending over 16 days, 14.6 per cent. sucrose.

Besides the investigations above mentioned, there have been made 35 experiments 



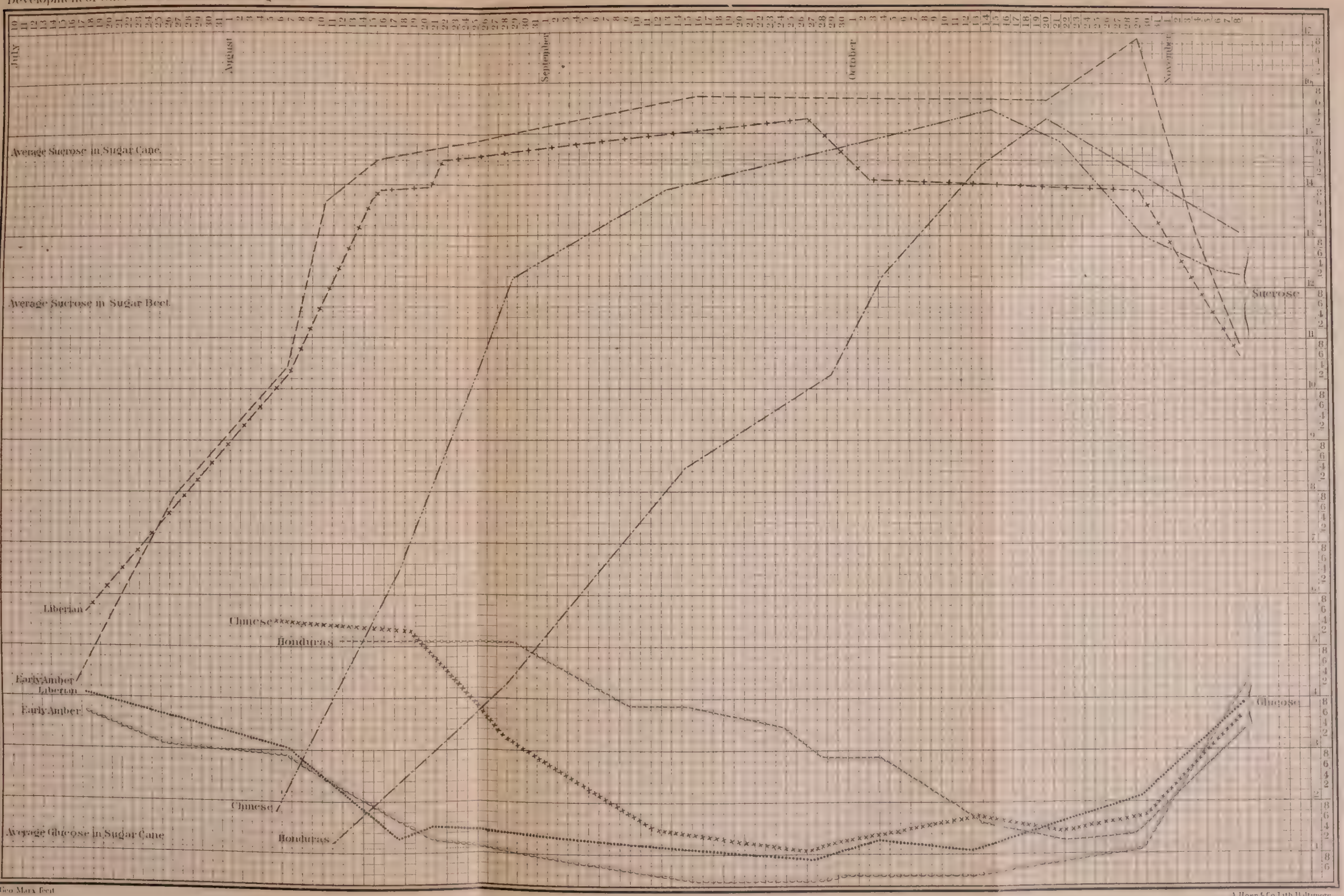



in waking sugn from comstalks, sorghums, pearl millet, \&c., in all of which there have been used over 23 toms of stalks. The result of these experiments has been to fully confirm all the experiments of the prerious year, not only, but also to help towards the solution of certain questions of the highest practical importance. In every case it has leew foumd that tho quality of the sirup obtained has been precisely such as the previous analysis in the laboratory of the juice nsed made probable. Au average of the nine best sirups obtained showed a percentage of eane-sugar present erumal to 92.7 of the amount origrinally present in the juice, while an average of the nime poorest (i.e., containing the lowest percentage of cane-sugar) showed a percentage of cane-sugar present eriual to 90.1 of the amount present in the juice.

This must not be understood to menu that there has been no loss of sugar in the process of manufacture, as such conchsion would be quite erroneous, as will be seen by consulting tables further on in this report.

Below are given the detailed results of 33 experiments in the making of sirups from sorghum, pearl millet, and cornstalks, and analyses of tho juices from which these sirups were made. These stalks were obtained from neighboring farmers, and, as will be seen, were never in the condition best suited for working, but the results obtained from them are, however, of great practical value, and aro given in detail.

The last column represents the relative loss of sucrose in malking sirup, as compared with the glucose presdnt, but gives no indication as to the alosolute loss which may have been incurred, and since the ecouomical production of sugar largely depends unon the amount of this loss, this matter is cliscussed more fully in another place. 


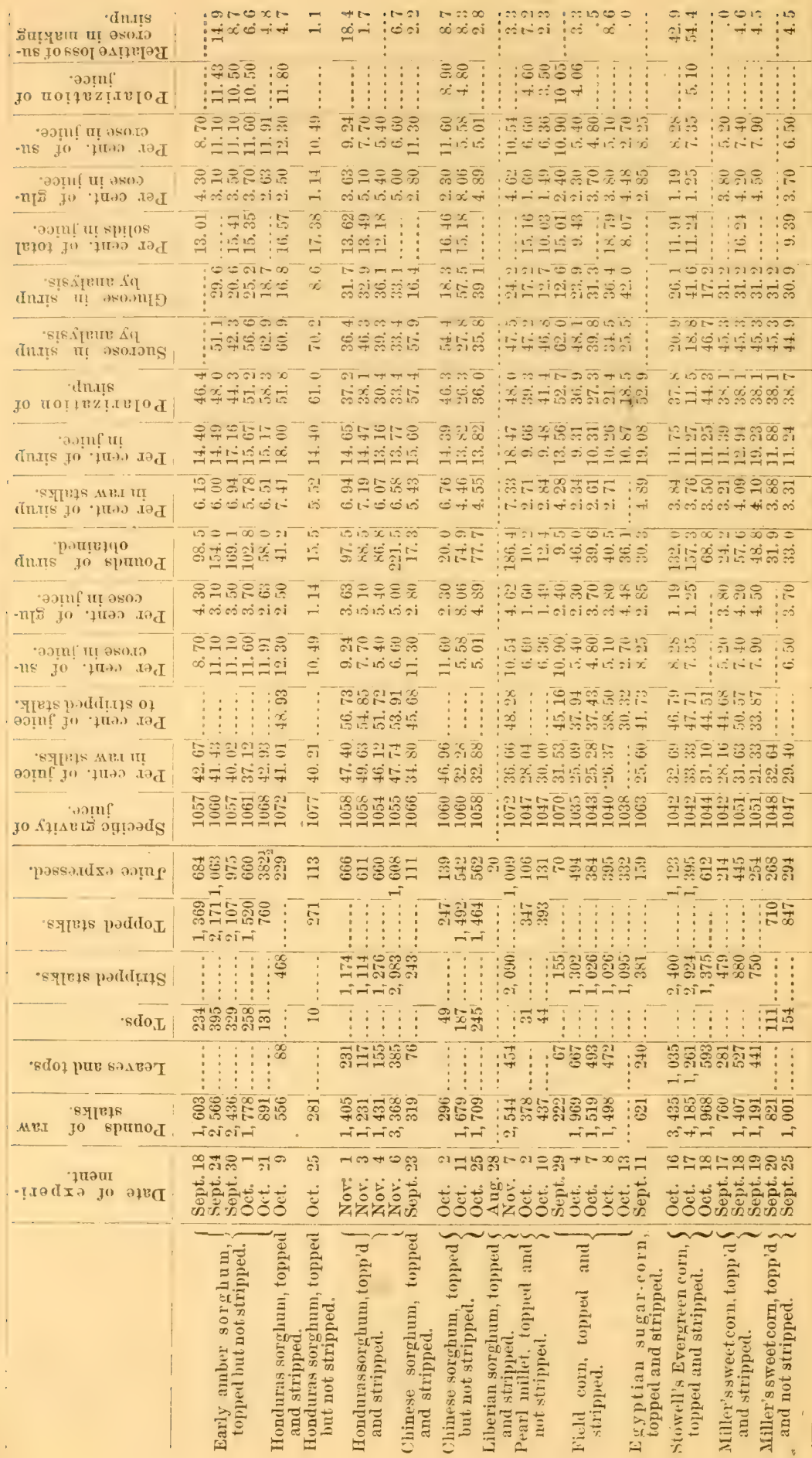


The apparatus used in the experiments, besides a fow barrels and pails for holding the jnice, consisted of a copper tank of the following dimensions: 4 feet 3 inches long, 2 feet 3 inches deep, 2 feet 3 inches wide; a galvanized iron pan 9 feet long 8 inches deep, 3 feet 6 inches wide. This iron pan was surrounded by a wooden frame of Einch plank so as to support the sides, and each pan was placet in brickwork with chimney, and so arrangen as to permit a fire to be kept beluw it in direct contact with the bottom. In the case of tho copper tank the flame played about the sides also, so as to heat the contents more rapidly. The ralvanized iron pan was such as could readily be constructed by any ordinary tinsmith or mechanic. The copper tank was used for defecation with lime; the galvanized iron pan for evaporation. The process, in brief, is as follows: after topping and stripping the corn or sorghum, it was passed through the mill, and when sutficient juice had been obtained it was heated in the copper tank to a tempernture of $82^{\circ} \mathrm{C} .=180^{\circ} \mathrm{F}$. After the juice had reached this temperature, there was added to it, with stirring, crean of lime, until a piece of litmus paper dipped in the juice showed a purple or bluish-purple color. The heat was now raised to the boiling point, and, so soon as the juice was in good ebullition, the fire was drawn and a thick scum removed from the surface of the juice. After a few minntes the sediment from the juice subsidect, and by means of a siphon the clear liquid. was decanted off, leaving a muddy sediment, which was equal to abont one-tenth to one-twentieth of the bulk of the juice. It was found that by means of the stop-cock at the bottom of the defecator, it was possible to draw off the clarified juice more thoronghly than by menus of the siphon, so that this method has been adopted for removing the juice. It is only necessary to eollect in a separate ressel the first portions of juice coming from stop-cock, which are turbid, aud passing this through the bag filter with the sediment. This mudly sediment was then drawn off br means of a stop-cock and filtered through a plaited-bag filter, and the clear filtrate therefrom was added to the liquid previously siphoner off. The elarified juice, which. cluring the above operation, is not allowed to cool below a temperature of $66^{\circ} \mathrm{C}$. or $150^{\circ}$ F., was now emptied into the evaporating pan, and there was added to it, with stirring, a solution of sulphurons acid in water until the lime present was nontralized, as was shown by the reddening of litmus paper when it was dipped in the juice. The cvaporation was now liasteued as nuch as possible, and the juice concentrated to a sirup at a boiling point of $112^{\circ} \mathrm{C}$, equal to $2: 34^{\circ} \mathrm{F}$, or thereabout. During the close of the evaporation there is great danger of scorching the sirup, and this was obviated by allowing only coals beneath the ovaporator and briskly stirring the syrup by means of paddles 8 or 10 inches wide. When the sirup reached the density above indicated it was drawn oft into wooden tubs, the fire having previously been drawn from beneath the evaporator.

It is doubtless true that many failures result in securing a crystallizable sirup even from good juice, owing to the operations of pressing of the cane, defecation, and evaporation being too much protracted. In order that those wishing to enter upon this inclustry may know what is practically attainable, even with common appliances, the following data are given.

In experiment No. 3, 2,107 pounds of topped stalks of Early Amber cane were pressed by the mill in $3 \frac{1}{2}$ hours, yielding 975 poumds of juice. The time required for heating the jnice, defecation with lime, and evaporation to sirup was $5 \frac{9}{4}$ hours. In order that the inferior eharaeter of the material supplied for these experiments might bo known, specimens were taken from the seremal lots of stalks in experiments Nos. 1, 2, 3, 4; and it was found that the average weight of the stalks in these lots was four ounces each.

In most of the experiments above recorded the juice was raised to the temperature of $82^{\circ} \mathrm{C}$. (188 F.), and then neutralized with mills of lime, but several experiments were made to learn the effect produced by neutralization with lime at different temperatures.

In experiment No. 4 the juice was divided into two portions, and the lime was

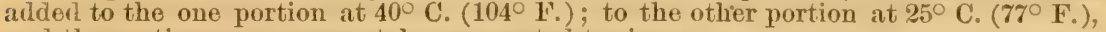
and the portions were separately evaporated to sirup.

In experiment No. 13 the lime was added directly after the juice was obtained from the mill, the temperature being $16^{\circ} \mathrm{C} .\left(61^{\circ} \mathrm{F}\right.$. $)$.

In experiment No. 18 , the lime was added at $80^{\circ} \mathrm{C} .\left(176^{\circ} \mathrm{F}\right.$.).

In the above-mentioned experiments the results were entirely satisfactory, and seem to indicate that the neutralization by means of lime may be effected at any stage below $820 \mathrm{C}$. No experiments were made in neutralizing at higher temperature than $82 \circ \mathrm{C}$.

An experiment was also made to determine whether splitting the canes before they were passed through the mill would increase the percentage of juice obtained from the stalks. One hundred pounds of butt ends of Honduras sorghum were split lengthwise and then passed through the mill. Another parcel of one hundred pounds of luntts of the same variety of sorghum, equal in all respects to the provious lot, was passed through the mill without splitting them. The results obtained were as follows: Percentage of juice obtained from split stalks, 54 per cont.; percentage of juice 
obtained from unsplit stalks, 57 per cent., from which it womld appear tinat in this case, at least, the previous splitting of the stalks occasioned an appreciable loss in juice.

In plate 27 the apparatus used in these experiments is figured, showing the relative position of mill, pans, \& $\mathrm{c}$.

Two pans only are representel as being in use, viz: the defecating pan upon the left land in the wood-ent and the evaporator upon the right hand. The stop-cocks by which the contents of the defecating pan are remored is not shown in the plate, being concealed by the small evaporator in front. A space of about two feet separates the brick work underneath the several pans, permitting one to pass easily about them.

The apparatus represented in the rear is used for making sulphurous acirl solution, and consists of a small-sized hot water tank for kitehen range, about 40 inches loug and 10 inches diameter. Into this powdered charconl and oil of vitriol are yut, and the sulphurous gas is passed through iron pipes into a wash-lottle containing oil of vitriol, and from thence into a barrel nearly filled with water. A safety tube is connected with the wash-bottle to prevent any possible rushing back of the water into the generator in case of the withdrawal of the heat. By this apparatus a barrel or two of the solution may be made in a short time and at an exponse not over 75 cents per barrel. For two barrels there would be required 75 pounds of oil of vitriol and 7 pounds of powdered charcoal.

A few of the experiments male give a reasonable basis for estimating the probable vield of sirup and sugar to the acre; and, therefore, an approximate estimate of the cost of produeing sugar.

Below is a tabulated result of a few of the experimeuts from stalks grown upou the grounds of the department. These stalks were grown in rows 3 feet apart, and in irills, and although a good crop, there is no doubt but that moon good land the estimated yield to the acre could be obtained:

$\ldots$
$\ldots$

The first and second columins give the results actually secured, but the several juices were not in their best condition as compared with the results given in the first table. The third column is the amount of sirup the same weight of stalks would have yielded had they been ent at the proper time. The juice obtained from the stalks by the imperfect means at command of the department was little more than half the amount present in tho stalks.

The fourth colmun represents the results attainable by the use of a mill that would give 70 per cent. of juice from the stalks; a result which is possible, and which is claimed by manufacturers of mills.

There is 10 doubt but that, when the present industry shall lave secured the employment of the capital and scientific ability which has developed the beet-sugar industry, even these results, which may appear extravagant to maus, will be assured.

Although, as has been stated, these sirups wero obtained from stalks in which the maxinum content of sugar had not yet been developed, they did, howover, all erystallize well, and all yielded excellent sugar.

At the present the sugar has been separated from but the Chinese sorghum sirup, which yielded in the first crop of erystals 54.7 jer cent. of its weight in sugar; the Eariy Amber sirup, which yielded 47.5 per cent. of sugar; and from the lield-corn sirup, which fielded 39.3 per cent, of sugar. 'lhis latter experiment is worthy of especial mention, since the result secured is not only most surprising, bnt contrary to an almost universal belief. The corn-stalks used were of three rarieties: Lindsay's Horse Tooth, Improved Prolific, and White Dent; three coarse-growing white field corns. The stalks grew in drills 3 feet apart, and about 9 or 10 inches apart in the drill. The ears were plucked after they had thoroughly ripened, and the husks were dead and dry. The corn was plump and somd, and yielded at the rate of 69,1 bushely of shelled corn ( 56 pounds to the bushel) to the acre. The stalks were then topped, stripped, and crushed, and the juice proved to bo the best juice yet obtainel from corn-stalks, at any period of growth or of any variety. 
Below aro given the rosults of the examination of the stalks of Egyptian sugar-corn, Honduras and Early Amber sorghums, and the leaves from the same. This examination was made for the purpose of determining the loss of sugar in the method employed in its extraction, also to determine the relative nutritive value of the leaves and stallis, pressed and muressed. The stalks selected were split lengthwise, so that a fair average might be taken, and ono-half was dried thoroughly without pressing, and the other half was passed through the mill, and the bagrisse, or pressed stalks, carefinlly saved and dried.

Leaves, stalks, and bagasse from corn and sorghums

Egrptian sugar-corn, leaves

Egyptian sugar-corn, one-half of 4 stripped stalks, unpressed Egyptian sugar-corn, one-half of 4 stripped stalks, pressed ...

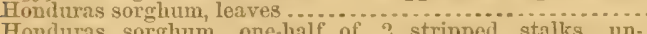

Honduras sorghum, one-half of 2 stripped stalks, un- 1,428
prossed.

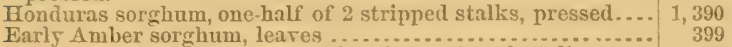

Early Amber sorghum, one-half of 3 stripped stalks, unpressed.

Early Amber sorghum, one-lialf of 3 stripped stalks, pressed.

\begin{tabular}{|c|c|c|c|c|}
\hline 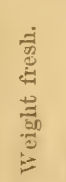 & 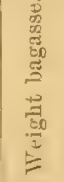 & 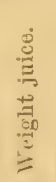 & 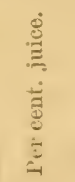 & 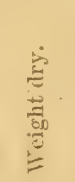 \\
\hline $\begin{array}{r}380 \\
832 \\
875 \\
432 \\
1,428\end{array}$ & \begin{tabular}{c}
460 \\
\hdashline.. \\
\hdashline
\end{tabular} & $\begin{array}{l}415 \\
\ldots . . \\
\end{array}$ & 47.43 & $\begin{array}{r}116.6 \\
126.0 \\
99.0 \\
100.8 \\
285.3\end{array}$ \\
\hline $\begin{array}{r}1,390 \\
399 \\
651\end{array}$ & $\begin{array}{c}724 \\
\ldots \ldots \\
\cdots\end{array}$ & & 47. 91 & $\begin{array}{r}222.7 \\
99.7 \\
157.9\end{array}$ \\
\hline 905 & 458 & 447 & 49. 39 & 147.8 \\
\hline
\end{tabular}

A determination of the proximate coustituonts of the dried leaves, stalks, and bagasse is given below, from which it will appear that there still remains a large amount of sugar in the bagasse which the process employed failed to remove from the cane or stalks, also that the per cent. of starch componnds is greater in the pressed than in the uupressed stalks, and that the percentage of nitrogenous matter romains nearly the same. Since the nutritive value of the pressed stalks is nearly if not quite equal to that of the umpressed stalls, weight for weight, and as they are left in a mechanical condition suitable for their preservation as green fodder by the system of ensilage, it would appear desirahle that experiments be made leading to their utilization for this purpose.

Proximate analyses of stalks, bagasse, and leaves of sweet com and sorghum, caleulated to the dry substance.

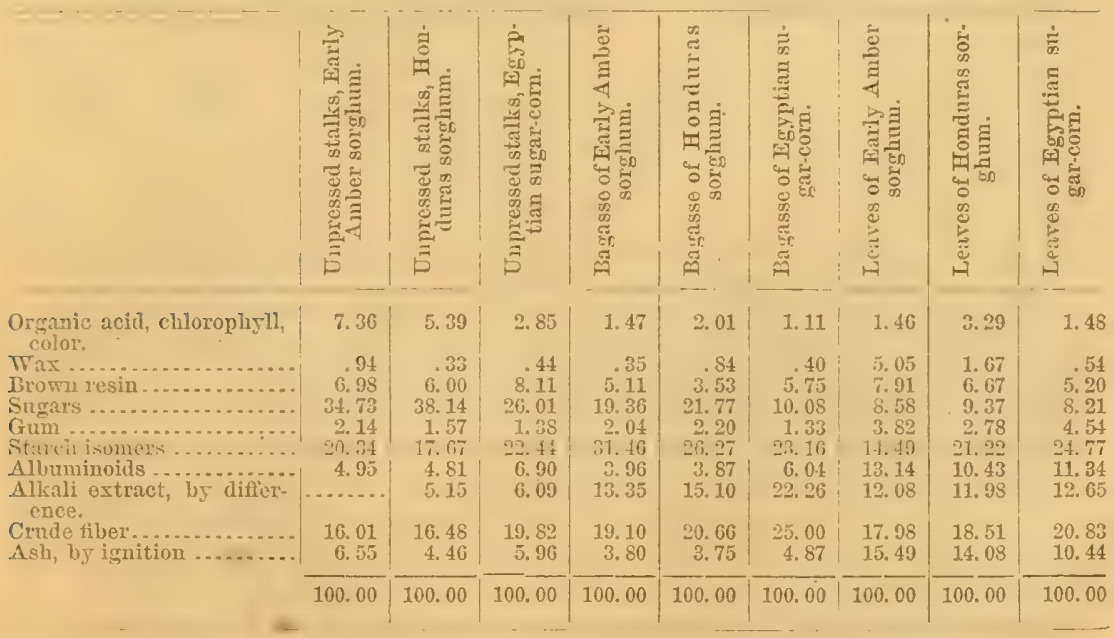


By reference to the two preceding tables, it will be seen that a very large porcent age of the sugar was lost by the method employed in its production.

The amount of sugar in the Early Amber cane, dry, is to the amount present in th Early Amber bagasse, Ary, as 100 is to 55.74.

In Honduras cane, dry : Honduras bagasse, dry : : $100: 57.08$.

In Egyptian sugar-corn, dry : Egyptiam sugar-corn bagasse, dry : : 100 : 38.75.

As will be seen from these analyses-

The Honduras eane, fresh, contained .............................. 7.62

The Early Amber cane, fresh, contained ..................... 8. 8 . $4 \%$

The Egyptian sugar-corn, fresh, contained... . . . . . . . . . . . . . . . . 3.94

while the sugar remaining in the bagasse, calculated to the fresh cane which produced these bagasses, gave as follows:

Per cent. sugar

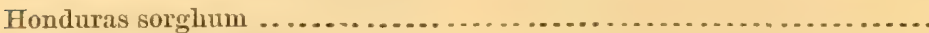

Early Amber sorghum ... . . . . . . . . . . . . . . . . . . . . . . . . . . . . . .

3.49

3.16

Egyptian sugar-corn ............................................ 1.14

In other words, it will appear that there was oceasioned a loss of-

46.4 per cent. of the sugar present in Honduras sorghum.

37.4 per cent. of the sugar-present in Early Amber sorghum.

28.9 per cent. of the sugar present in Egyptian sugar-corn.

'The importance, therefore, of' a good mill cannot be overestimated, and it is desir. able that efforts be made to devise some process by which results approximating those obtained in the extraction of sugar from beets shall be attained, since it is obvion that should the beet-sugar industry be couducted in so wasteful a manuer as is the production of sugar from cane or from sorghum, this important industry could no survive a year, even in those countries most favorably circumstanced in regard to the production of beet sugar.

For convenience the following results which were obtained last year are appeaded since these experiments were only confirmed this year, but the results have not beex tabulated.

In the experiments made with corn-stalks the stalks were invariably stripped, the tops being cut off' at about the second joint. 'The percentage of stripped stalks, leaves and tops is given in this table:

\begin{tabular}{|c|c|c|}
\hline Corn-stalks. & $\begin{array}{l}\text { Per cent. of } \\
\text { stripped } \\
\text { stalks. }\end{array}$ & $\begin{array}{l}\text { Per cent. o } \\
\text { leavesani } \\
\text { topis. }\end{array}$ \\
\hline $\begin{array}{l}\text { No. } 1 \\
\text { No. } 2, \ldots \ldots \\
\text { Nos. } 3 \text { and } 4 .\end{array}$ & $\begin{array}{l}67.57 \\
58.69 \\
67.46\end{array}$ & $\begin{array}{l}32.4 \\
31.3 \\
32.5\end{array}$ \\
\hline Average.. & 67.91 & \\
\hline
\end{tabular}

In those eases where the sorghum was stripped and topped the following percentag of stripped stalks and of leaves and tops was obtained:

Sorghum.

\begin{tabular}{|c|c|}
\hline Per cent. of & Percent. of \\
\hline $\begin{array}{l}\text { stripped } \\
\text { stalks. }\end{array}$ & $\begin{array}{l}\text { leaves anc } \\
\text { tops. }\end{array}$ \\
\hline
\end{tabular}

No. 5 .

Arerage.

\begin{tabular}{l|r}
72.67 & 27.38 \\
72.55 & 27.45 \\
\hline 72.61 & 27.39
\end{tabular}

On account of the trouble in stripping the stalks, experiments were made with stalk unstripped, the tops alone being removed, and these experiments appear to prove tha this troublesome operation of stripping may be avoided without any diminution 0 the amount of juice or of sugar obtained therefrom.

Below are the results obtained from stripped and nnstripped sorghum, calculated to the raw stalks used.

By raw stalks is meant the stalks as they were out in the field; leaves, tops, and all

\begin{tabular}{|c|c|c|}
\hline & $\begin{array}{l}\text { Average per } \\
\text { cent. of juice } \\
\text { to raw stalks. }\end{array}$ & $\begin{array}{l}\text { Arerage pei } \\
\text { cent: sirur } \\
\text { in juice. }\end{array}$ \\
\hline 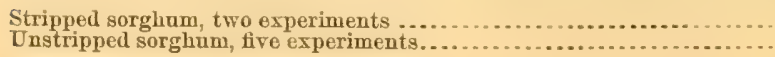 & $\begin{array}{l}35.02 \\
40.60\end{array}$ & $\begin{array}{l}15.01 \\
15.47\end{array}$ \\
\hline
\end{tabular}


From the above it will be seen that not only was an increased amount of jnice obtained, but that this jnice gave an increased percentage of sirup, and there appears mothing unusual in the treatment of this juice from the unstripped cane, nor was there any appreciable difference in the readiness of the sirup to crystallize, nor in the eharacter of the sugar finally obtained.

Althongh perhaps further experiments are desirable before considering this point as settled, it wonld appear from the above that not ouly was stripping unnecessary, but that it really involved a loss in the amount of sugar to be obtained; at least the above results indicate a difference of twenty per cent. increase in product in favor of the unstripped cane. It is not ignprobable that the above result is che to the fact that the leaves in passing through the mill tended to fill up the interstices between the compressed cane, and thus prevented the expressed juice from flowing through between the rolls with the bagasse. In case of discoloration by action of moisture or other causes, it will, however, be advisable, and probably necessary, to strip the stalks.

Several experiments were also made with both corn-stalks and sorghum to determine the relative value of the upper and lower half of the stalks, with the resilts given in the following table:

\begin{tabular}{|c|c|c|c|}
\hline & $\begin{array}{l}\text { Percentage of } \\
\text { juice to stalks. }\end{array}$ & $\begin{array}{l}\text { Specific grar. } \\
\text { ity of juice. }\end{array}$ & $\begin{array}{l}\text { Percentage of } \\
\text { sirup in juice. }\end{array}$ \\
\hline 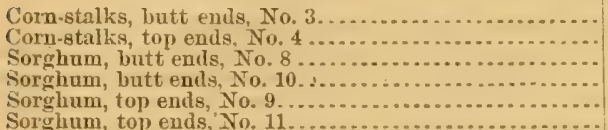 & $\begin{array}{l}29.04 \\
19.94 \\
47.49 \\
41.49 \\
43.16 \\
34.09\end{array}$ & $\begin{array}{l}1053 \\
1050 \\
1059 \\
1062 \\
1057 \\
1059\end{array}$ & $\begin{array}{l}14.6 \% \\
13.46 \\
16.41 \\
16.47 \\
14.70 \\
14.26\end{array}$ \\
\hline
\end{tabular}

Nos. 8 and 9 were the butts and tops of the same stalks, and were eut just after a rain, as were also Nos. 10 and 11, from which the rain had evaporated, and the difference in yield of juice and sirup between butts and tops is nearly constant. The increase in specific gravity of the juice from butts over that from the top is also worthy of notice.

From the above table the conclusion from the average results is, that the proportion, by weight, of sugar in the lower half of the stalk is to the sugar in the upper half as follows: Corn butts to corn tops as 159 to 100 ; sorghum butts to sorghum tops as 131 is to 100. As will be seen by reforence to the first table, the stalks of both corn and sorghum in the above experiment were divided almost equally by weight into butts and tops, so that the above proportion fairly represents the proportion of yield of sugar in the npjer and lower half of the cane. There was a marked difference in the appearance of the juice as it flowed from the mill (that from the butts being lighter in color, especially in the experiments with corn), but after clarification no appreciable difference could be observed, nor was there any difference in the product except the quantitative one above mentioned, which was, however, a marked difference. Also, there was a marked difference in granulation in favor of the juice from the butts.

The experiments of this year (1879) doubtless explain some of the results of the previous year; since it is probably true that, owing to immaturity, the tops had not yet attained their maxumum content of sugar. A study of the previous tables giving results of the analysis of sorghums shows that up to a certain period the lower half of the cane is the best, but that this does not remain true of the sorghum, as it does of the sugar-cane in Louisiana, since the sorghum does have time to completely uature, which is not true of the sugar-eane in our country.

In the following table there have been calculated from the results given of the experimeuts in the making of sugar the following:

1st. The percentages of the sugar present in the juices operated upon, which were obtained in the sirup.

2d. The percentage of erystallizable sugar (sucrose) present in the juices which was obtained in the sirup.

3d. The percentage of uncrystallizable sugar (glucose) present in the juices, which was obtained in the sirup.

4th. The percentage of crystallizable sugar present in the juices, which was inverted. by the process of manufacture.

5th. The percentage of unerystallizable sugar (glucose) destroyed during the process of manufacture.

The presence of the same relative proportions of crystallizable and uncrystallizable sugar in a sirup to those present in the juice from which this srup has been prepared, by no means implies that there has been no inversion of the erystallizable sugar; for the destructive action of an excess of lime upon glucose is well known and is not unfrequently made available in the production of sugar. Hence it not unfrequently happeus that the relative quantity of erystallizable sugar in the sirup may be great 1y in excess of that present in the juice, even alter a large quantity of the crystalliwablis 
sugur has been destroyed by iuversion. It is ouly possible then to determine the character of the changes which have taken place in the sugars during the process of manufacture, by quantitatively determining the amounts of sucrose and glucose in the juices and in the sirups prepared from them.

Since, obviously, this is a question of the greatest practical importance, as boaring mpon the profitableness of the produetion of sugar from eorn-stalks or sorghum, the tables following will be studied with interest by those engaged in this production.

As will have been observed in the previous table, there is a coustant but not niniform discrepancy between the polarization of the sirups and the anome of erystallizable sugar found present by analysis.

Almost in raxiably the amount of sucrose fomnd prosent is somerrlut in excess of the amount indicated by the polariscono, and this variation is such as to forbid any supposition that it is the result of error in observation or in analytical work.

This explanation may be found by consulting the following tables, by which it aypears that, although there is generally about the sane amount of ylucose in the sirups yelative to the amount present in the juice (averaging 97.1 per cent.), there is still evidence of the destruction of an average of 35 per cent. of the glucose. This destruction of glucose alppears to be compensated, in part, by the inversion of a certain portion of the erystalizable sugar, and this inverted sugar possesses such action upon the polarized rav as to render the results of the polariscope practically worthless.

Practically, it appears that the proportion of crystallizalyle sugar prescut in the juice, which may be obtained in the sirul, depends greatly upon the condition of the stalks when worker. For, as will be seen, the average anount secured in all these experiments was but 77.1 per cent., still in those sirups prepared from canes which were in the proper conclition the amonut was orer 90 per cent of the crystallizable sugar present iu the juice operated upon. (Sce oxperiments Nos. 6 and 7.) It is not improbable that even better results may he seumed after further experimonts shall have perfected the process of manufacture; but in view of the fact that such results have heen attained with such crude and simple apparatus as that employed in the experiments here recolded, this result is highly gratifying.

We may hope then to secure in sirup 90 per cent. of the erystallizable sugar present in the juice operated upon.

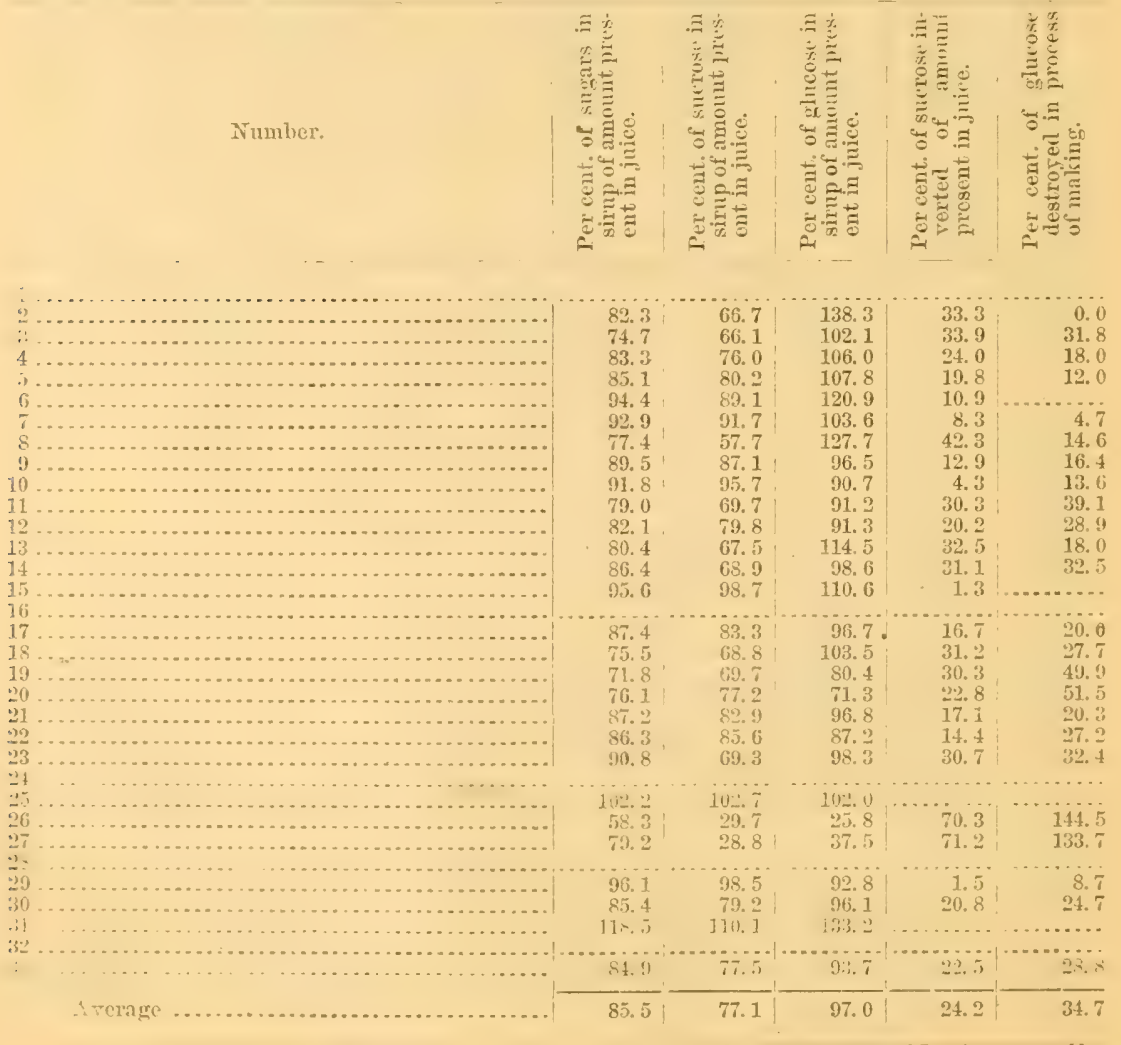


The results obtained in the experiments male with stalss from Stowell's Erorgreen Swoet Corn are most remarkablo and demand explamation. It will be seen that the juice obtained from these stalks gave in the laboratory excellent results, and promisea

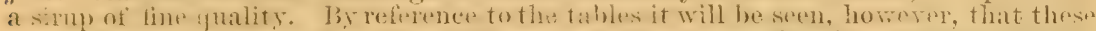

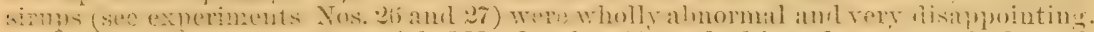
These stalks were cut in Frederick, MId., Octoher 11, packed in a close car, and, thronwh an orersight, allowed so to remain during oppressively hot weather mntil the $15 \mathrm{th}$. Ther were worked up on the 16th, 17th, and 18th. Upon their irrival at Washington

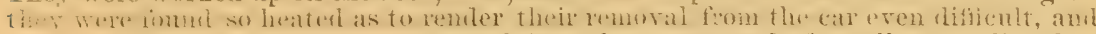

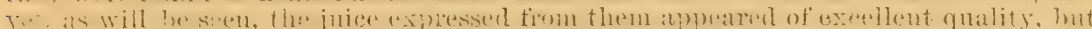
crery attempt to proulnce from it a crystallizable sirnp failed, and an analysis of the sirmp showed that a very large percentage of the sugar had been inverted (in exper-

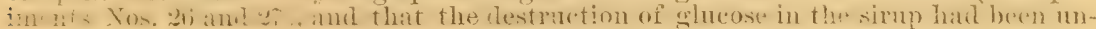
ustally large, while tho amount of erystallizable sugar present in the juice, aud rocovered in the simup, was less than 30 per cent.

$A$ yem of the results attained appear to be only explicable upon the supposition that there have been slight errors in aualysis, but rovision of the work fails to reveal sueh erroxs, and the results are given in full withont omission, hoping that future investigation may enable us to solve diffienlties which at present appear irreconcilable.

\section{Comparison of the upper and lower halves of sorghum-canes.}

Arerage per cent. of water in 17 specimens of Clinese sorghum.....tops. Average jer cent. of water in 16 specimens of Chinese sorghum .... . butts. Arerage per cent. of water in 20 specinens of Honduras sorghum ....tops. Average per cent. of water in 20 specimens of Honduras sorghum .. . butts.

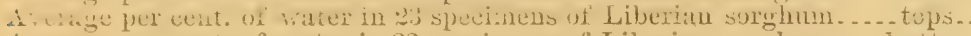
Average per cent. of water in 23 specinens of Liberian sorghum ... . butts. $\Lambda$ Terage jer cent. of water iu 22 specimens of Early Amber sorghnm... tops. A verage ver cent, of water in 22 specimens of Early Amber sorghum . butts. Average per cent. of juice from 10 specimens of Chinese sorghum.... tops. Arerage pex cent. of juice from 10 specimens of Chinese sorghum... butts. Average per cent. of juice from 16 specimens of Honduras sorghum ... tops.. Average por cent. of juice from 17 specimens of Hondurns sorghum . butts. Average per cent. of juice from 13 specimens of Liberian sorghum.... tops. Average per cent. of juice from 13 specimens of Liberian sorghmm ... butts.

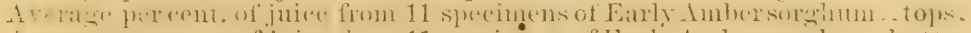
A Arerage specific gravity of juice from 17 specimens of Chinese sorghum, iops . . . . . . . . . . . . . . . . . . . . . . . . . . . . . . . . . . . . . Arerage slecific gravity of juice from 17 specimens of Chinese sorghmm,

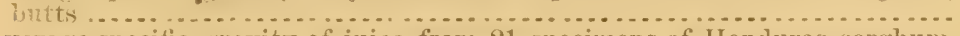
Average specific grivity of juice from 21 specimens of Honduxas sorghum,

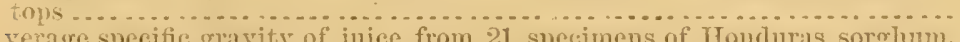
Averasco specific gravity of juice from 21 specimens of Houduras sorghm,

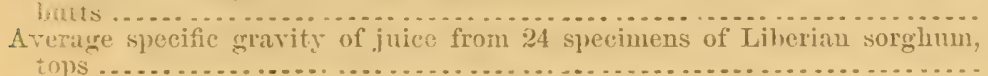

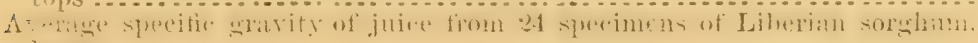

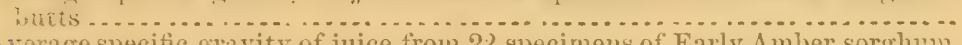
Average specific gravity of juice from 22 specimens of Early Amber sorghm, Aterage specifie gravity of juice from 22 specimens of Early Amber sorghin,

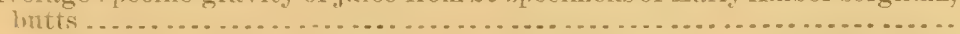
Arerage per cent. of solid matter in juice from 16 specimens of Chimese sorghum ................................................ tops...

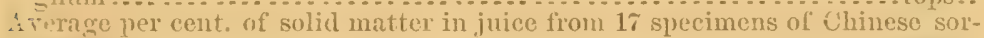

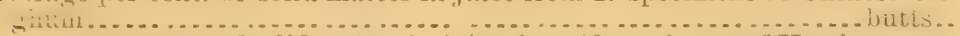
Average per cent. of solid matter in juice from 19 specimens of Honduras sor-

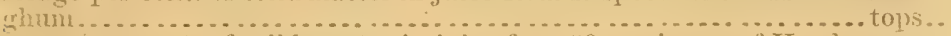

A terage per cent. of solid matter in juce from 20 spccinens of Honduras sor-

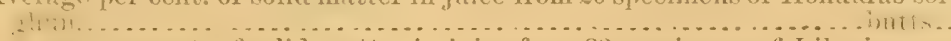

ATernge jer cent. of solid matter in juice from $2: 3$ specimens of Libcrian sot-

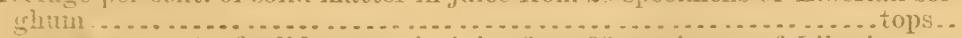

Aremge per cent. of solid matter in juice from 22 specimens of liburiau sor-

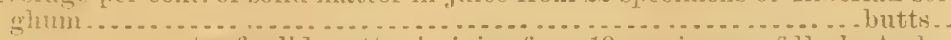

Arerage per cent. of solid matter in juice from 19 specincus of Lar!y Amber:

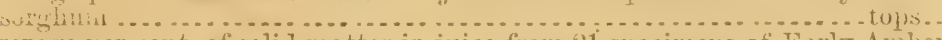

Arerage per cent, of solid matter in juice from 21 speeimens of Larly Amber sorghum .............................................. butts..

I'er cent.

7:3. 05

74.46

72.57

76.15

i1. $6 \pi$

75. 22

7\%. 73

72. 1:3

45. 17

49.89

42.88

45. 44

4?. 63

44. 50

fii. 1 is

.41). 5

1.0725

1.0708

1. $19 ; i+3$

16. 21

11i. -1

13. 85

1:. - *

1.. 5 !?

16. 75 
Average per cent. of water in tops, 79 specimens ..................... 72.45

Averago per cent. of water in butts, 79 specimens.................. 74.51

Average per cent. of juice from tops, 50 specimens. . . . . . . . . . . . . . . . 43.96

Average per cent. of juice from butts, 51 specimens . . .................. 46.90

Average per cent. of solids in juice from tops, 77 specimens ............... 16. 1s

Average per cent. of solids in juice from butts, 80 specimens . . . . . . . . . 16. 92

Average specific gravity of juice from tops, 84 specimens ................ 10.71

A verage specific gravity of juice from butts, 84 specimens ............ . 10. (i)

From the above comparison it will appear that there exists no marked difterence in the amount of juice present in the upper and lower halves of the canes, nor in the quality of this juice as indicated by either the relative specifie gravities or the total amount of solid matter present in the juices.

But by reference to the previous tables, giving the results in detail, the fact will appear in the case of each of the sorghums examined that, during the early stages of slevelopment of these plants, the total sugars present in the juices is comparatively low, often not one-third of the maximum afterwards found in the plant, and cunsequently the amount of sirup possible to be made from this immature cane is proportionately less than that which the same stalks would yield when fully matured.

It will also appear that, during this early and immature state of the plant, the reiative amount of crystallizable sugar (sucrose) as compared with the total sugars present is much greater in the lower half of the eanes. This condition remains, apparently, until the seed has reached the milky state, at which time the juices in both parts of the plant appear to be of equal valne. But it must not be understood that the maximum content of sugar in the plant has been reached at this period of developuent, since, as will be seen by the tables, this is far from the fact.

From this period in the plant's development until the perfect ripening of the seed, the juices appear to uniformly increase in their content of crystallizable sugar, and to decrease in their content of uucrystallizable sugar.

Still later in the history of the plant there appears a slight deterioration in the quality of the juice from the lower half of the stalk, and it is found generally to be somewhat inferior to the juice from the upper half.

It appears probable that this deterioration of the juice from the lower part of the eane marks the incipient stages of death and the ultimate decay of the plant, the roots and leaves failing in their oftice to supply the full amount of nourishment which the plant requires. It begins to feed upon itself, so to speak, and it is to be observed that at this period the off-shoots from the upper foints of the stalk begin a vigorons growth and appear to live as parasites npon the parent stalk.

It will appear also that at tho first examinations the specific gravity of the juices from the lower half of the cane is almost invariably greater than that of the juices from the upper halves, and that an equality of specific gravity appears to indicate an equality between the juices in their content of sugar not only, but in its relative proportions of sucrose and glucose.

Proximate analyses have been male of the seed of two varieties of sorghmm, the early amber and the Chinese, the results of which are given below. It will be seen that this seed differs but little in composition from the othar cereals, and closely resembles corn, and it will doubtless prove valuable as food for farm stock.

\begin{tabular}{|c|c|c|}
\hline \multirow{2}{*}{ - } & \multicolumn{2}{|c|}{ Sorghum seeds. } \\
\hline & "Early amber. & Chinese. \\
\hline 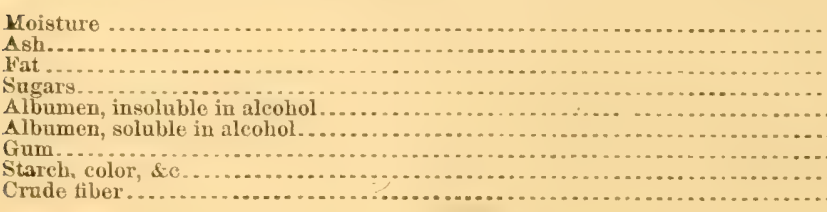 & $\begin{array}{r}10.57 \\
1.81 \\
4.60 \\
1.91 \\
2.64 \\
7.34 \\
1.10 \\
68.55 \\
1.48\end{array}$ & $\begin{array}{r}\text { 9. } 93 \\
1.47 \\
3.95 \\
2.70 \\
2.64 \\
6.90 \\
.72 \\
70.17 \\
1.52\end{array}$ \\
\hline & 100.00 & 100.00 \\
\hline
\end{tabular}

Moisture was estimated from loss by drying at $105^{\circ} \mathrm{C}$. Ash, by simple ignition; total albuminoids from total nitrogen multiplied by 6.25. Under "sugars" is given that portion of the 80 per cent. alcohol extract which was found soluble in water. The insoluble portion of this alcohol extract included a little red coloring inatter, but otherwise seemed to be identical with the "zein" of maize. Gum was extracted by 
water, after use of ether and alcohol. Fat was extracted directly from the sample by absolute ether; it was yellowish, semi-solid, and very much resembled the fat similarly extracted from corn. Starch, color, \&c., were determined by difference. In early amber there was fonud 64.05 per cent, and in Chinese sorghum 64.74 per cent. of starch by titration, with Fehling's solution of an acid extract made after extraction with ether, alcohol, and water.

Crude fiber is that portion, ash free, which still remains iusoluble after treatmerit of the sample with ether, aleohol, water, dilute hydrochloric acid, and dilute potassic hydrate. It is usually white or slightly gray, and free from nitrogen.

Proximate analyses have also been made of the scum and sediment obtainch in defecating the juice, with a view of throwing light upon the chemical character of this important process.

The results of these analyses are given below.

\begin{tabular}{|c|c|c|c|}
\hline 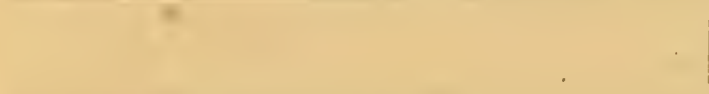 & $\begin{array}{l}\text { Liberian } \\
\text { lime pre- } \\
\text { cipitate. }\end{array}$ & $\begin{array}{l}\text { Honduras } \\
\text { lime pre- } \\
\text { cipitate. }\end{array}$ & $\begin{array}{l}\text { Honduras } \\
\text { skimmings. }\end{array}$ \\
\hline 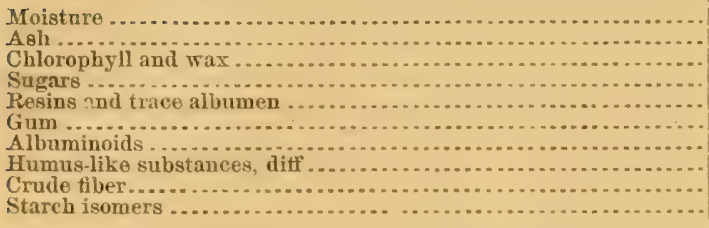 & $\begin{array}{r}9.77 \\
21.69 \\
17.60 \\
10.80 \\
-3.61 \\
6.02 \\
22.58 \\
-5.73 \\
2.20 \\
\text { Traee. }\end{array}$ & $\begin{array}{r}7.69 \\
7.00 \\
8.95 \\
43.96 \\
3.26 \\
11.40 \\
4.55 \\
12.71 \\
\text { Trace. }\end{array}$ & $\begin{array}{r}5.72 \\
14.39 \\
14.41 \\
15.06 \\
5.08 \\
11.10 \\
8.05 \\
5.58 \\
5.49 \\
15.18\end{array}$ \\
\hline & 100.00 & 100.00 & 100.00 \\
\hline
\end{tabular}

The large amount of ash in Liberian lime precipitate aud Honduras skimmings is due to the presence of considerable elay, which had been used to hasten the clarifieation of the juice. There was little or no clay present in Houduras lime precipitate. The claying seems mechanically to have carried down a large proportion of the albumen in the Liberian lime precipitate.

The very great difference in these waste products is probably due almost wholly to differences in the manipulation of the juices.

Very probably there exists in line precipitates a combined organie acid; this will be investigated in the future.

Whoever may detect error in the methods employed, or in the results stated, will confer a favor by mentioning the same.

It is certainly most desirable that these experiments be contiuued upon a larer scale, and with at least a dozen varieties of sorghum and an equal number of varieties of sweet, yellow, and white corm.

At least an acre of each variety should be grown, and the development of each should be watched through the seasom, and when the proper time for working up the crop has come, let the acre be worked up for sugar. Such an experiment would require little outlay and be productive of invaluable results. It would require at least three or four assistants additional in the chemieal laboratory to attend to the continued analyses of the canes, and would necessitate a somewhat larger apparatus for working up the crop.

The correspondence addressed to this division upon this subject of sugar has steadily increased until it requires nearly all the time of one assistant to attend to it.

THE PERMANGANATE PROCESS FOR THE ESTMMATION OF SUGARS IN JUICLS.

\section{Preparation of the juice.}

Usually two stalks were selected for analysis. Their maturity, as shown by the development of blossoms, seeds, and the color and condition of tho glumes, was recorded. Then were noted-

a. The weight, of the unstripped stalks.

$b$. The weight of the stripped and topped stalks, and, by difference, the weight of leaves and tops.

c. The average length and diameter of the stripped stalks.

These stripped stalks were then divided so that tops and butts were of equal weight. Then was found-

d. The average length each of tops and butts. The tops and butts were then separately analyzer. Each by itself was cut tinely with a hatchet, and then bruised in an iron mortar. The bruised mass was then placed in a small bag, and submitted to a heavy pressure in an orlinary iron press. 
The oxpressed juice was collected and weighed, and the percentage calculated to the unstripped stalks taken.

'The juice thus obtained usually was greenish from the presence of chlorophyll. As the plant matmred, the color of the juice inclined to amber, and in perfectly ripe stalks (especially of the Early Amber variety) the color was red, from the presence, in the central portion of the stalk, of a red coloring matter sparingly soluble in ether, readily dissolved by 80 per cent. alcohol.

The specific gravity of the juice was determined usually by a piknometer. It was found that the realings given by an accurate hydrometer accorded well with the specific gravity indicated by weight, if the juice vas previously allowed to stand for about half an hom, to allow included air to escape.

A weighed portion of the juice was dried, at a heat not exceeding $100^{\circ} \mathrm{C}$, until two sucessive weights showed but little variation; the percentage of residue thus found was stated as total solids in juice. These figures can be regarded only as fair approximations, for chemists are vell aware of the difficulties attending the perfect desiceation of saceharine juices. In this comnection, hotvever, the results are valuable as checks upon the sugar determinations.

For determination of sugars in the juice $100 \mathrm{c} . \mathrm{c}$. were taken, and made in crery case to $125 \mathrm{c}$. c. by addition of solution of subacetate of lead and water. Among other substances precipitated by the treatment were chlorophyli, albumenoid matter, gum, and leat salts of the inorganic acids of the ash.

The linid was filtered perfectly clear througl dry paper, and was sometimes colorless and sometimes amber. Every $10 \mathrm{c}$. c. of this liquid represented $8 \mathrm{c}$. c. of the original juice.

For the determination of inverted sugar, $10 \mathrm{c}$.c. of this filtered linuor were taken, aud for sucrose $5 \mathrm{c}$. c.

The portion for glucose was treated with considerable excess of Fohling's solution, and carefully heated on the water-bath, a thermometer being inserted in the liquid, which was mot allowed to rise above $75^{\circ} \mathrm{C}$. At this temperature perfectly pure suerose does not reduce Fehling's solution in the least.

The portion for suerose was inverted by boiling half an hom with slight excess of dilute hydrochloric acid. The inverted sugar thus formed was then treated with large excess of Fehling's solntion, exactly as above (leseribed, except that it was not nocessary to keep the temperature lower than the heat of the water-bath $\left(100^{\circ} \mathrm{C}\right.$. $)$.

The precipitated red suboxide of copper was then thoroughly washed with hot water by decantation and filtration (without aspiration usually) through fine paper. It was then dissolved in an acid (sulphuric) solution of ferric sulphate, and tho amount of ferrous salt determined by titration with potassium permangariate.

'This method for determining glucose depends upon the following facts:

1. That two molecules ( 360 parts by weight) of glucose $\left(\mathrm{C}_{6} \mathrm{H}_{12} \mathrm{O}_{6}\right)$ will reduce from Echling's solution five molecules of cuprous oxide $\left(5 \mathrm{Cu}_{2} \mathrm{O}\right)$.

?. That the five molecules of cuprous oxide thus preeipitated will reduce in acid sol. five molecules of ferric sulphate $\left(\mathrm{Fe}_{2}\left(\mathrm{~S} \mathrm{O}_{4}\right)_{3}\right)$ to form ten molecules $(1,520$ parts by woight) of ferrous sulphate $\left(\mathrm{Fe}_{\mathrm{S}} \mathrm{S} \mathrm{O}_{4}\right)$ as is explained by the following equation:

$$
\begin{gathered}
\left\{\begin{array}{c}
5 \mathrm{Cu} \mathrm{O} \\
715 \text { parts }
\end{array}\right\}+\left\{\begin{array}{l}
5 \mathrm{Fe}_{2}\left(\mathrm{sO}_{4}\right)_{3} \\
2,000 \text { parts }
\end{array}\right\}+\left\{\begin{array}{l}
5 \mathrm{H}_{2} \mathrm{~S} \mathrm{O}_{4} \\
490 \text { parts } \\
10 \text { Fe } \mathrm{S} \mathrm{O} \mathrm{O}_{4} \\
1,520 \text { parts }
\end{array}\right\}+\left\{\begin{array}{c}
5 \mathrm{H}_{2} \mathrm{O} \\
90 \text { parts }
\end{array}\right\}=\left\{\begin{array}{l}
10 \mathrm{Cu} \mathrm{S} \mathrm{O}_{4} \\
1,595 \text { parts }
\end{array}\right\}+
\end{gathered}
$$

The tun molecules of ferrous sulphate thus formed rill decolorize one molecule ( 316.2 parts by reight) of potassium permanganate $\left(\mathrm{K}_{2} \mathbf{M n}_{2} \mathrm{O}_{3}\right)$, thus:

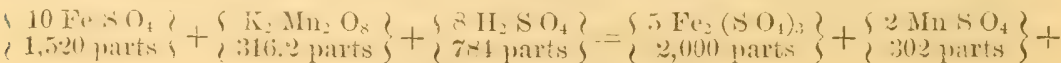

$$
\begin{aligned}
& \left\{\mathrm{K}_{2} \mathrm{SO}_{4}\right\}+\left\{8 \mathrm{II}_{2} \mathrm{O}\right\} \\
& \{174.2 \text { parts }\}+\{144 \text { parts }
\end{aligned}
$$

By following this explanation, it appears that two molecules of glucoso are exactly represented by one molecule of potassium permaugauate, as will appear from the following, by owitting the second ant third members of the series. Thus:

$$
\left\{\begin{array}{c}
2 \mathrm{C}_{6} \mathrm{H}_{12} \mathrm{O}_{6} \\
360 \text { parts }
\end{array}\right\}=\left\{\begin{array}{c}
5 \mathrm{Cu}_{2} \mathrm{O} \\
715 \text { parts }
\end{array}\right\}=\left\{\begin{array}{c}
10 \text { lie } \mathrm{S} \mathrm{O}_{4} \\
1,520 \text { parts }
\end{array}\right\}=\left\{\begin{array}{c}
\mathrm{K}_{2} \lambda \mathrm{Mn}_{2} \mathrm{O}_{8} \\
316.2 \text { parts }
\end{array}\right\}
$$

In other words, 316.2 parts by weight of potassium permangamate are equivalent to 360 parts of glucose, or oue part of permanganate corresponds to 1.1385 parts of glucose. If, then, the amount of permanganate decolorized be multiplied by 1.1385 it will correctly represent the amount of rlueose present. So much for the theoretical orplanation. In practico it is found that each chenist must determine for himself his titration eror by estimations malo upon sugar of known purity. 
'This individual enor is due to the difficulty in determining the exact end reaction; experience has shown, in the connse of this work, that the point where the color of the permanganate barely appears in the rapidly agitated liquid is nearly iclentical with the true cud reaction. Some operators carry the titration a little further until a faint rose tint is permauent for about two secouds. Each man who has tone this work has carefully determined his titration error, and all figures submitted lave been corrected therefor: Tho iron solution works best if very strongly acidulated with sulphuric acid. The most convenient strength for the permanganate solution is 4.392 grares to the liter, oqual to .005 grams glncose for each cubic centimeter.

In the earlier part of these determinations it was not consideren necessary to thoroughly wash the precipitated suboxide of copper before dissolving it in the ferric sulphate solution. Carefully performed experiments, however, showerl that washing was best, and that the results obtained on unwashed suboxide would equal those on the washed if multiplied by .9676 for glucose and by .9438 for sucrose.

As the results of much careful work it apivears that, if the suboxide be well washerl, and if each operator determines his titrution error, the determination of glucose by this method is very acunrate.

The amount of glucose found was tivided by the weight of $8 \mathrm{c}$. c. of the juice ana1yzed for percentage of glneose. The sicerose was found by subtracting from the totai glucose after inversiou the amount originally present in $4 \mathrm{c}$. c. of the juice, and multiplying the remaining slucost 65.95 . 'The percentage was then calculated in the usual way.

Respectirlly,

PETER COLLIER,

Chemist, Agrioullural Department.

\section{MACHINERT.}

Replyiug to your inquiry relative to the difirent kinds of machinery for making sngen from sorghm, I would lemapk that the juices of the various kinds of sorghum examined by the department (and the ame is true without dombt of all valdetes of sorwhm) are so nearly similar to the juice of the tropical sugatr-enne (Nacharum offeinarum) that the same madhinery and the same processes will molonibedly be as useful in the manipulation of the one as of the other.

Heretofore sorgtum has been swown for the jurpese of making sirup, in almost every part of the conntry where corn would grow; and in this nianufacture a "ertain class of machinery, known as sorgo-machinery, has becone general. This machinery is simple and strong in stucture, and as now macle consists ordinarily of three roller's, which are either vertical or horizontal, and are driven by horse, steam, or other power. Hisving a capacity for work in proportion to the power employed and the size of the mill, and rarying but little in ronstruction, it is mannfactured in all parts of the United States and can be obtained at low rates at almost any large machine-shop.

The cuts hore presented in illustration of the leading classes of sugurmaking machinery have been kindly furuished by two or three houses largely entaled in the mannfacture; but mathinery of like character is made in almost every comuty in the United States in which there is a large iron-working establishment. Whaterer difference of opinion may exist relative to the comparative efficiency of the several mills and pans on the market must be decided by the individuals who wish to purchase. They will not and need not necessarily be confined to any special kind, as there are many desirable sorts for sale throughout the comtry. liy way of comparison the illustrations embrace some that represent the primitive methols of sugar-maling among the Hindoos and other nations.

The cost of a small outfit necessary to work up the product of the ten to fifty acres of sorghum that one or two farmers might raise in a neighborhood, would be from $\$ 150$ to $\$ 500$, while mills required in Jarger operations wonld, of concse, necessitate a proportional increase in 
ixyenditure. The plant or apparatus commonly employed at this time in the manufacture of sorghum syrup cousists of a small three-roller mill, for expressing the juice; one or more tauks for receiving it and heating it to a point where lime or other defecating agents may be used (if it he thought necessary to use them at all), and a shallow pan or two for evaporation. Howerer, mel fuller information on this subject than I can now give will be found in the proceedings of the convention of the Northwestern Sugar Grower's Association, before referred to.

In the practical manufacture of sugar, in a large way, from sorghum and corn-stalks, it will be found necessary, I have no (loubt, to establish larye central factories or mills, having the same relatious to this indnstry as do the suist-mills of a neighborhood, to-day, to wheat and corn. Mills of this character should be capable of handling at least 500 acres of sorghum or corn cluring one season, and I am informed by manufactnrers of machinery who have considered the subject with care that such mills may be built for a sum not exceeding 812,500 , and that possibly this anomit woukd also affort a margin for a fair working capital for the operations of a single season. This central factory would be able in work up not only the cane from 500 acres during a season, but also to rework into sugur the product of the suall mills established at greater or Iess distances around it that had carried their operations no further than the manufacture of concentrated sirup), weighing, way, ten pounds to the sallon.

Erohably it will be more protitable to the average farmer to simply emrert the juice of his stalks into a sirup and sell it as such to a mill mreprared for making sugar in a large way, with vacuum-pans and centrifugals, than it would be to work his cane into sugar himself. For although good sugar has been made during the past season by open-pan evapuration by small fiumers in many parts of the conntry, and made at a jrotit, jet the time must come when the competition in the mamfacture of sugar will he so great as to reduce the profits materially, and to demand the closest economy in all the various processes of cultivation and subsequent manipulation. Until, however, the supply shall begin to equal our home demand there will probably be a very fair profit to the average farmer with his small mill and open-pan evaporation in making sugar, molasses, and viuegar ; for vinegar is one of the products of this industry which is of importance, the skimmings and other refuse making an excellent article that finds ready sale at remunerative prices.

The entire cost fiom the first breaking up of the land, and carefully connting every expenditure at the current cash prices of the country for labor and other things, the entire cost of production in the Western States, the past season, of a gallon of (lense sirup), weighing say 13 pounds, did not exceed $16 \frac{2}{3}$ cents on an average. (It is quite possible to produce it at less cost.) These 13 pounds of sirup, if properly managed, should give from 6 or $\$$ pounds of sugar; and, if handled by the centrifugal, the susar can be separated from the sirup at a fraction of one cent. per pound.

I am informed by Mr. Thoms, an experienced sugar boiler, employed last season at the Crystal Lake Sugar Works, Illinois, at which were sade many thousand pounds of good sugar, that with trimmed cane fielivered at the mill door, he can make and deliver the sugar at the mill for $1_{4}^{1}$ cents per pound, a statement corroborated by Mr. Russell, of Tanesville, Wris., late superintendent of the Crystal Lake Factory turing the season of 1879 .

The trimmed stalks cau be bought for from $\$ 2$ to $\$ t$ per ton debivered at the mill: and the farmer can very well afford to rleliver them 
for this price, as he ean raise from 15 to 30 tons per acre, and obtain besides a crop of seed equal in value to a fair crop of oats from the same number of acres, to say nothing of the large supply of excellent bladle fodder. If we assume 20 tons of stalks per acre (and it is not too high an estimate for goor land), the yield per acre would be from $\$ 60$ to $\$ 80$ delivered; and if the haul was not too long, this would be exceedingly proditable to the grower. If the haul should be so long as to preclude a profit, then it would be necessary for the famer to have al small mill to reluce the juice to a dense sirum, as has bern deseriber, and to market it at the large factory in that condition.

Although a finir measure of success* has rewarded the efforts of many who were engagerl. the past season, in the manufacture of sugar from sorghmm, yet to obtain sugar unifomly and profitably from the juice of the rarious sugar-producing plants, under differing conclitions of soil and seasons, experience is rerguisite as well as theoretic: knowledge.

Instruction in this matter is of the utmost importance, and hence it is riesirable that the Department of Agrieulture slonkl be anthorizen

- The following tablo is an epitome of the reports received by the department from those to whom the seed of the Early Amber came was sent. Many of those reporting were antirels uncenstomed to the eultivation of this crop, and eonserpentl wrir only partially successful. Others had the experience of some years to aid then, and from these the reports are uniformly favorable, and some remarkably farorable. A yiold of at least 200 gallons of ileuse sirup per acre (worth 40 cents to 50 cents per gallou) it wonk seem reasonable to expect as the result of good seasons, good soil, gool cultivation, and good milling.

State.

\begin{tabular}{|c|c|c|c|c|c|c|}
\hline - State. & 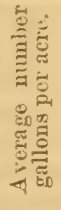 & 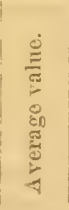 & 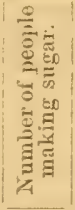 & 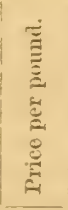 & 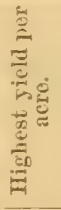 & 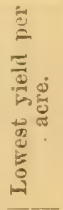 \\
\hline 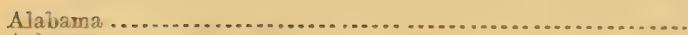 & 122 & $\$ 050$ & & ...... & 192 & 60 \\
\hline 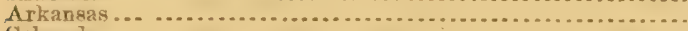 & 117 & 48 & $=$ & -. & 256 & 52 \\
\hline 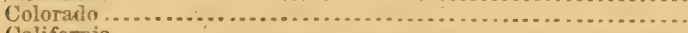 & 116 & 90 & & $\ldots$ & 124. & 109 \\
\hline 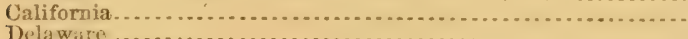 & 196 & 50 & & & 200 & 192 \\
\hline 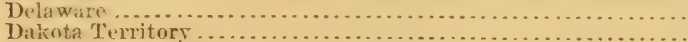 & & & & & & \\
\hline 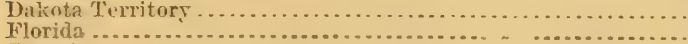 & 113 & (iti & & & $\begin{array}{l}168 \\
240\end{array}$ & 50 \\
\hline Georcia ............. & 104 & 48 & & & 192 & $\begin{array}{l}50 \\
42\end{array}$ \\
\hline 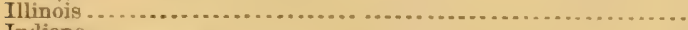 & 132 & 46 & 8 & $\$ 010$ & 325 & 40 \\
\hline Indiana & 127 & 40 & 3 & $\ldots$ & 400 & 25 \\
\hline 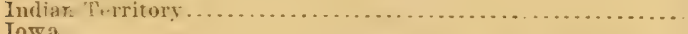 & 127 & 75 & & & 200 & 82 \\
\hline & 130 & 52 & 16 & .. & 350 & 60 \\
\hline & 1 & 49 & 7 & .. & 300 & 25 \\
\hline $\begin{array}{l}\text { Kentucky } \\
\text { Maryland }\end{array}$ & 1 & 39 & 2 & $\ldots \ldots$ & 244 & 31 \\
\hline $\begin{array}{l}\text { Maryland } \\
\text { Michigan }\end{array}$ & 111 & 60 & $\cdots$ & .. & 150 & 40 \\
\hline & 6 & 51 & 2 & $\cdots$ & 480 & 75 \\
\hline 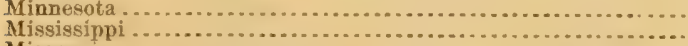 & 38 & 56 & 5 & & 376 & 43 \\
\hline ississippi & 1 & $\begin{array}{l}43 \\
40\end{array}$ & 30 & & 500 & 36 \\
\hline 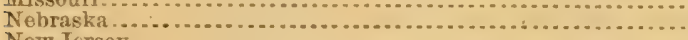 & $\begin{array}{l}135 \\
124\end{array}$ & $\begin{array}{l}40 \\
55\end{array}$ & 30 & & $\begin{array}{l}300 \\
300\end{array}$ & $\begin{array}{l}48 \\
50\end{array}$ \\
\hline 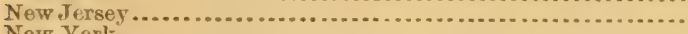 & 147 & & 2 & & 200 & 90 \\
\hline 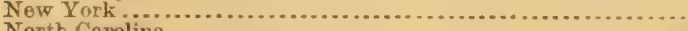 & 175 & 75 & 2 & $=$ & 214 & 136 \\
\hline 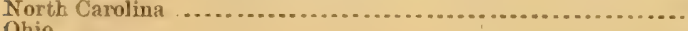 & 163 & 57 & 3 & .. & 176 & 40 \\
\hline Ohio & 151 & 48 & 9 & & 453 & 50 \\
\hline 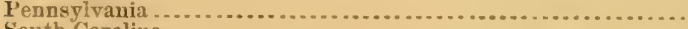 & 138 & 50 & $\ldots$ & & 176 & 100 \\
\hline 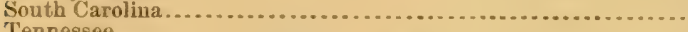 & 94 & 50 & 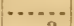 & & 136 & 25 \\
\hline 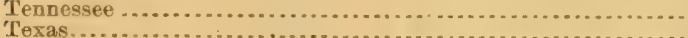 & 138 & 41 & 3 & .. & 392 & 40 \\
\hline 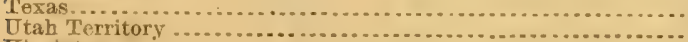 & 114 & 57 & 11 & & 361 & 30 \\
\hline 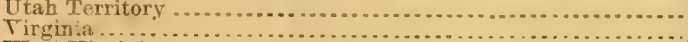 & & 62 & $\frac{1}{3}$ & & 150 & 98 \\
\hline Wirgin wa & 12 & 51 & $\begin{array}{l}3 \\
8\end{array}$ & 11 & $\begin{array}{l}18 \\
21\end{array}$ & 60 \\
\hline \multirow[t]{2}{*}{ Wisc(s) } & 149 & 54 & 17 & & 260 & 69 \\
\hline & 128 & 50 & & 10.5 & 500 & 25 \\
\hline
\end{tabular}


and empowered to make such cxperiments (at various central points,

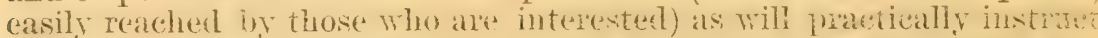
the jerople in all the various proeesses and madinery heretofore stescessfilly need, and to diseurer, if possible, other" and bettere methouls of

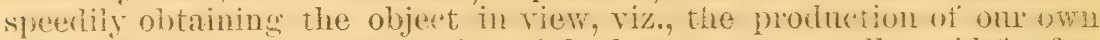
sugar and the (wiserient saving of the large sum ammaly paid tor forcign sugar. The passage of senate bill No. 151t (relerrerl to me) would emakle the besmetnent to institute important experiments in at least

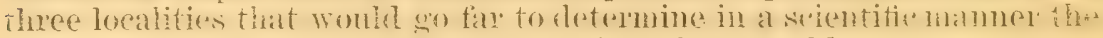
questions in the way of a speedy solution of the problem.

\section{CONSUMPIION AND PRODUC'ION.}

Of your several inquiries there remains to be considered only the ques-

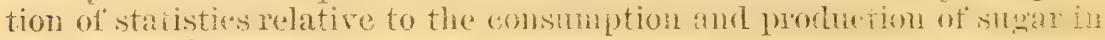
the United States.

Perhaps I cannot make better reply to this inquiry than has already been made in my annual report for 187s. In that report the consump-

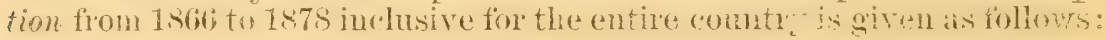

\begin{tabular}{|c|c|c|}
\hline 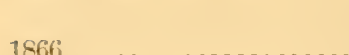 & 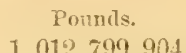 & Poumds. \\
\hline & $870,566,017$ & $\cdots .1,925,964,981$ \\
\hline $8 \ldots \ldots \ldots$ & $1,195,120,413$ & $1865 \ldots \ldots \ldots \ldots \ldots \ldots \ldots \ldots \ldots$ \\
\hline 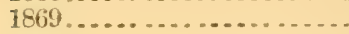 & $1,309,847,125$ & $1876 \ldots \ldots \ldots \ldots \ldots . \ldots \ldots 4,6 \ldots 4,94,164$ \\
\hline & 1, $306,202,065$ & $1877 \ldots \ldots \ldots \ldots \ldots \ldots \ldots \ldots$ \\
\hline (n. & $1,327,456,300$ & $1878 \ldots \ldots \ldots \ldots \ldots \ldots \ldots \ldots$ \\
\hline
\end{tabular}

For the same years the production of eane sugar in the United States was as follows:

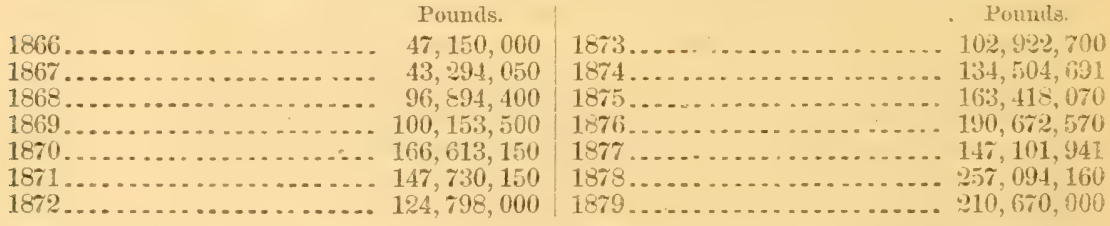

In additiou to this amount of sugar fiom cane there were produced, from 1866 to 1877 inclusive, 459,031,151 pounds of maple sugar.

The consumption of sugar for the year 1879 was within a small fraction of 40 pounds per capita of on populatiou, being an increatse of nearly 10 pounds per eapita since the dearle of $1860-70$ and of 15 pomals since the decade $1850-60$.

From these and other tables in our possession, it is found that over and above the amomnt of all sugar's profluced in the Innited states since 18.19 we have consmmed during the same perjod not lesis than eightern hundred and odd millions of dollars' worth of foreign sugars and thete allied products, or an amonut of sugar more than erpul in value to all the precions metals nimed in the comtry since the diseorery of wold in Califomia, and neary equal to the public debt at the present time. Whtimating the population of the Cnited States at 50,0(90,000, and multplying this number by the pounds (40) per eapita consumed in 1879, we

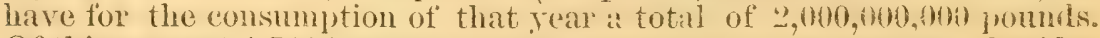
Of this amount 1,74\%,560,000 pomids, or mone than sol per vent., besides $38,395,575$ gallons of molasses (the whole valued at \$75,017,14.5, 91, duty added, $\$ 114,516,745)$, were imported. To bring the rast amount of 
sugar inporter into the comntry within more easy comprehension, we have mily to imagine five ressels of nearly 500 tous each and loaded with sugar aniving daily at our ports each day in the year. To convey the whole amount consumed would require five trains of twenty cars each starting daily for one thousand days.

I have the honor to be, very respectfully,

\author{
WM. G. LE DUC, \\ Commissioner.
}

A.

\title{
ILLUSTRATIONS OF SUGAR PLANTS.
}

Of the following plates the first four represent varieties of sugar-cane grown, during the past season, on the grounds of the Department of Agriculture at Washington and used in the experiments of the Chemical Division, as detailed in Professor Collier's accompanying report. The drawings were mado by a gentleman employed in the department. The designations given them are somewhat different from those current in some parts of the country, but are conformed to what are believer to be the most anthoritative standarls.

Plate I represents the Early Amber sugar-cane, the favorite variety with planters in Mfinuesota and the North west. What is now called the Minuesota Warly Amber cane is claimed as an improvement upon the Early Amber varieties growing formerly in different parts of Minnesota, by Hon. Seth M. Kenuy and Mr. C. F. Miller, of that State. Acting on the theory that cane in a high latitude will degenerate if grown continuously from its own seed, these gentlemen selected the finest specimens of seed from their own crops and sent them to a southern latitude to be grown. The seed product of thissonthern growth was returned to Minnesota. By this alternation of seed, and by other intelligent processes of culture, they have succeeded in establishing an new and permanent variety, which they claim to be more productive in weight of cane and to contain a higher per cent. of saccharine matter than any other grown in that State. This claim needs to be substantiated by more carefui and extenderl observations before it can be said to be finlly established.

Messrs. Kenny and Miller deseribe the Early Amber cane as presenting "the characteristies of both sorgo and imphee." By sorgo they mean the Chinese sorgo (Plate II), and by imphee, the White Liberian (Plate III), and its kindred African varieties. The Early Amber receives its name from its early ripening and from the bright amber color which characterizes its sirup when properly made. It is very rich in saccharine matter. When scientifically treated its products are destitute of that peculiar "sorghum" taste formerly complained of ; the flavor is very similar to that of pure honey. The sirup readily granulates and yields sugar equal to the best ribbon cane of Lomisiana.

The Early Amber cane on the department grounds did not grow quite so tall as the White Liberian. Its seed-heads were of moderate fullness and of very dark color.

Plate II shows the Chinese sorgo cane grown on the department grounds. Its height is about that of the Early Amber. Its seed-heads are fuller and nore compact and somewhat resemble a head of sumac; hence the synonym "sumac cane." It is also known as "Chinese cane."

Plate III represents the White Liberian cane grown on the department grounds. This variety is rather taller than the Early Amber. The stalk curves at the top, leaving the head peudent; hence the symonym "Gooseneck." It is also styled a variety of the White Imphee. The seerl-heads are shorter, more compact, and of lighter color th an the Early Amber.

Plate IV shows the Honduras cane grown on the department grounds. It grows almut me-half taller thau either of the above varieties. It seud-top is of reddish brown and spreading; hence its synonym "Sprangle Top." It is also called "Mastodon" aud "Honey cane."

B.

\section{MINNESOTA CANE GROWERS' CONVENTION.}

A nnmerons and intelligent convention of the Early Amber caue growers and manufacturers of Minnesota was held at Minneapolis, January 22, 1880. The Commissioner han the pleasure of attending this convention aud securetl a phonographic report of its proces?ings. As it embraced men of scientific attaimments and of specific acruaint-

$$
\text { is } \Lambda \mathrm{G}
$$


ance with this new branch of productive industry, the discussions were remarkable for the vast number of facts and principles alrearly accumulated in their experience. Of these it is proposed to furnish, here, an abstract showing the drift of opinion upon ail the points of culture and manufucture.

SOIL.

'There were some differences in the opinions expressed as to the availability of new land and, as nsual in such cases, experiences varied. Some having expressed the fear that new land will impart a strong Haror to the cane-sirup, Mr. Wiley, who had large experience in both enlture and manufacture, emphatically denied the fact. He said that while old land might produce a sirup of brighter color it was not at all better in taste. An advantage in using new timber land is found in the small amount of cultivation required. Costly culture on old land will not pay in opposition to cheap culture on new land. Mr. Wiley had paid as high as $\$ 15$ per acre for hoeing. New land is comparatively free from foul seed aud consequently less liable to a troublesome growth of weeds.

On the other hand Colonel Coleman, of the Saint Louis Rural World, and others contended that old land required less cultivation and produced better results. It was suggested that if it were necessary to clear old land of weeds or to fertilize it with barn-yard manure, a crop of corn should be grown npon it before planting the cane. The general opinion was in favor of a sandy upland soil, well drained, bnt not freshly manured.

In regard to manuring, facts were alleged to show that it spoiled the flavor of the sirup. A farmer had selected for his cane patch an old cow-yard. The stalks were tall and luxuriant, but the sirup would nearly "take off" the skin of the mouth."

The great majority of opinion was in favor of the indefinite repetition of this crop on the same soil. The president of the convention mentioned the case of a neighbor who had cultivated the same ground most successfully for seven years without deterioration, his product ranging from 250 to 300 gallons of sirup per acre. Mr. Day and $\mathrm{Mr}$. Dyer, of Hastings, corroborated this opinion from their own experience. 'The latter thouglit that his continued crops improved not only in quantity but also in quality.

The soil required for the cane is not necessarily very rich. A gentleman planted several knolls, too poor for wheat, in cane, and realized 200 gallons per acre of excellent sirup.

I'REPARATION OF THI GROUND.

The generai opinion was in favor of fall plowing. Mr. Farmer plows in Angtist putting the plow to the beam. This caused all foul seed and especially pigeon grass to germinate in the fall and to be killed by winter freezing. Another advantage of fall plowing was that the crop was less liable to injury from droughts in the early season. Mr. Bozarth, of Iowa, after twenty-one years' experience in raising cane was decidedly in favor of fall plowing. In one case a portion of his eane patch, replowed in spring, yielded but half as much sirup as that which had been only fall plowed. On the other hand, Mr. E. A. Chapman, of IVindham, had "demonstrated that a very large crop of cane can be raised the first year on the open prairie and at the first breakage." He had "broken 2 acres with tho La Dow harrow, harrowing it completely, and it produced the best cane ont of 5 acres." It was planted Jume 1, ou black, loam soil. He believes that with the La Dow harrow "large crops can be raised on new breakings." "It did the work so well that several farmers got down on their knees to look at the soil ; it lookerl so much like old soil." Those who practiced fall plowing were careful to stir the ground in the spring in order to destroy the weeds. Mr. Farmer, when the ground becomes sufficiently warm in the spring, goes over it with the Beaver Dam seeder and then with the drag and roller. This treatment effectually disposes of the grass, which point was generally considered of first importance.

TIME OF PLANTING.

There was same discussion on this point. The drift of opinion was expressed by the following resolution:

"Resolved, That the cane be planted as early as it is possible to work the ground properly, avoiding late frosts."

The ground should be well warmed before the seed is placed in it. In Minnesota. the average seeding time is in the fore part of May, thongh several growers had been successful with plantings still earlier. The president of the convention thought that planting should not be quite so early on ground impreguated with grass seed. Mr. Wiley advised against planting till the season was warm enough to germinate the seed quickly. He had had later plantings which produced better than some earlier ones. A late spring frost might cut down early plantiness and before they grow again the pigeon grass was apt to start up profusely. Mr. Woor had seen a fiold of cane 
some 8 or 10 inches higher than a neighboring field. He found that in the former case the seed lad lain in the ground all winter and the latter had been planted early in spring. Experience and discretion were considered requisite to settle for each locality the exact time of planting as they are in all other cultures.

\section{VARIETIES OF SORGHUM.}

In a more southeru latitude the cane grower may have cousiderable range of choice between different varieties, but for a locality so far north as Minnesota, the Early Amber, ripening within the productive season, is the only one that can be relied upon. The Commissioner of Agriculture, General Le Duc, by request, gave some very interestiug facts in regard to the experiments with different sugar plants under the direction of the chemist of the department. The Early Amber cane was tested July 18, when the seed-head was just out, and showed 3.77 per cent, of glucose and 4.43 per cent. of sucrose. It was again tested August 16, 29 days afterwards, and found to contain but 1.54 per ceut. of glucose, while the sucrose had risen to 14.67 per cent. Here was indicated a most important chemical change, in which not only the sucrose was enlarged, but over half of the grape sugar or glucose changed to cane sugar or sucrose. A third examination, September 16,31 days afterwards, when the seed was ripe, hard, and dry, showed a still further enlargement of the sucrose to 15.95 per cent, and a still further absorption of the glucose, of which 0.65 per cent. was detected by analysis. Another examination, not long afterwards and just following a severe frost, showed little or no change, the sucrose had increased to 17 per cent. and the glucose to 1.00 . These experimental results place the Early Amber almost on a par with the best Lonisiana cane.

The departmental experiments included several other varieties of sorghum and other sugar plants. The Chinese cane was examined at the same times that the Early Amber, and gave the following results. When the seed-head was just out, there was 5.55 per cent. of glucose and but 1.85 per cent. of sucrose; when the seed was hard and dry, there were developed 1.85 per cent. of glucose and 13.90 of sucrose; after the frost, the glucose had enlarged to 1.85 and the sucrose had declined to 13.10 . The White Liberian cane showed its maximum of sucrose 15.20 per cent., and its minimum of glucose 0.95 per cent., when its seeds were dry. The Honduras, before the seed-head was out, gave 5.13 per cent. of glucose and 1.20 per cent. of sucrose; when the seed was hardening, its ghcose had fallen to 1.30 per cent. and its sucrose had risen to $\mathbf{1 5 . 1 0}$.

The Lollisiana cane of 1879 gave a maximum of but 12.47 per cent. of sucrose; the growth of $1 \times 78$ gave 16 per cent. The fact seems sufficiently evident that the sorghum as a sugar plaut contains an amount of crystallizable sugar fully equal to the Louisiaua cane.

\section{SEED.}

It was suggested that by steeping the seed in warm water for 24 to 48 hours it would become sprouted, and hence would grow more rapidly. "But, on the other land, it was urged that a dry season would kill the sprouted seed and the crop would be a failure. Nature porvides the most opportune moistening.

The weight of opinion was decidedly in favor of seed brought from the latitude of Saint Louis. Some cane-growers had sent their seed to Missouri and Kansas to have a crop grown and its seed retumed. Among the decisive facts reported, Mr. Miller statel that his seed imported from. Sonthern Indiana 11 years before had produced on its first sowing stalks from 12 to 15 feet high; but by planting the seeds of each crop its successor shorred a declining height of cane until it grew but 7 or 8 feet high. Mr. Wylie had averaged, with seed brought from the South, 273 gallons per acre; the following year, using his own seed, he obtained but 223 gallons, a falling off of 50 gallons. The president of the convention had found, as a general thing, that the deterioration of seed was not very marked till the thixd year. The Southern seed did not excel so much in an earlier ripening of the crop as in its increased product, the excess, in some cases, amounting to one-third. The sentiment of the convention was expressed in the following resolution:

"Resolved, That Early Amber eane-seed, grown in the latitude of Saint Louis, is the best seed for Mimnesota for two years."

The seed has a value of its own. for consumption on the farm. It was pronounced excellent for feeding liogs, sheep, or ponltry. The 5 or 6 tufts growing upon a hill of cane were estimated as equal in feeding value to three average ears of corn. A member of the comvention promounced it equal to oats. Another had foumd that the seed fed to sheep made the fleece look lively and polished.

\section{PLANTING.}

Plant just deep enough to secure moisture. Hence, earlier plantings should be shallotwer than late ones. There vas some difference of opinion as to the arrangement of the hills. The presislent of the convention, Mx. Kenny, plants in rows $3 \frac{1}{2}$ feet each 
way and uses 2 poumds of seed per acre or 6 or 7 seed to the hill; at the second hoeing lie thius them out. Mr. Day marks the rows 3 feet each way. Seed should be planted not down in the trough of the marking furrow where a heavy rain is apt to wash it away, but on the edge. Mr. Wiley plants from 15 to 18 inches one way and 3 feet the other way, the rows rumning north and south, thus doubling the number of hills planted by Mr. Day. A tract of 4 acres sown broadeast was reported as producing at the rate of 450 gallons per acre.

Mr. Miller practiced stepping upon the seed as they were placed in the ground. Several planters present sanctioned this practice, urging that the close pressure of the

- soil around the seed enables it to germinate more rapidiy. It was objected that stepping the seed caused the ground to bake, but it was replied that this was the case only with wet clay ground.

\section{CULTIVATION OH 'THE CROP'。}

The leading point presented in the culture of cane is keeping it clear of needs. This requires prompt action with the hoe, drag, and cultivator. A grain farmer suggosted the use of Thomas's harrow, of 90 steel teeth, but the general sentiment was that the cane-plants were too tender for any such treatment. It slould be thoroughly hoed until large enough to cultivate with the plow or cultivator.

TIME TO CUT THE CANE.

Mr. Whiting had found the best results from early eutings, but admitted that in the later cuttings it was the extreme hot weather that had changed the sucrose to gincose. The president thought the proper time was when,the seed is in the stiff ilough, or from August 28 to September 1. It seems to improve for a few clays, hut afterwards it begins to decline in saccharine matter. The earlier the cutting after the seerl has reached the dough stage the larger the product and the brighter and cleaner the sirup. The question of suckering was considerably debated, and facts both pro and con were alleged, but the convention expressed no collective opinion.

\section{HARVESTING.}

The question of stripping the leaves elicited consicterable discussion. On the ono hand it was urged that if the leaves were put through the mill with the stalk they would absorb a large portion of the juice. It was replied that this would not be the case with mills of sufficient power. Force enough should be applied to express the whole of the juice.

It was complained that cane-crowers lost a great deal by purchasing cheap and poor machinery. One gentleman estimated the cost of stripping the leaves before cutting at $\$ 15$ per acre. Some advocates of stripping were disposed to admit that it would not pay unless labor were plenty and cheap. The Commissioner of Agrieulture stated that the department experiments showed little or no difference between stripped and unstripped cane, although the department mill was an indifferent one. Several urged that if the leaves were dry they would not in any way affect the quality of the sirmp. 'The convention did not express any general opinion upon this point. It was cousidered of first importance that the tops be completely removed, as a single top sent through the mill would spoil a large amount of sirup.

The cane should bo cut, some say, 6 ot 8 inches from the gromul, aud others, at the first joint. The top should aiso be cut off from 18 inches to 2 feet; there is no sweetness in either the tops or the roots. Some planters laid the cane in windrows, and others were opposed to the practice as exposing the leaves if not the stalks to mildew. The storing of caue after eutting started discussion. Some insisted that it should be inmediately placed under cover to avoid the evaporation of the sun's rays. Others piled in ridges 4 feet high, and covered the mass with marsh hay. To this it was objected that the lack of rentilation would spoil the eane. To obviate this difficulty some planters were in the habit of laying poles along the piles every i feet, in order to ahmit fresh air. Some would pile it as eane is sometimes piled in the ficld, crossing the hills in such a way as to secure ventilation and to shed the rain. Caue that had been kept in these different ways for several weeks were reported as liaviug produced large and fine sirup products. One planter produced juice that ranged from 7 to 10 , from cane that had been stripped and covered with leaves, while other cane of the same lot, that had been ground with leaves on, ranged as high as 12 . Dr. Goesman, of Massachusetts, was quoted as saving that there was a rain of 3 per cent. by being allowed to lie with the leaves on. One planter had found such cane to test 11, while stripped cane tested only 10. The higher per cent., however, was by many attributed to the evaporation of the watery part of the sirup, leaving the saccharine matter in larger proportion to the residne. Others had not found the juice to be any sweeter after evaporation. 
Mr. Wiley thought it would pay every farmer to have his own mill. The yrice of the sirup in the market ranged frow 35 to 50 cents per gallon. The mill owner will charge from 15 to 25 cents per gallon; if to this be added a charge, say of 10 ceuts per gallon, for lauling to a distant mill, it is easily seen that the grower gets but a swall proportion for his labor. It cost the president $\$ 19.14$ to liaul the cane of 12 acrespart of it near the mili, and the remainder about a quarter of a mile away. It is better for the farmer to have the profit of manufacturing the cane as well as of raising it. In moving the cane from the field there was a strong expression in favor of bunding it. Some would decapitate it with a broad-ax, after binding. Some used a common dump-cart with an elongated box. The points kept in view, both in the transportation and in the storing of the cane, were protection from the weather, and such rentilation through tho mass as wonld prevent mildew.

\section{(IRINDING.}

The first step in the manufucture of sugar and simp is the grinding or crushing of the cane to express the jnice. Mr. Miller saw men at work with a very indifferent apparatus, which extracted but a small portion of the juice. On remonstrating with them he was told that if you extracted too much of the juice it soured the whole. This ignorant prejudice assumes what chemical analysis and intelligent experience has exploded-that only a portion of the juice is fit for evaporation. The almost univerRal expression of the convention was in favor of extractiug the last possible portion of the juice. For this purpose tihe most powerful mills were considered as essential to the working of the crop. The president, Mr. Kenuy, has a mill weighing 4,000 pomm, with rollers 16 inches long and 16 inches in diameter; with a 24 -horse power engiue it expresses 4,0010 sallons of juice per day, getting from 65 to 70 per cent. of the juice in the stalk.

Mr. Keating had a small mill, expressing about $\mathbf{7 5}$ gallous per day, that worked very well, cutting overy stalk at the joints and feeding 8 to 15 stalks at a time. Mr. Whitney says that small mills, like the Victor, it not too much erowded, will crush the cane ferfectly dry. Clark and Utter's mill, manufactured at Dodge Center, with back gearing, was reported as a very efficient mechanism; its cost was \$100. The general sentiment was that the milling machinery should be snficiently powerful to obtain the largest practicable per cent. of juice in the stalk. It was estimated that Minuesota farmers had lost thousands upon thousands of dollars through the use of poor machinery. Mr. Whiting gave a humorous account of his efforts to construct a wooden mill, which amounted to nothing.

In regard to the method of feeding the mill, it was urged that the caue shonld be inserted evenly, and with the butt ends foremost. The supply shonld be regular and up to the normal capacity of the rollers. It is not desirable that it be full at one time and lialf full at another. There is a considerable art in properly feeding a mill. An incompetent feeder will clog it up, from time to time, by an irregular supply.

\section{TREATMENT OF THE JUICE.}

After a thorongh extraction of the available juice in the cane, the next step is its evaporation and defecation. Heat is the great agent in the clarification of the juice. Hence Mr. Earle claimed that the most important element in the whole process of manufacture is a good furnace. He would select a hillside fronting the direction of the prevailing winds in September, so as to secure as great draught as possible; place the furnace on a level lower than the mill, with a fali of at least 10 feet. With a furnace in this position, properly construeted, he has had but littlo difficulty in throwing a flame 16 feet higher than any ordinary height of stack, using the bagasse as fuel. It can be done also with light wood, but not with heavy wood. The furuace must have a ventilating flue. Mr. Wylie had scared his horses at night by the bright flames coming out of his stack: Tho president, Mr. Kenuy, suggested it was not just the thing to send the heat in tiames 15 feet above the stack; all that can be utilizesl is that which operates under the evaporating pan. Under the instructions of Mr. Swartz he had reconstructed his arch so that instead of a great blaze at the top of the stack there was an inteuse heat uuder the pan.

Mr. Earle had arranged his pans on difforent levels so that the back pan was $\tau$ inches higher than the other. Mr. Dickenson followed the directions of an expert in the construction of his furnace, but conld not get the back part of the pan to boil till he had torn ont the furnace and reconstructed it in accorlance with his own. ideas. He raised his stack from 15 feet to 28 feet and would prefer at least 30 feet. 'To coutrol the draught he put in dampers. He adopted other contrivances for concentrating the heat nnder the pan. As cord-rvood was too coarse, he hired a man to split it fine. Oak and maple were unfit, but basswood, poplar, and other light, free-burning kinds 
will just meet the demands. The more rapid and intense the heat under the pan, the more complete the evaporation and defecation of the juice. Mr. Miller, who had formerly shared Mr. Dickenson's prejudice in favor of light wood, saw a counter-demonstration in Mr. Swartz's factory. There heavy red oak and jack-oak sticks were made to proluce an intense heat by mingling them with coal. Mr. Swartz's arch was 2 feet deep and $2 \frac{1}{2}$ feet wide. It is bost not to cramp the arch, but make it wide enough for the embers to spread and present a broader heating surface.

There were differences of opinion in regard to smoke-stacks. The prevailing tendency to make the pipes too small was noted by several spoakers. One inember stated as a scientific principle that the cubic contents of the stack or ehimney should be at least two-thirds of that between the grates and the fire. Mr. Miller thought Mr. Swartz's chimney a perfect pattern. It was 35 feethigh, and from 2 to 3 feet in diameter. No flame came above the stack at night. The width of his own fire-place is about :30 inches, with which he is able to boil as fast as desirable with dry basswood. and poplar.

Mr. Swartz does not break the seales off his pan, but lets them remain till they become loose of themselves; then they would be removed in the daily cleansing of the pans. He finds that the Liberian cane deposits a seale entirely different from the Early Amber. The sirup of the former does not turn neariy as early as that of the latter. Mr. IVylie gets rid of them by burning a forkful of straw under the pan when it is perfectly dry and clean. 'Then under the quick flame the scales will blister and fall off.

Mr. Wylie for five years had nsed the "Cook" paus. A neighbor, Mr. Stubbs, had marie a new one, that is patentable, costing but $\$ 35$, while Cook's cost $\$ 90$. It is from 14 to 16 feet long, and has two partitions in it. It easily makes 100 gallons a day, a result requiring hard labor with Cook's pans. One man, with two of Stublos's pans, can easily make 200 gallons a day, and read the nerspapers besides. This opinion, however, was far from unanimous. A member had used Stublos's pan for two years, but was dissatisfied with its results. It employs the principle used in the Faribault refinery in the collection of the skimmings. Mr. Wylie described the "Stubbs" pan with the airi of a diagram; sides 14 inches high, 36 inches broad on top, 16 feet long. It is arranged with a center foundation so that it camnot burn; the heat is ent off with a damper. In producing 2,725 gallons of sirup, Mr Wylie had used $4 \frac{1}{2}$ corls of wood; at $\$ 1.25$ per cord. The center arch is within 5 feet of the front of the pan. It is set level. Five years ago the Cook pan only was used in Medina, Minn., now not one is in use there, while twenty Stublos pans are used. It is better than the Blymyre pan becanse it skims itself, and there is no clinging of the skim to the sides.

Mr. Miller had invented an attachment to the Cook pan, which orercomes all the difficulties heretofore complained of. Cook's pan, with this attachment, runs the juice in and the simp out without change. It does not discolor the sirup by reboiling. Hence the sirups made in Cook's pans are clearer, and freer from muddiness, than other siruns. Mr. Wylie denied that sirups boiled in the Stubbs pan were at all muddy, and showed a very fair specimen. The merits of different pans were presented at somo length by different speakers.

C.

\section{ILLUSTRATIONS OF SUGAR MACHINERY.}

The following illustrations of the mechanical processes of sugar-making in different parts of the world are not intended to advertise the business of the mannfacturers who have so kindly furnished cuts of their machinery for this report, but to present to farmers desiring to engage in sugar-production type specumens of approved methods of working up the caue. There are other manufacturers whose models do not appear in this report, who, doubtless, are able to furnish machinery at reasonable prices. The purpose of these illustrations is to present to sugar-growers some of the facilities which the market affords for their enterprise and to put them upon inquiry as to where they can obtain the best machinery and at the lowest prices.

Plate $V$ shows the Vietor eane mill, an apparatus in very common use. It is constructed with vertical rollers on a plan suited to horse-power, or with horizontal rollers for water or steam power. The horizontal mills are fitted with extra gearing, are necessarily heavier auh require greater motivo power to accomplish the same result. Plate V shows the vertical mill, of which seven sizes are on the market; the smallest is a 1-horse power mill, running 40 gallons of juice per hour, and weighing 395 pounds, at a cost of $\$ 48$; the largest is a 4 -horse power machine, 1,900 pounds weight, rumuing 170 gallons per hour, and costing $\$ 230$.

Plate VI shows the vortical Victor mill, with the horse-power operating in a lower story. The advantages claimed for this arrangement are, 1 , the mill is more steady; 
2 , horses and cane do not interfere with each other; 3 , the bagasse is more easily removed; 4 , the juice flows down into the evaporator. For five different sizes the prices are $\$ 90, \$ 105, \$ 140, \$ 155, \$ 240$.

Plate VII represents a horizontal Vietor mill adapted to steam or water power, of which three sizes are in the market, viz, No. 1, weighing 2,200 pounds, and valued at $\$ 250$; No. 2, 3,500 pounds, $\$ 350$; No. 3, 4,000 pounds, $\$ 450$.

Plate VIII, Fig. 1, represents a portable "Cook" evaporator, of which three sizes are for sale. These pans are 44 inches wide and from 6 to 9 feet in length, ramging from 40 to 90 gallons per day. When the paus are of galvanized iron, the prices aro, respectivel $5, \$ 6.5, \$ 75$, and $\$ 35$. With copper paus the prices are from $\$ 55$ to $\$ 70$ higher. Each coutains a portable furnace. The whole can be lifted into a wagon by two men and trausported from field to field with a light Vietor mill, and thus save the transportation of the cane.

Plate VIII, Fig. 2, represents a "Conk" stationary evaporator, of which there are seven sizes, adapted to corresponding sizes of the Victor mills. They are bedded npon brick or stone arches, and are 44 inches wide, ranging in length from 6 to 15 feet. Their capacity is from 40 to 180 gallons per day, and their price from $\$ 30$ to $\$ 90$ for galvanized-iron jans, and from 80 to $\$ 2010$ for copper pans. Furnace frouts and thots cost from $\$ 5.50$ to $\$ 8$; irrates, from $\$ 4$ to $\$ 8$.

Plate IX represents still larger sizes of these pans.

Plate X represents a complete sugar factory, the size and cost of which must necessarily vary with the number of acres of sugar-cane to be worked up. A is the juicetank; the juice, after running from the crushing-mill into a tank on a lower level, is pumped up to the juice-tank in the npper portion of the building. $B$ is the defecator for the elimination of crude impurities. C C are settling tanks; D, supply tank from which the evaporator is feel; $\mathrm{E}$, a Cook evaporator; $\mathbf{F}$, supply-tauk for the strike-pan; $\mathrm{G}$, strike-pan, in which the semi-sirup is reduced to the proper consistency for sugar; $\mathrm{H} H$, receptacles for seum; I, truck for carrying the sirup to the sugar room; $J$, the sugar-room, with cooliug-boxes, barrels, \&c. ; here an even temperature is kept un to assist gramulation; here, also, the sugar is drained and stored.

Plate XI represents a stean plant, or steam train, consisting of a duplex mill for grinding the cane. It has two sets of housing, and each set two rollers. Each stand of housing and rollers is placed 6 or 8 feet from centers, and the intermediate space occupied by an endless carrying frame traveling in the same direction as the rotation of the wheels, and at the same speed. The cane is fed to one set of rolls. called the roughing-rolls, which slit and crush it. It is then received by the carrying-frame of wooden slats and carried to the other set of rolls. It is moistened, on its way, by a spray of water thrown by a steam jet. 'This saturates and fluxes the suerose, not yet extracted, which is then obtained. 'This residuum, though diluted with water, is the richest of the whole. 'This mill, when properly fed, will grind from 5 to 6 tons of cane in twenty-four hours.

Plate XII is a vertical view of the last.

Plate XIII is a defecating tank 8 feet long, 5 feet wide, and 2 feot deep. Over the bottom is spread a manifold of steam pipe, and contains a strainer throngh which the juice, perfeetly elear, can be drawn off. The tank may be cleansed with pure water for a fresh filling. Each tank-finl can be handled in thirty minutes. Two of these tanks are comnected with the mill, and are ample for defecating 600 gallons per hour.

Plate XIV represents an evaporator 6 feet in diameter and 4 feet deep. Each is furnished with coils of stean-pipe 1.25 feet long, and a diaphragm directing the currents of evolntion over the steam-coils up the outside and down the middle axis. In the center of the pan is an adjustable, funmel-shaped skimmer, which may be raised or lowered, so as to be on a level with the surface of the boiling juice. It catehes all the seum gatbered by the currents and delivers it through a pipe penetrating the bottom, outside of the evaporator. 'Two evapor ators will reduce 600 gallons of defecated juice to one-half the volume in an hour and a half.

Plate XV represents the concentrator, which differs from the evaporator by having a closed top and a water-jet condenser, producing a vacunm. In this vacuum 600 gallons of evaporated juice are reduced to 200 , or only one-sixth the volume that entered the evaporator. 'This reduced liquid is called semi-sirup, and can be stored in tanks or shipped in barrels to a refinery, or reduced to a dense sirup in a vacuum-pan constructed very much on the same plan as the coucentrator.

A complete sugar-mill, embracing the above apparatus, with engines, boilers, centrifugal dryer, tubs, tanks, and all other necessary appliances for making sirup and sugar, will cost about $\$ 10,000$.

Plate XVI represents a very lieavy crushing mill. The smallest size of this series of mills has rollers 12 inches in diameter and 20 inches long, expressing from good ripe cane about 150 gallons of juice per hour. Larger sizes do a proportionately larger share of work.

Plate XVII is an "exhaust steam clarifier." Heat is applied to the juice; the albumen is coagulated and the acid nentrulized by milk of lime, which also renders insol- 
uble sundry soluble impurities and precipitates them. But as an excess of lime attacks the sugar in the juice it is of special importauce that its quantity be regulated. In this clarifier this is done by means of a vessel graduated by inches, each inch corresponding to $4 \frac{1}{2}$ cubic inches of milk of lime. The total quantity of the linae ranges from 0.01 to 0.03 per cunt. of the total weight of the juice. When the proper temperature has been acquired, the seum rises to the top and begins to break and show bulbs. The proper point of defecation is then considered to have been reached, and the clarified sirup is drawn off by means of a double cock in the bottom of the defecator. 'The seum and precipitates are discharged through another channel.

Plate XVIII is a "direct steam evaporator," which receives the clarified juice from the steam clarifier shown in Plate XVII. The juice is boiled by means of a coiled steam pipe. The resulting scum boils over into a trougls around the upper edge of the evaporator and is itself subjected to defecation afterwards.

Plate XIX represents a "steam train" of three clarifiers and one evaporator, represented in Plates XVII and XVIII. This steam train requires but fow men to work it and is very cleanly in its action. It dispenses with pumps aud ladles. The sirup is fully prepared for the vacuum-pan.

Plate XX represents a vacuum-pan. This pan can be placed upon framing or walls built up in the house, but it is considered preferable to support it upon iron columns as in the plate and independent of the building. The elevation should be sufficient to admit of discharging the "strike" into the "centrifugal mixer." The plate shows a vacumm-pan arranged to work on the "wet" system; that is, in combination with a watex-pump. The sirup is boiled at a very low temperature, producing a larger quantity and a better quality of erystallized sugar, yet the boiling is so rapid that the sugar loes not get time to becomo inverted. Heat is applied to the sirup by means of a coil of copper pipe filled with steam, which, on being condensed, is conducted back to the boiler.

Plate XYI represents a combination styled "Multiple effect." It embraces a direct fire evaporator for the first juice, working under a vacuum iu connection with a strike pan with the combined water and vacunm pump, also the mixer and centrifugal machine. 'This machinery is especially designed for making sugar from sorghum and cornstalks. The process consists in boiling the juice in a tubular or cylindrical boiler very similar to a steam-boiler, the fuel being only the bagasse. The vapor is conducted by pines to the valves in the vacuum-pan and admitted to the copper coil which serves as a surface condenser. A.vacuum-pump draws oft the condensed liquid and the vapors. As the liquid thiekens it is passed to the strike-pan where, by means of a higher vautum, the boiling is perfeeted into crystal. It is then discharged into the mixer, where it is gently stirred to prevent "settling." It is then drawn through valves in the bottom of the mixer into the centrifugal, where the molasses is eliminated and the graunlated sugar fitted for packing. The molasses is discharged into a tank and reboiled, after which it is passed into cans and allowed to granulate; finally, the molasses is eliminated, as in the first run. The only nse of a steam-boiler in this process is to drive the cane-mill and the centrifugal, which will require a small engine. This feature is claimed as a special advantage in cutting down the expense of the process. As there will be no very heavy pressure there is no danger of explosion, and consequently the boiler may be made less expensive. This method of reducing in vacuo prerents caramelization, as the air is kept off and only a low heat employed. The prices of this apparatus vary with the results to be obtained.

Plate XXII represents a form of centrifugal machine called the "German style." It rums in elastic bearings and does not require to be set in masonry. Its manufacturers claim that it will purge from 1,000 to 1,500 pounds of sugar per hour. Price, $\$ 100$, with $\$ 10$ extra for boxing.

Plate XXIII represents a "Hanging centrifugal machine," especially adapted to certain classes of rummy sugars. It requires no specific skill in the oporator. Price, without frames, $\$ 775$; with frames, $\$ 955$, or $\$ 900$ each for two machines; boxing, $\$ 10$ for each machine. It is larger than the German machino deseribed in Plate XXII, and discharges the sugar through the bottom. It will purge from 2,000 to 4,000 pounds of sugar per hour.

Plate XXIV represents the latest improved centrifugal driven from below. It will purge from 2,5 20 to 5,000 pounds of sugar per hour. Price, with frames, $\$ 1,000$; tivo miachines, $\$ 950$ each; a machine without frames, $\$ 350$. The sugar is discharged through the bottom.

Plato XXV, Fig. 1, is a cheap home-marle ovaporator, which can be put togetler by any ingeuious mechanic. It is constructerl by putting wooden sides and ends upon a galvanized iron or copper bottom.

Plate XXV, Fig. 2 , is a pau for enoling simp sent by a corresponilent. Its motloul is suthiciently clear from the diagram.

Plate XXV I represents a newly-invented "ovaporator." It is available either for concentrating eane-juice to the density of sirup to be finishor in the vactum-pin or, if the racum pan is not used, directly up to the point of granulation of sugar. Th 
defecated juice is bronght through a canal shown on the left of the picture aud deposited continuously in the first talble of the evaporator. When it has acquired a depth of two inches steam is introduced into the pipes and ebullition immediately commences and the impurities begin to rise. The latter llow ontward to the sides and are held there hF a constant outward current. They may be removed without any waste of the juice. The discharge of water resulting from condeusation is regulated by a valve. The gate is then opened and the juice is passed to the second table where it is subjected to the same process, and then to the third table. By the time it is ready to pass from the third table it is reduced to a density varying from $18^{\circ}$ to $32^{\circ} \mathrm{B}$. It then passes to the strike-pan on the fonrth level where it is bronght up to the sugar point. It is then drawn, either in a contimuous stream or by "strikes," into molds or hogsheads. Not less than 15 hogsheads or 30 moulds should be ready for the sirup. These should receive, each in its turm, about 2 inches depth of the liquid, and wheu the last has received its quota hegin again at the head of the series. This method of filling gives the sugar time to crystallize and cool; it dispenses with tanks and with a second handling. It is clamed in behalt of this apparatus that its elimination of impurities at the commencement of the operation, the limited time in which the sugar is subjected to the heat, and the low temperature used, cause only a minimum of inversion of cane sugar into grape sngar. An apparatus producing a cubic yard of sugar per hour is 29 feet long by 7 feet wide. It will require abont 4,000 bricks to constrmet the walls. 'These trains are of all sizes desirable, with capacities ranging from 100 gallons per day to 1,500 gallons per hour. Prices from \$50 for two small pans to $\$ 3,000$ for large trains complete.

Plate XXVII represents the Stublos Evaporator. The first cut shows the pan with two compartments. The first occupies three-fourths of the pan; the second compartment the remaining fourth. The jnice enters the first compartment near the smokestack in a regular stream, passing around the circle over the fire-box to cross-partitions, where it thickens to a semi-sirup. Being over the hottest part of the furmace, it raises to a light foam, which breaks to the lowest point where the cool juice enters, not only keeping back the green seum, but carrying all the seum off of thirty feet surface, where it is scraped off without loss of sweet. The semi-sirup is turned into the second compartment at intervals to be finished under full control of heat governed by dampers. When done, to be run oft with scraper, letting semi-sirup follow. Boil rapidly with two inches juice in order to cleanse well.

The second engraving represents the furnace. Shonld be built of brick, with eightinch wall fourteen inches above fire-grate; the balance seven inches. A sectional arch with one damper in center, hinged at the back end to swing to back wall; also damper across the mouth of left flue. The smoke-stack stands back as the cut indicates. The smoke-stack shonld be 16 feet high, 14 inches diameter.

Galvanized iron:

Price of evaporctors.

No. 20,16 feet long by 40 inches wide . . . . . . . . . . . . . . . . . . . . . . . . . . . 850

No. 20,12 feet long by 36 inches wide.................................... 40

Charcoal iron :

No. 20,16 feet long by 40 inches wide................................. 40

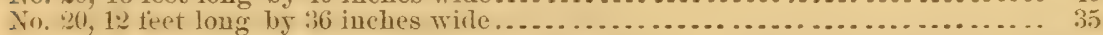

Plate XXVIII represents the mill, evaporators, \&c., on the grounds of the Department of Agriculture at Washington, where the experiments of the last two years were performed. A description will be found in the cliemist's report.

\section{SUGAR-MIKING AMONG THE HINDOOS.}

In 1822 the English East India Company published an exhaustive report upon "the culture and manufacture of sugar in British India." In the appendix is printed an extract from "Dr. Buchanan's journey from Madras, through Mysore, Canara, and Malabar, in 1800." The following illustrations present the processes in use among Hindoo sugar producers at the begimning of the present century.

Plate XXIX represents a sugar-mill consisting of mortar, beam, lever, pestle, and regulator. The mortar is constructed of a tree trunk, and is about 10 feet long and 14 inches in diameter, and is sunk 8 feet in the ground, leaving but 2 feet above the surfice. The upper end is hollowed into an inverted conical depression in which the cane is crushed by a pestle, the juice being delivered by a tube running from the lower part of the mortar. Around its edge is a groove which receives what juice may overHow and-conducts it by a pipe into the main receptacle. The beam is a portion of $a$ tree 16 feet long and 6 inches thick, cut below the forks. The angle is enlarged and rounded, so as to embrace the mouth of the mortar around which it revolves, supported by a flange. 'The forks are then drawn together. On this beam are seated the millfeeder and the ox-driver. The lever lolds the pestle in its place, being held at one 
end by an upright piece of timber, called the regulator, to which it is pinned, and at the other end by ropes. The revolution of the pestle upon the small cut cane expresses the juice; the bagasse is removed by hand. The shape of the lever and the cavity in which it receives the upper end of the pestle causes the latter to revolve on an oblique axis; the lower end of the pestle is conformed to the conioal depression in the mortan so that the cane may be subjected to the closest pressure. It is scarcely necessary to repeat the observation of Dr. Buchanan, that the machine is badly contrived. The sugar-makers of the village have rach his turn at the mill, which is run night and day till all the crops have been worked up. The mill grinds about 56 pots of juice, or 218 gallons, in 24 hours. The oxen are driven at a rapid gait, and require to be changed several times during the day and night.

Plates XXX and XXXI represent modified forms of the Indian sugar-mill. The principle of pressure is the same in all, being the revolntion of a pestle on an oblique axis in the conical depression of the mortar. The modifications are shown with suffi cient clearness in the plates.

Plate XXXII represents a set of sugar machinery in use at Burdwan, near Calcutta, in 1792, as described in the minutes of the Indian Board of Trade of that year. The mill consists of $t w 0$ small wooden grooved eylinders working in a horizontal plane and propelled by two men turning spokes connected with each eylinder. This apparatus secms to be very ineficient compared with what was employed on the West India su gar plantations, but it is cheap, and worked by cheap labor. Heavs iron cylinders brought from Eugland at great expense were unable to compete with the native ma chinery on account of the greater cost of working. In the left rear of the sugar-mill is seen a furnace with earthen pots for the boiling of the juice. The furnace is shielded from the weather by a shed open at the sides. The juice is dipped from one pot to another till, in the judrwent of the boiler, it is sufficiently condensed. In this state it is called goor, a word which has no equivalent in English. The English in Hindoos tan confound goor, sirup, or molasses under the general name of jaggary.

The goor goes to the myrah or boiler, who purities it by different processes. The gencral method is that of boiling. Sometimes the molasses is first drawn from the grain and the goor is then boiled with milk, or with milk and water. In other eases the foor is only boiled and purified. Milk, lime, and lye from plantain ashes are used to cleanse and gramulate the sugar. When boiled sufficiently it is put into earthen pot. and two sorts of aquatic weeds of a supposed alkaline quality are used to drain off the sirup as clay is by Europern refiners. Clay is also used in some parts of India. Suga thus prepared is called cheenee. Variations from the above methods are noted as prev alent in different parts of the country.

STEIVAR'T'S PROCESS.

Plat. XXXIII represents the necessary addition to the orlinary sorghum machinery if the process of Mr. F. L. Stewart, of Murraysville, Pa., be used in making sugar. The plate illustrates the mode of using his powder B. H is the heating-tank, D the defecating-tank, from which elear juice is passed from the heater $H$. A stout, wellhoojed half-harrel or ten-gallon cask, C, stands alongside the defecating tank, the head of which is pierced with two holes, at opposite sides, one five-eighths inch and the other one and a quarter inches in diameter. $F$ is a lacquered funnel, with a gun ring fitting around its neck; $r$ a plug, with gum fittings to insert tightly in the throat $P$, and a pieco of rubber tubing, $\mathbf{R}$. 


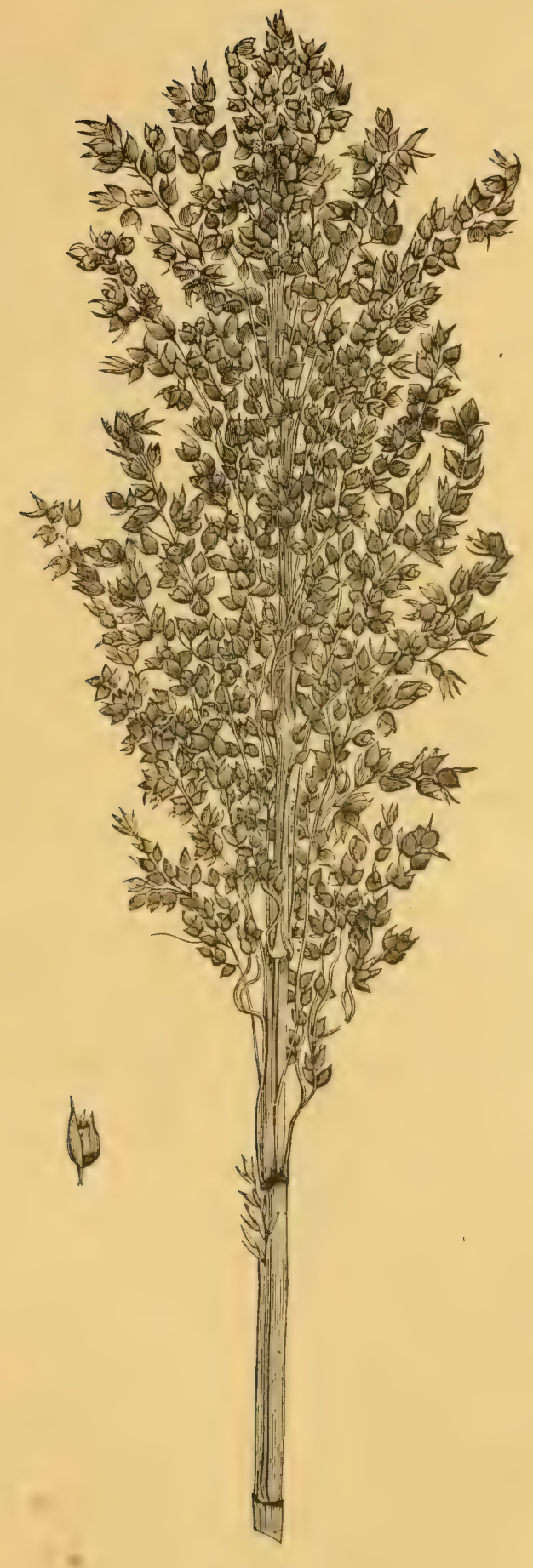

EARLY AMBER CANE.

|Gromn upon the Department groun ls luring the season of 1879. 



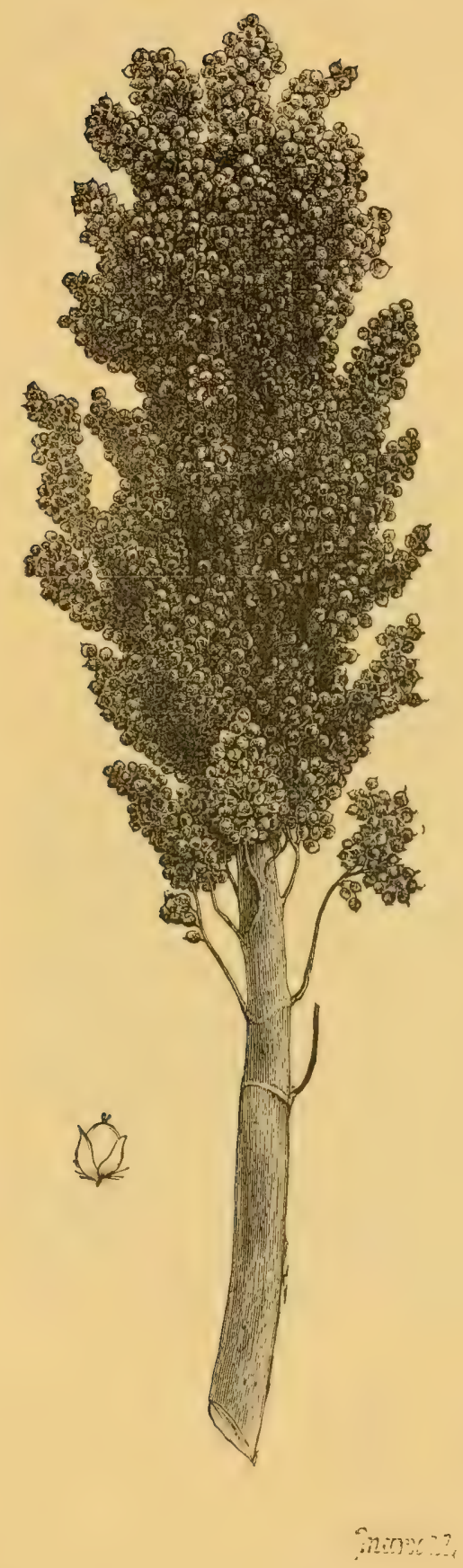

CHINESE SORGO CANE.

Symongm: Sumac Cane, Chinese Canj.

[Growu upon the Department grounds during the season of 1879.] 



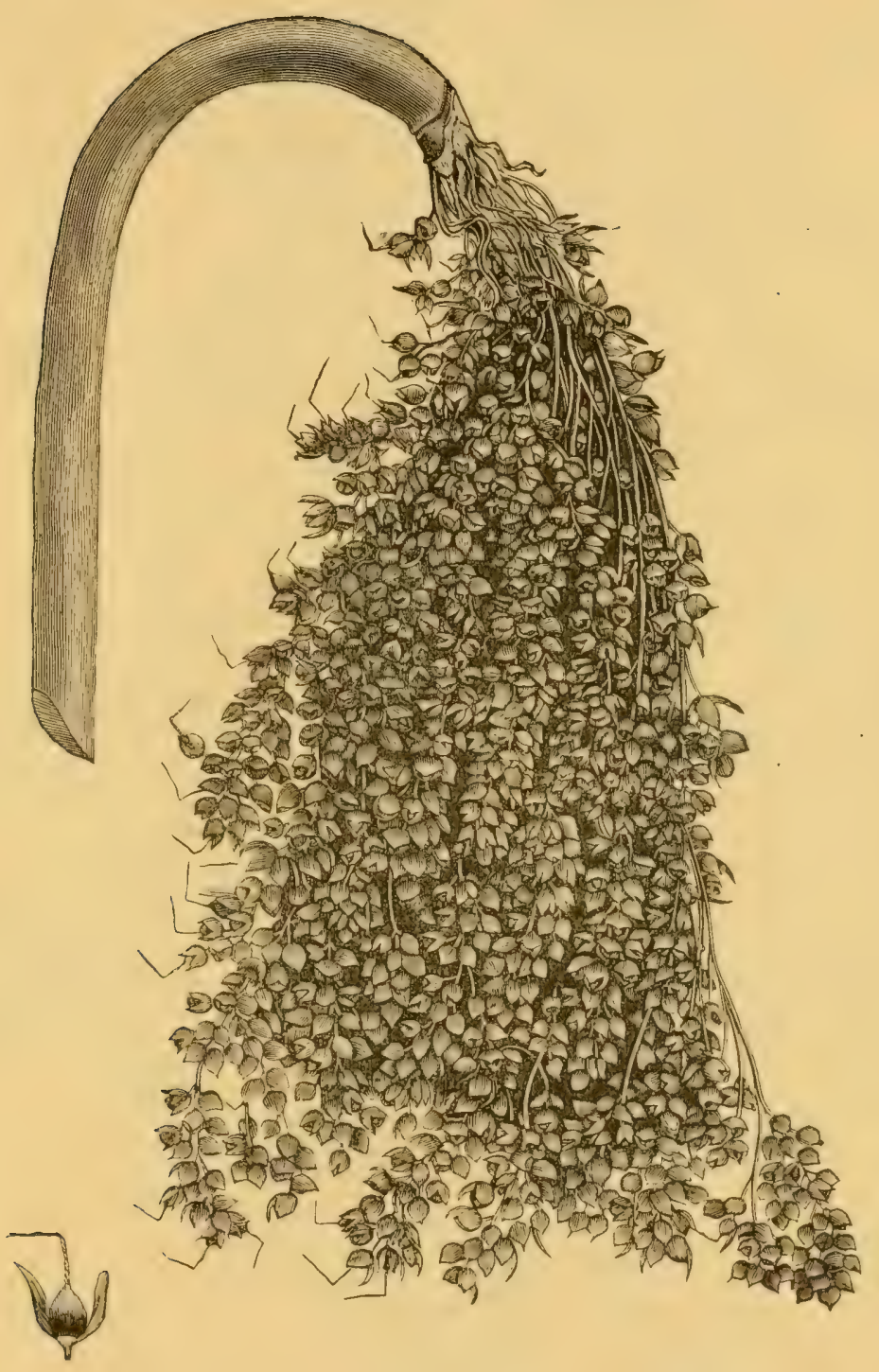

marx del.

WHITE LIBERIAN CANE.

Syuonym: Goose Neck, White Impliee.

[Grown on the Department groumls duringer the season of 1879.] 



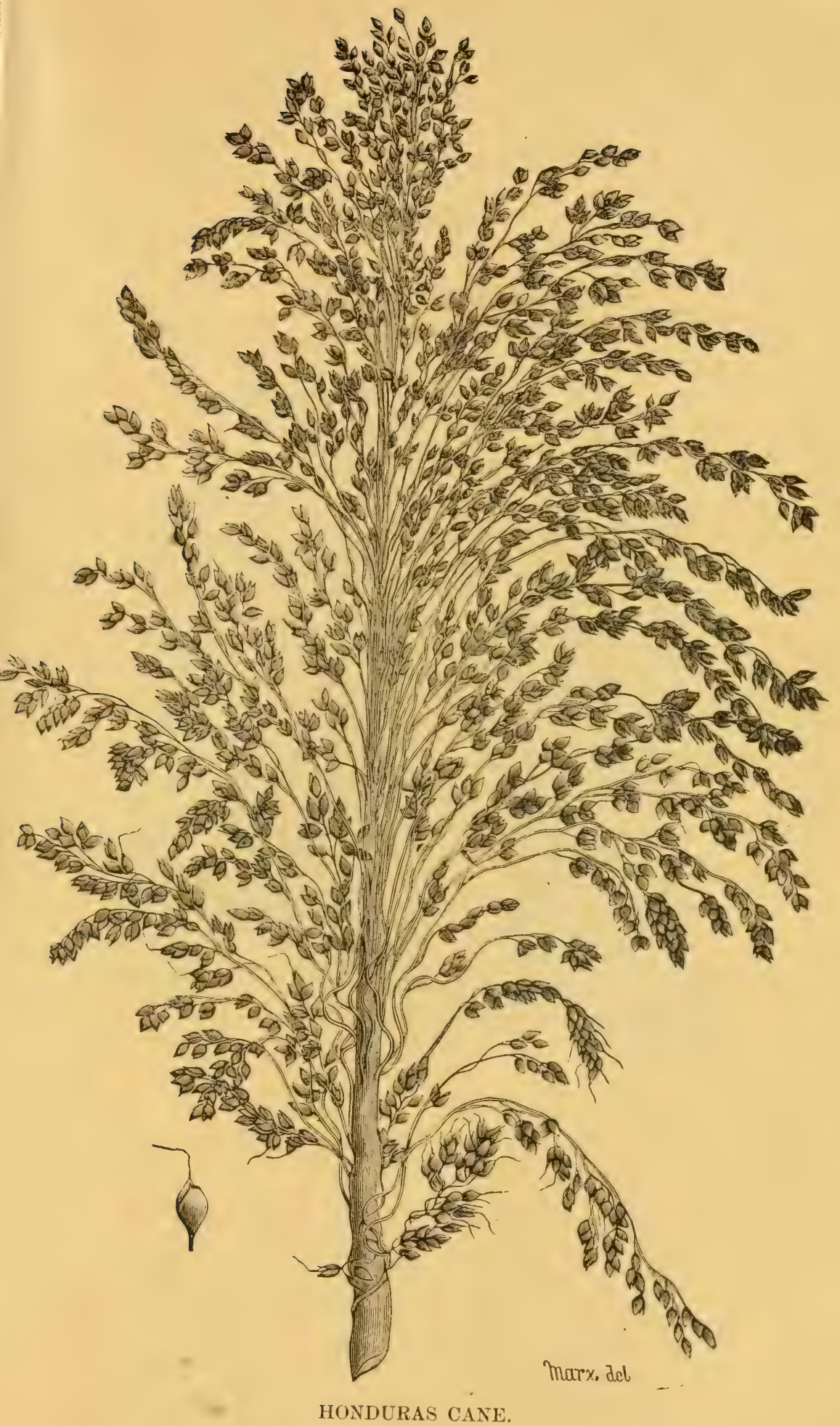

Syuonyms: Mastodox, Sprangle-top, Honey Cane.

[Grown on the Department grounds during the season of 1879.] 

Plate V

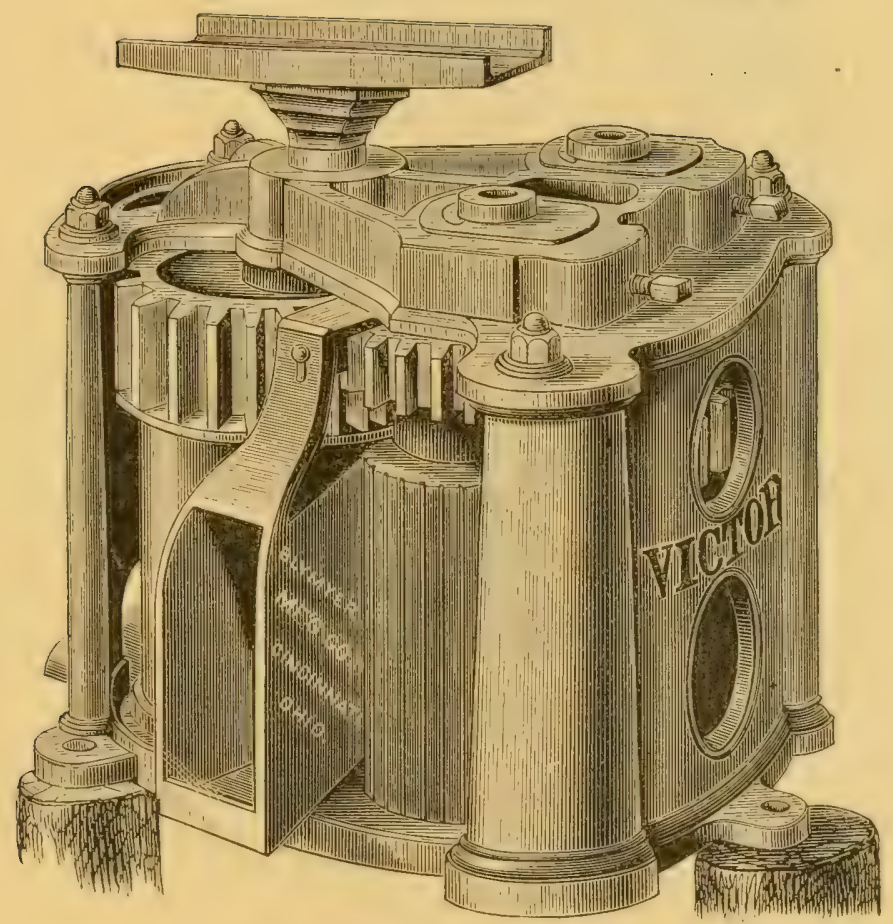

VICTOR CANE MILL (VER'TICAL). 

Plate VI.

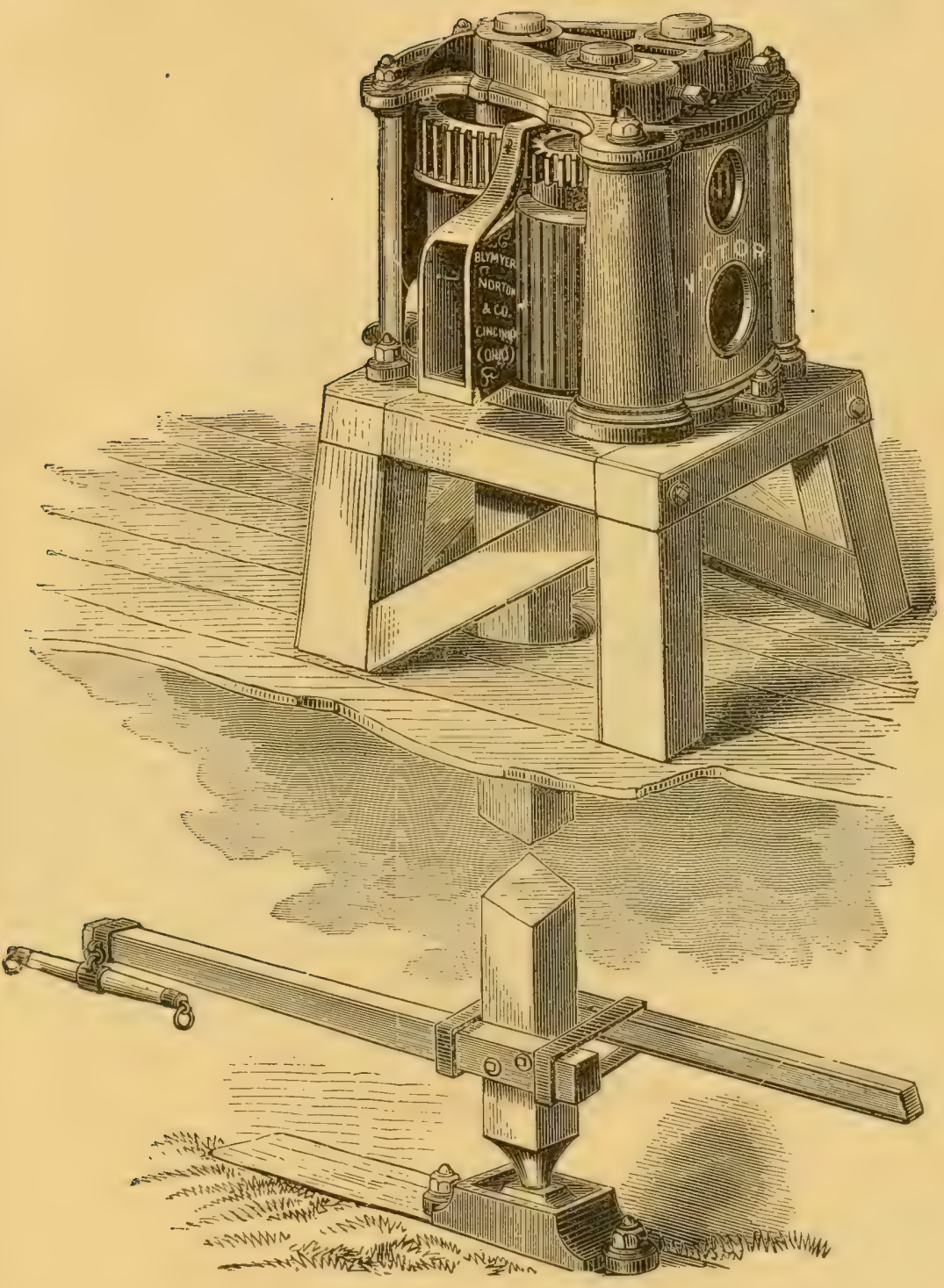

VERTICAL VICTOR MILL.

[With horse-power below.] 

Plate VII

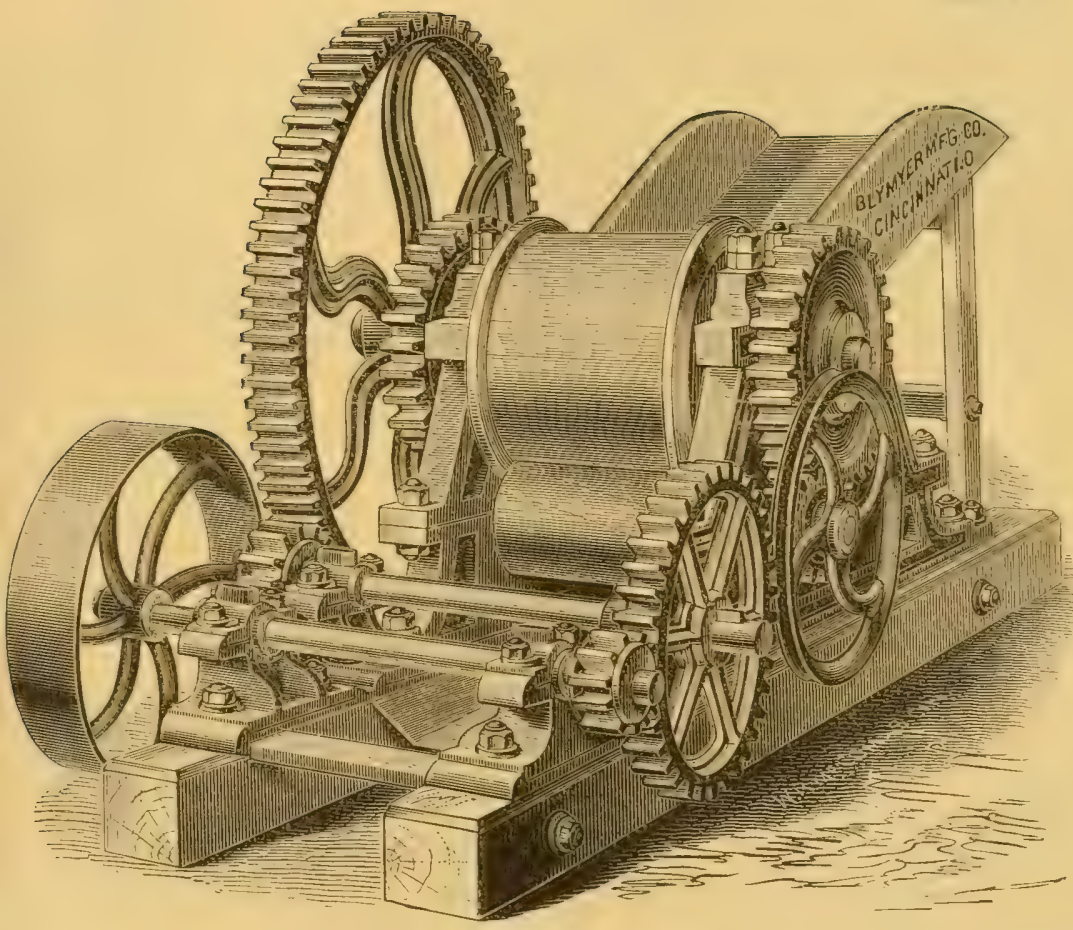

HORIZONTAL VICTOR MILL. 




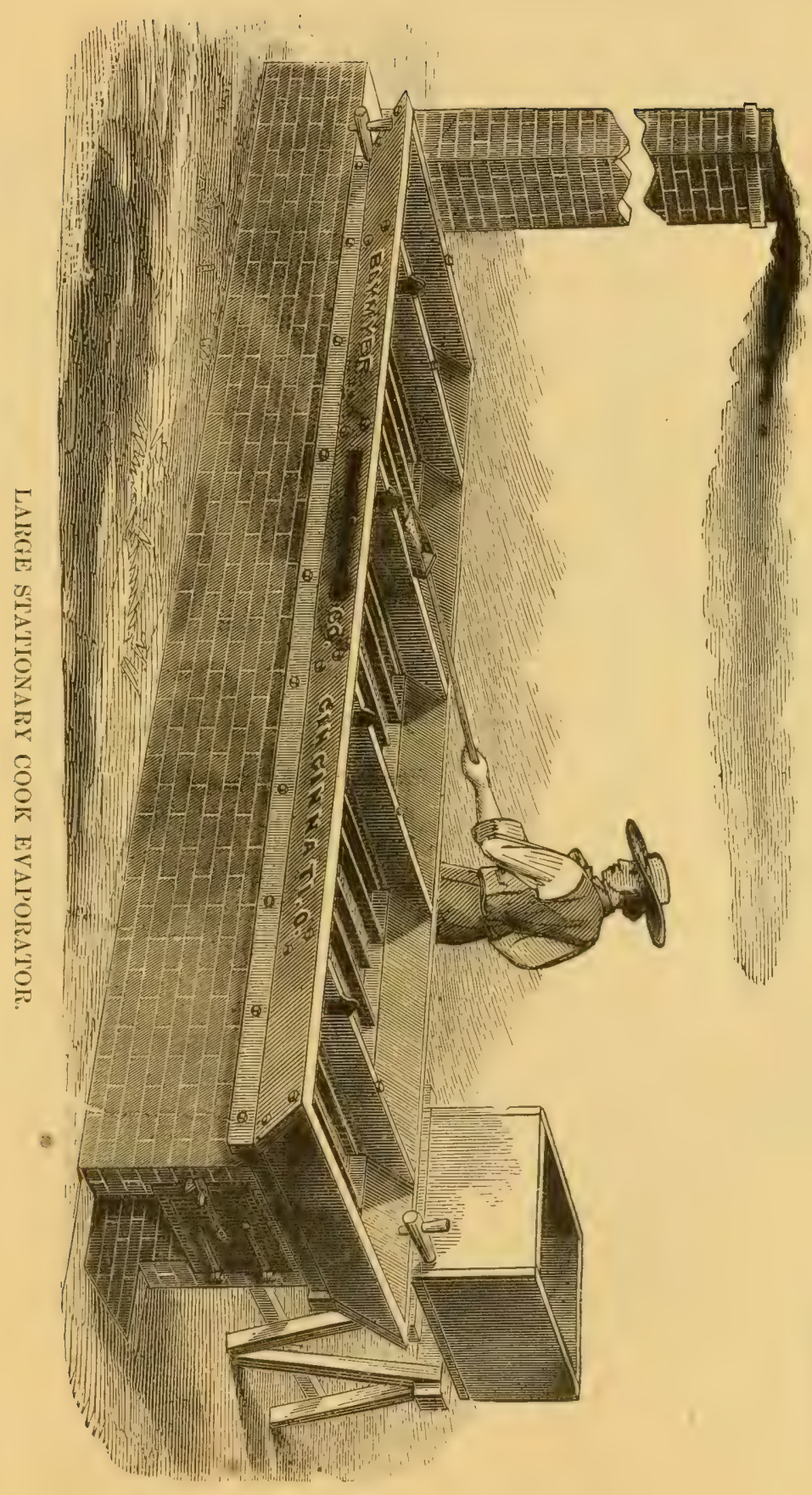

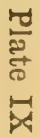





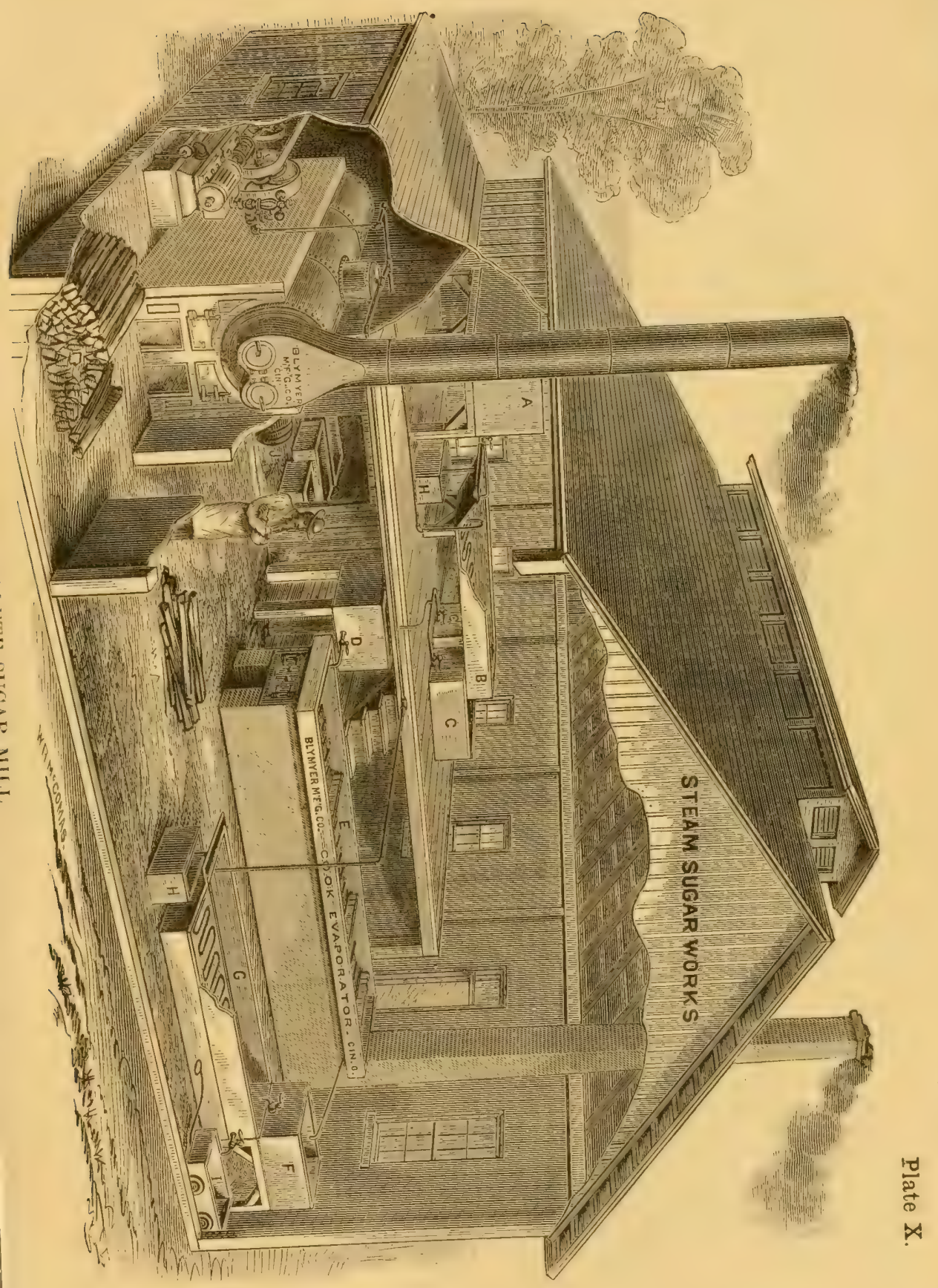



Plate X!.

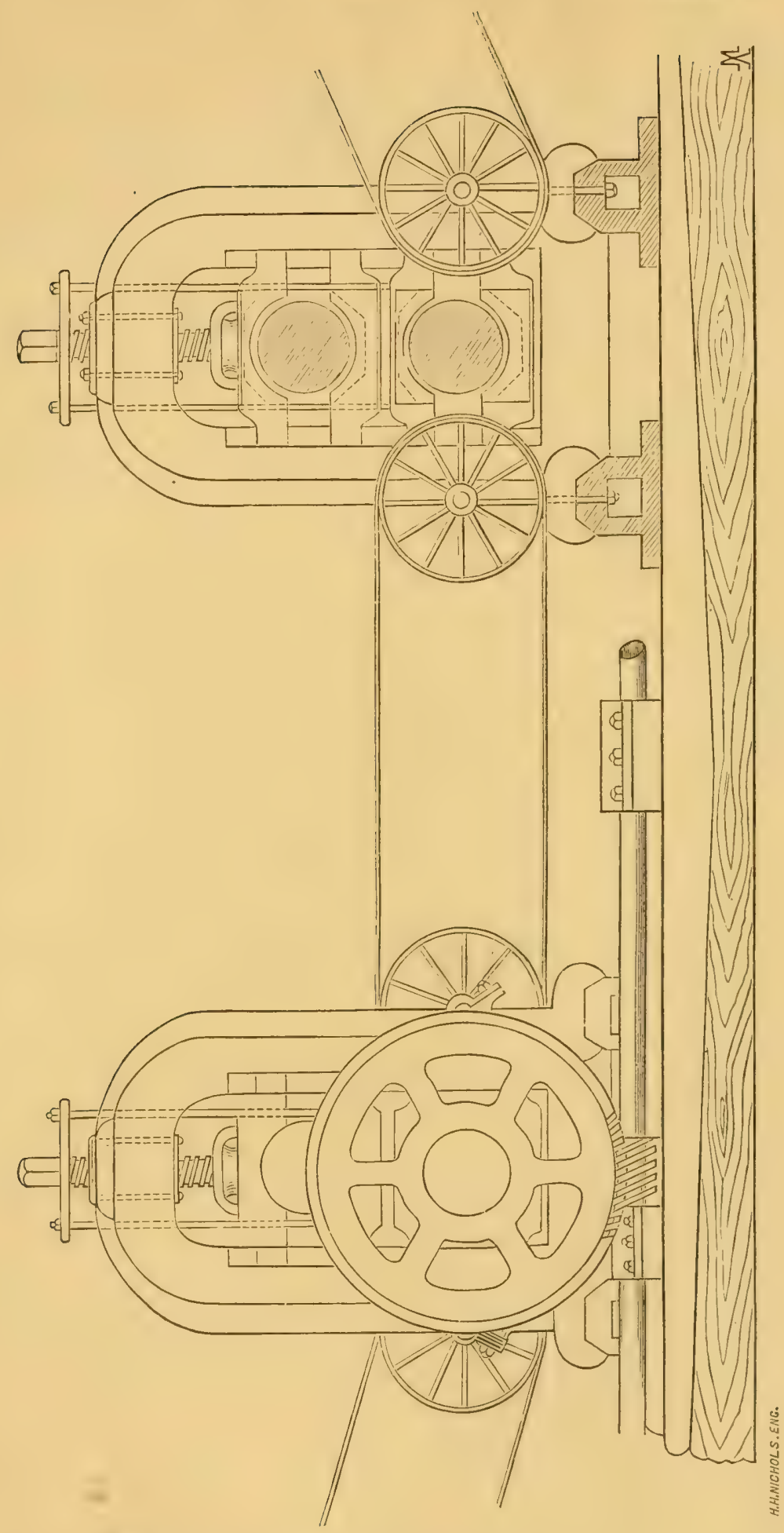

MCDOWELL'S S'TEAM PLANT GR TRAIN. 



\section{Plate XII.}

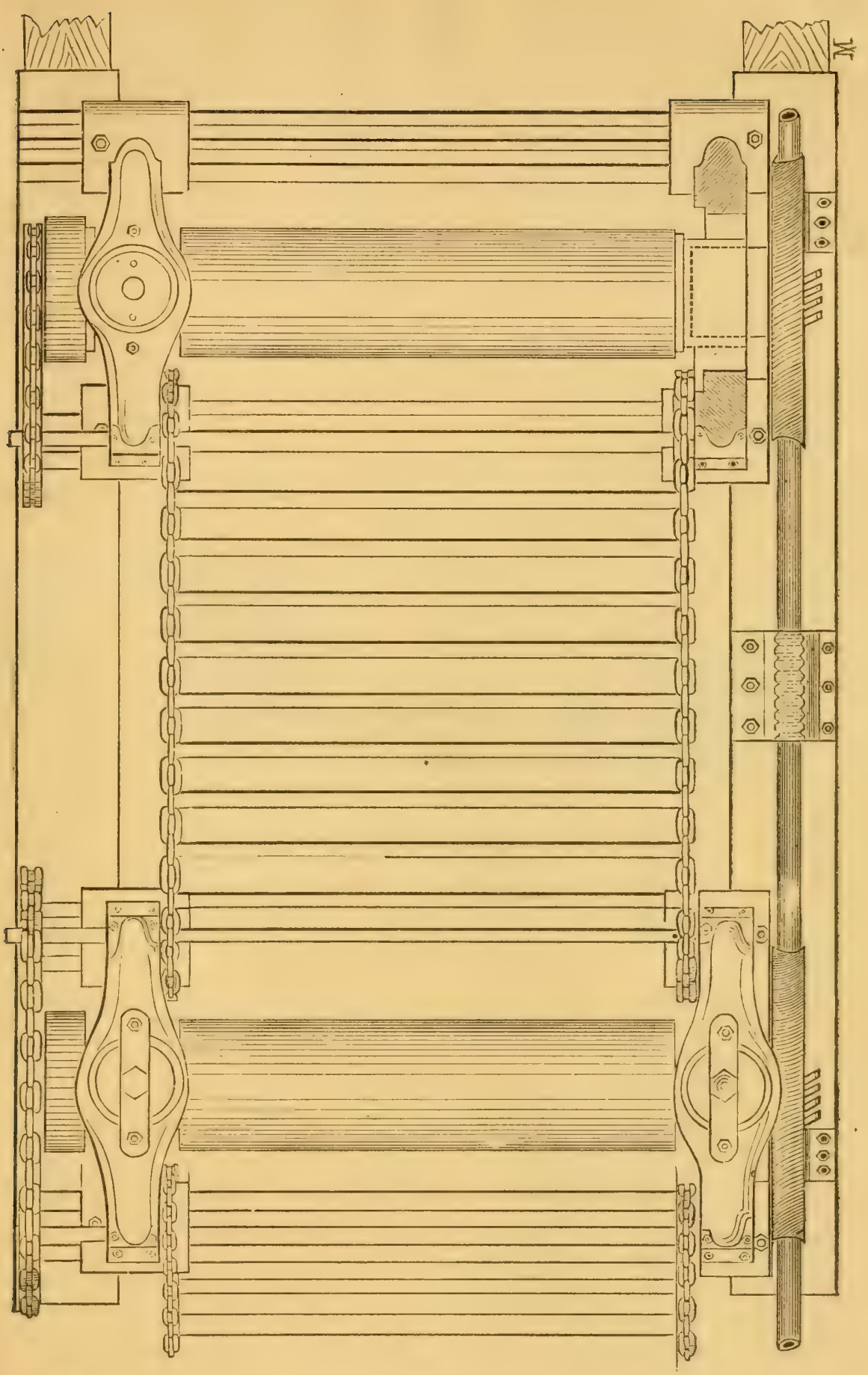

MCDOWELL'S S'TEAM PLANT OR TRAIN.

[Vertical view.] 

Plate XIII.

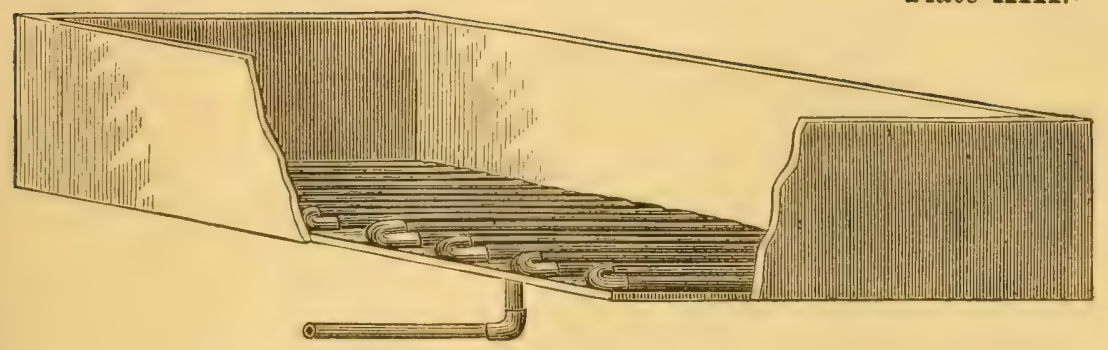

MCDOWELL'S DEFECATING TANK. 



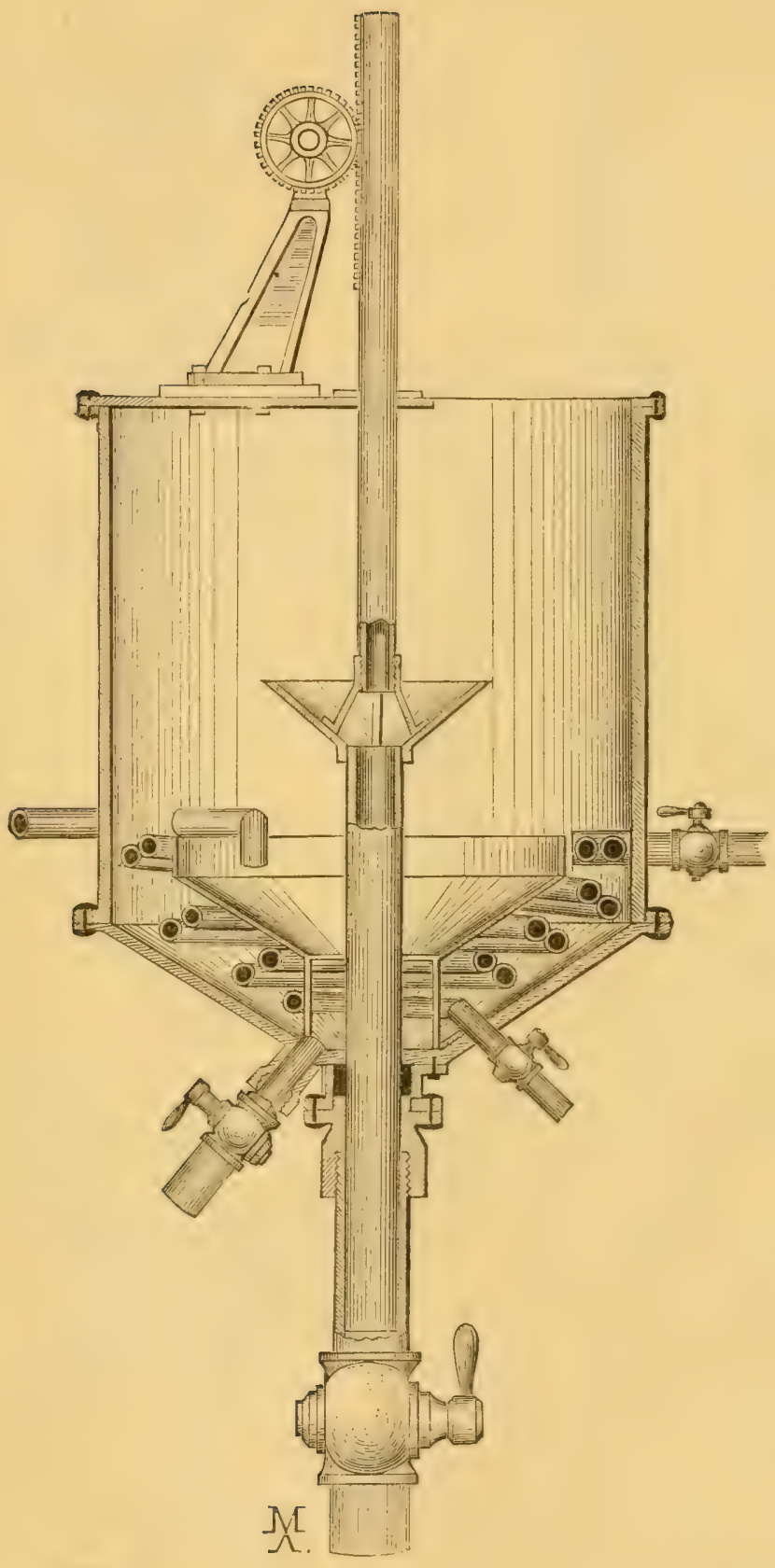

MCDOWELL'S EVAPORATOR. 

Plate XV.

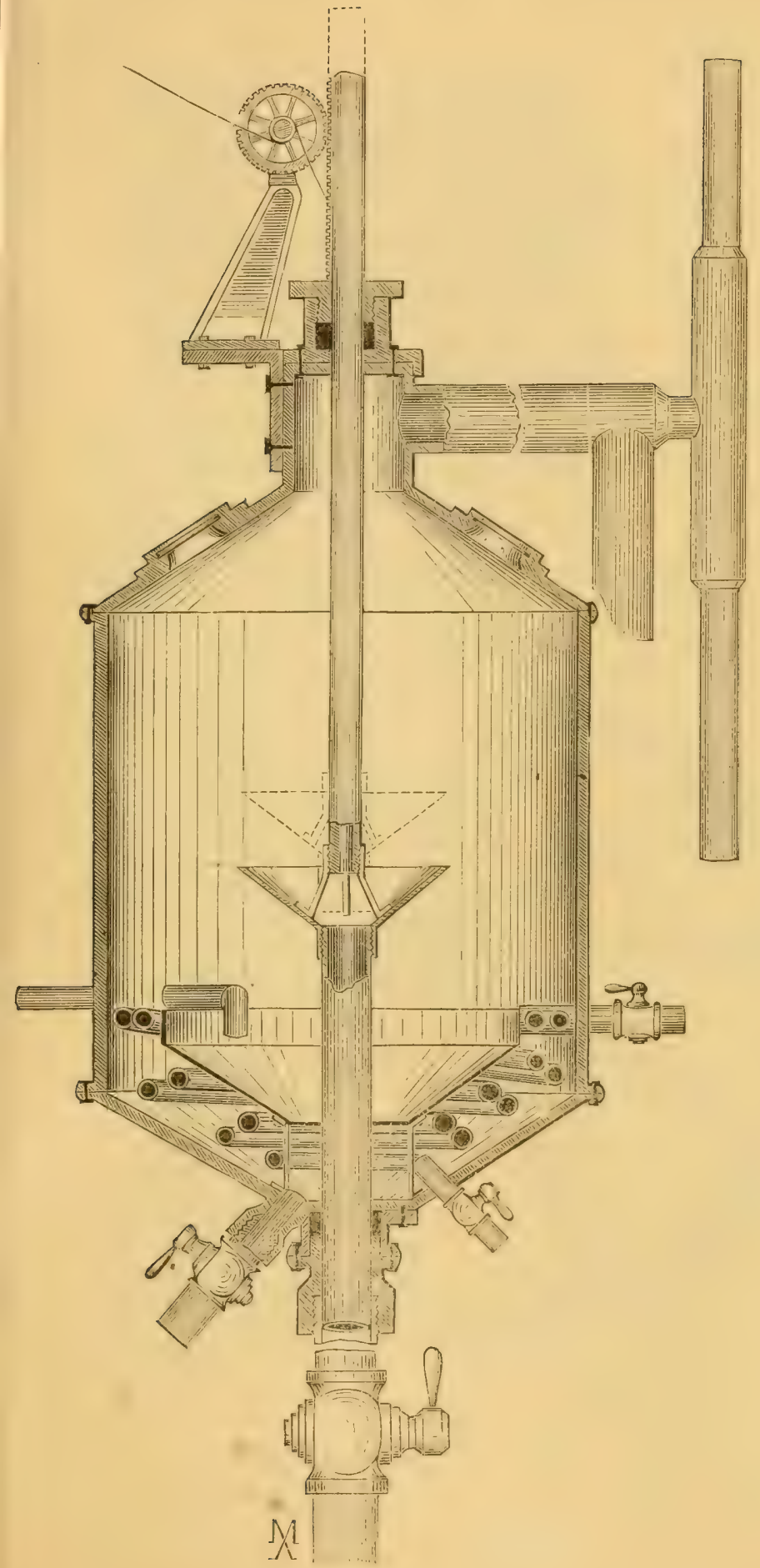

MCDOWELL'S CONCENTRA'TOR. 



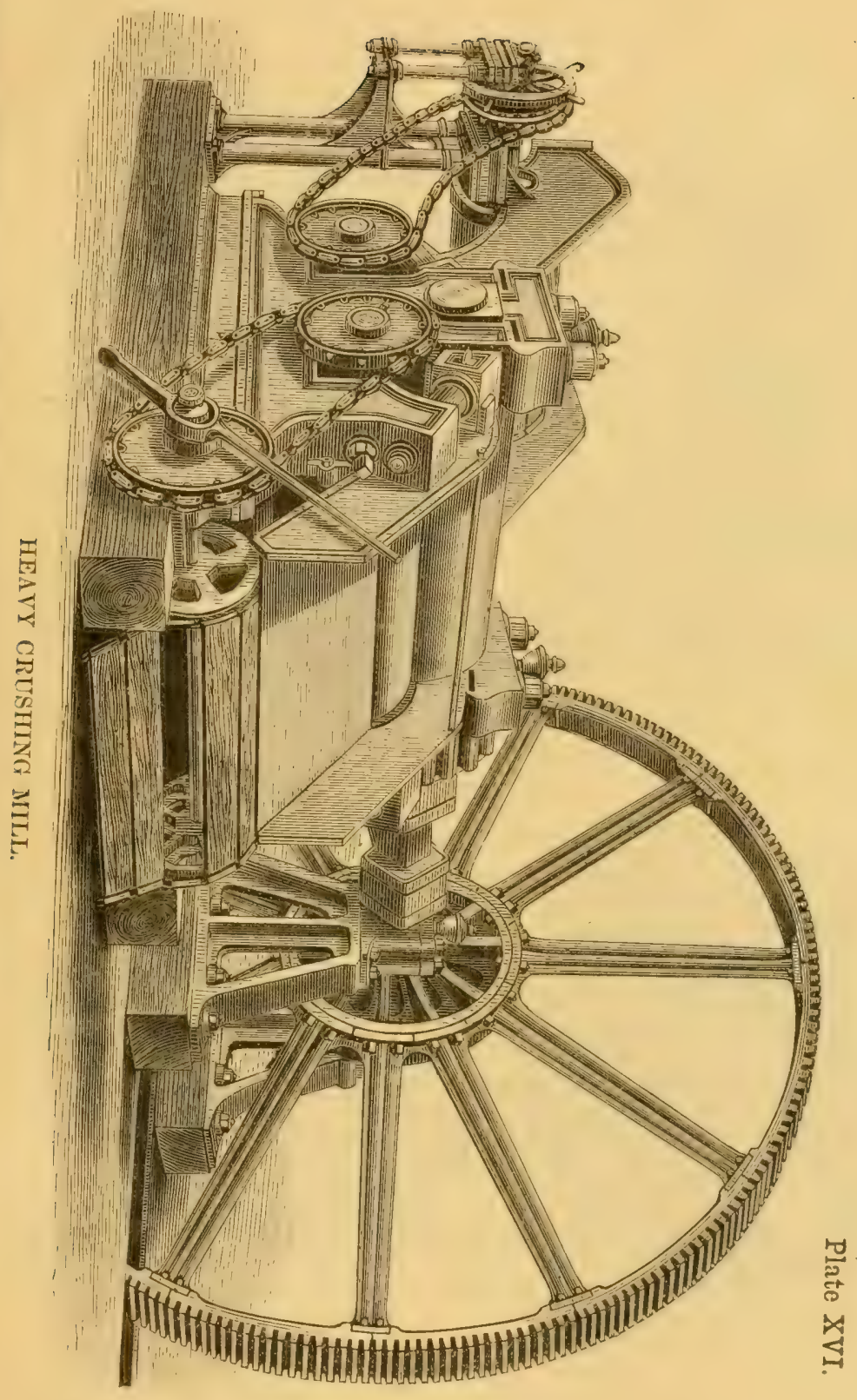



Plate XVII.
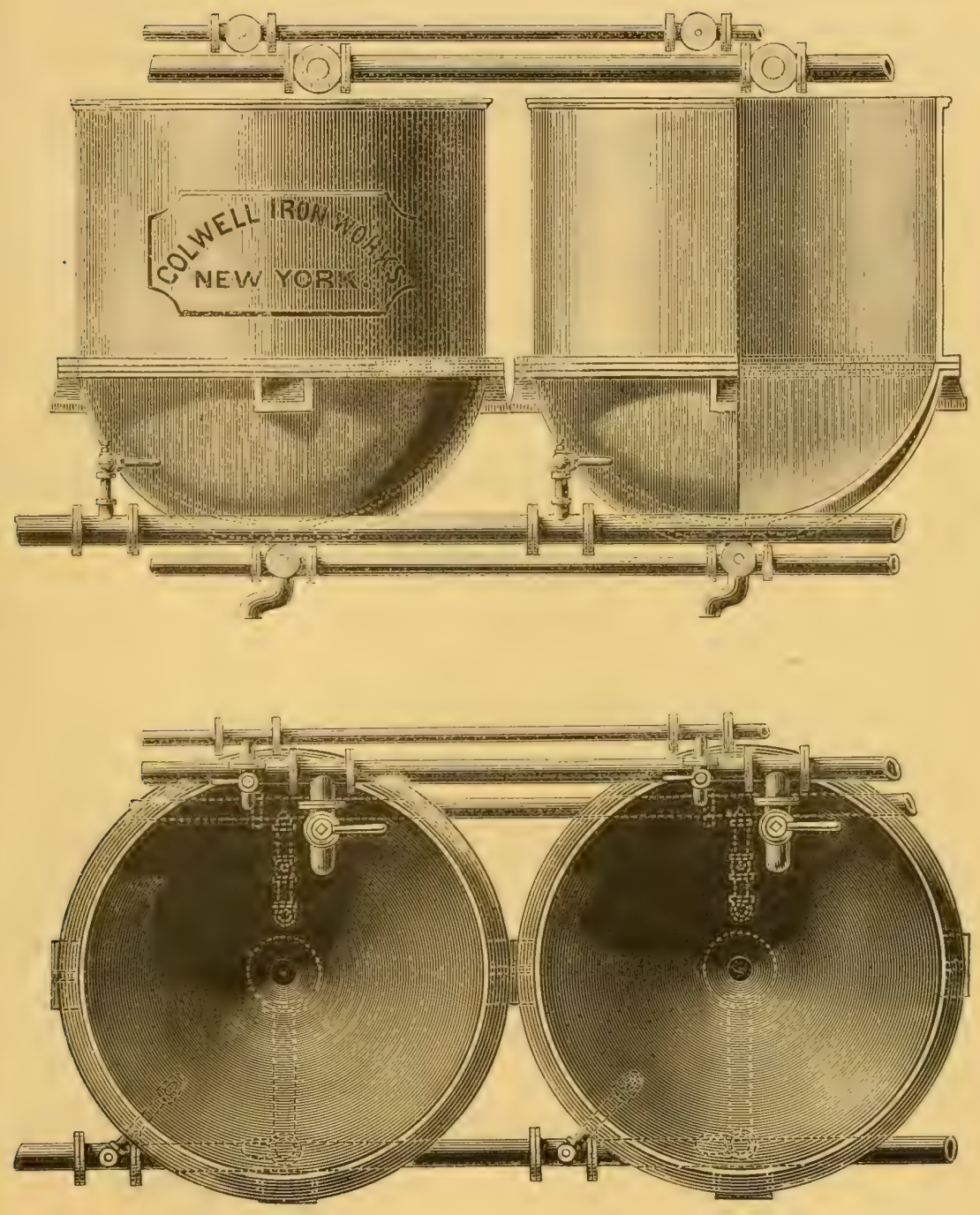

EXHALST STEAM CLAMPER. 




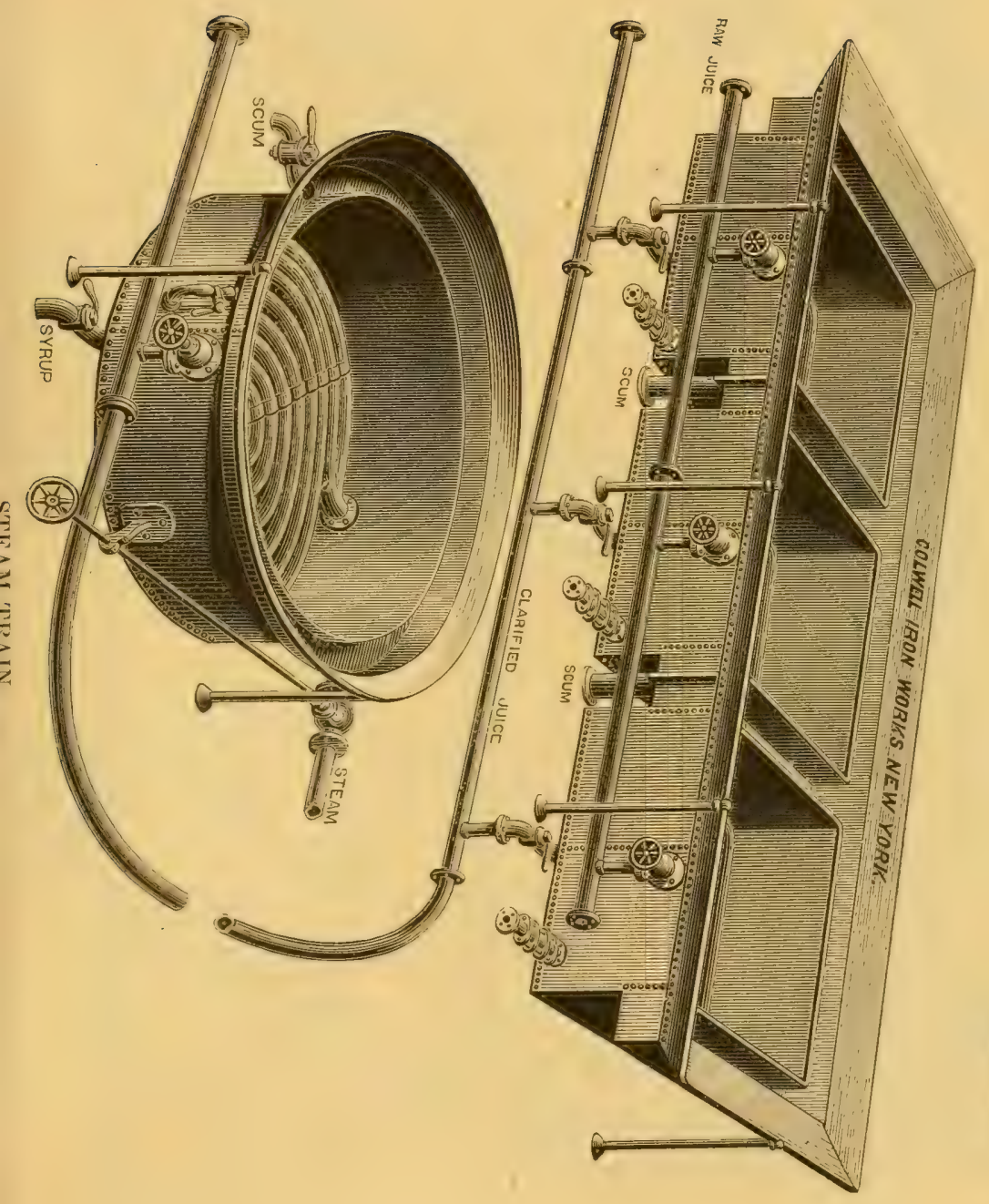

चु
है
त्र 



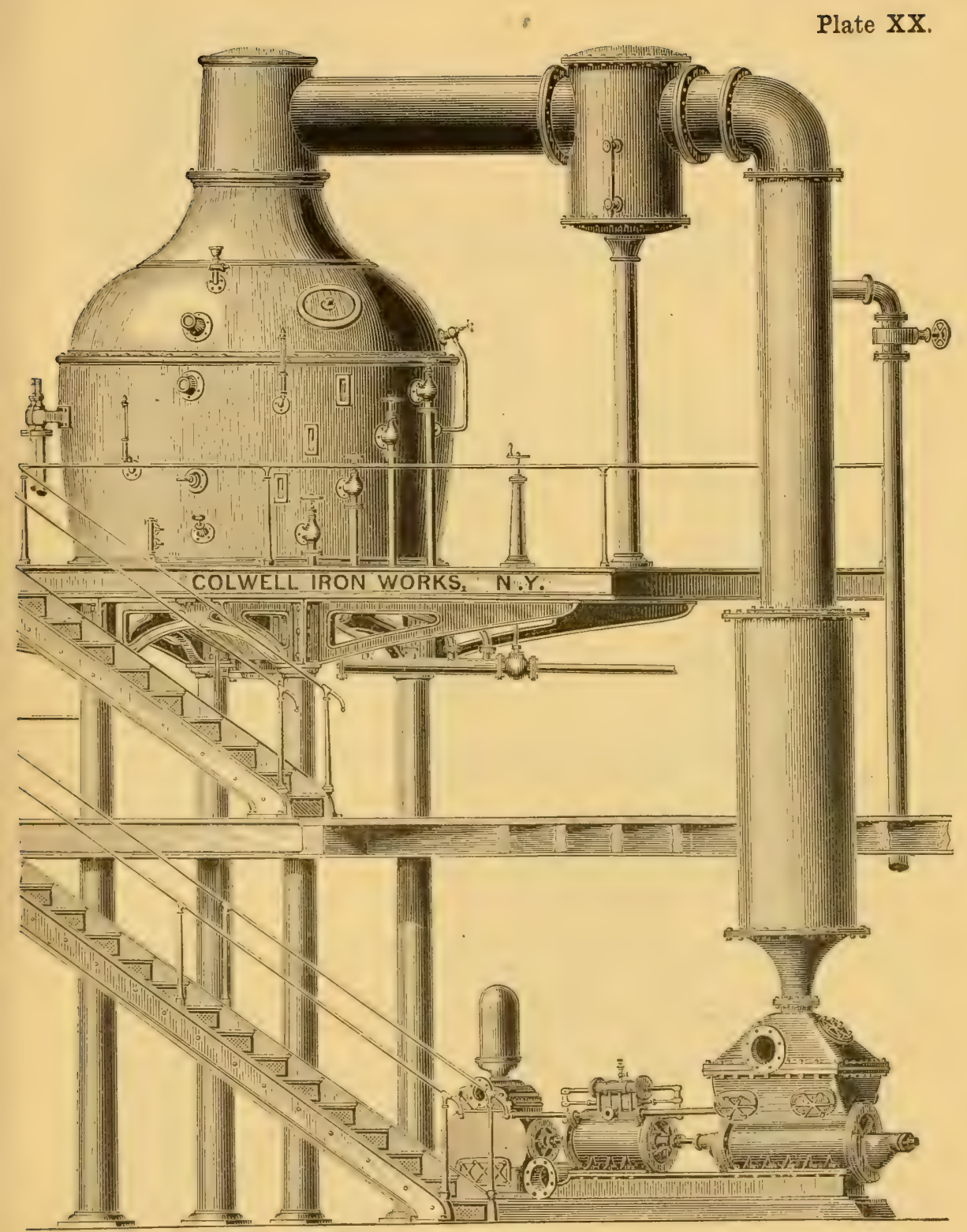

VACUUM PAX. 


Plate XXII.

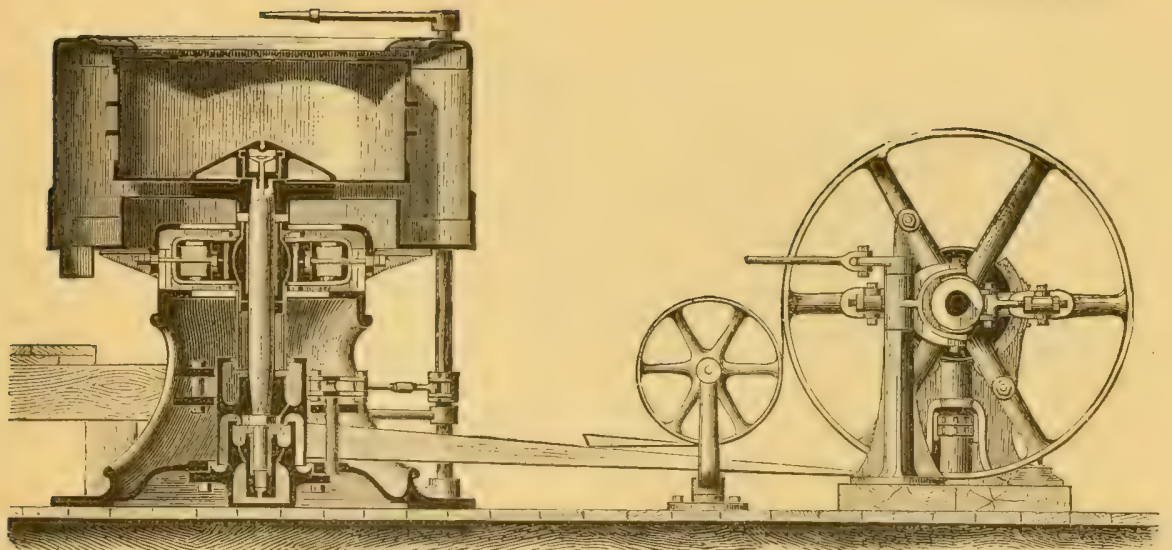

"MERMAN STYLE" CENTRIFUGAL. 



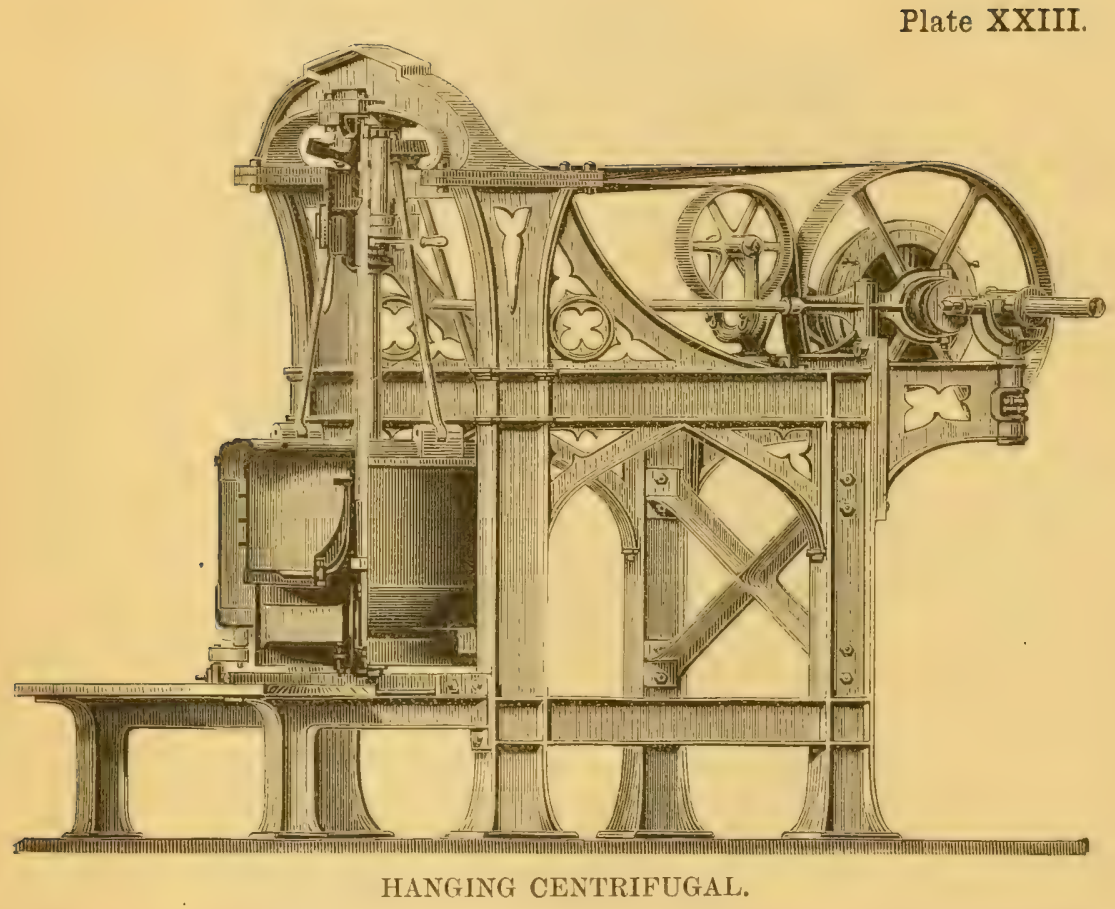





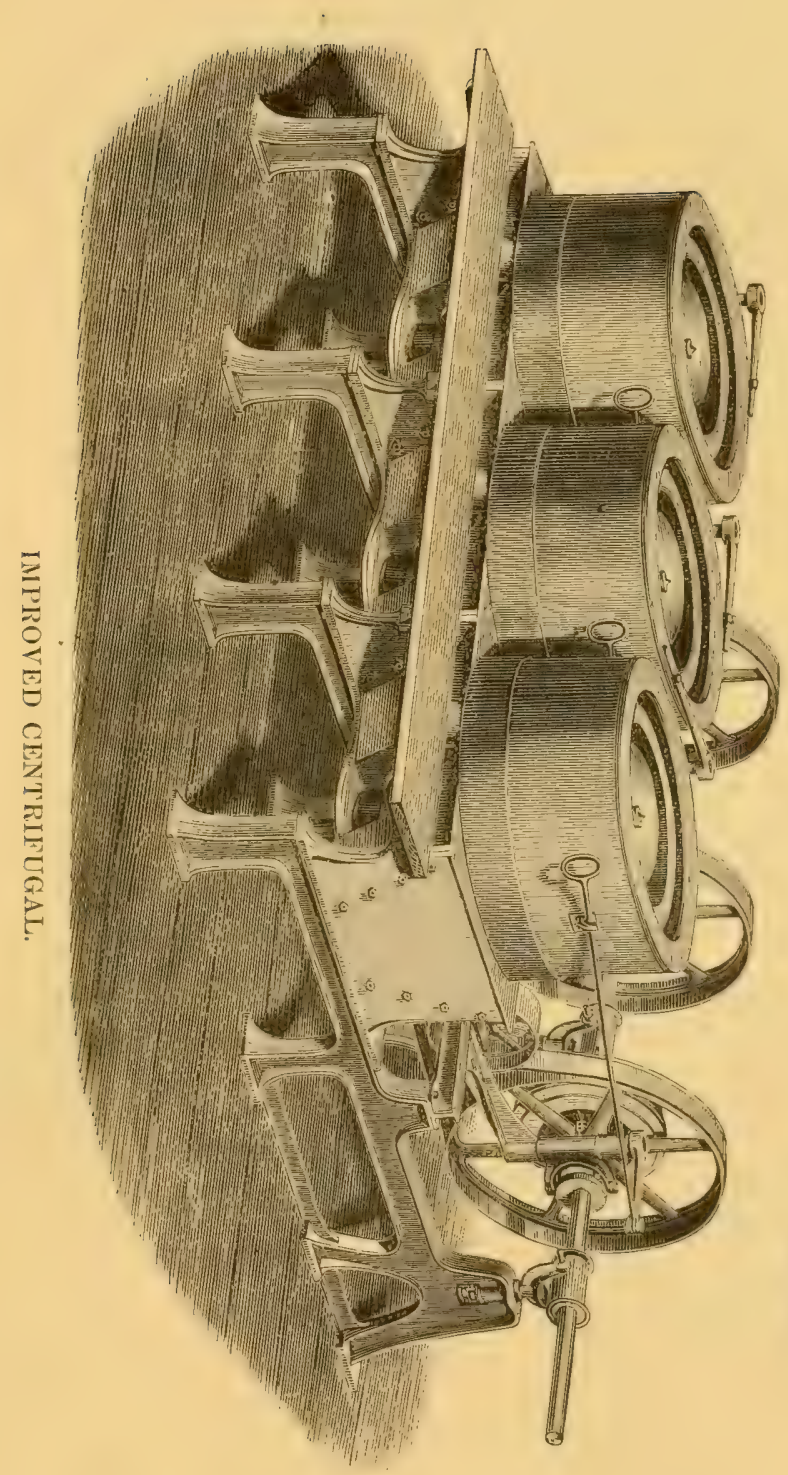

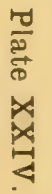





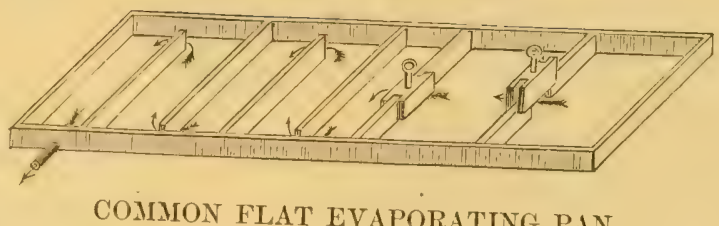

Wooden sides and partition.

Fig. 2.

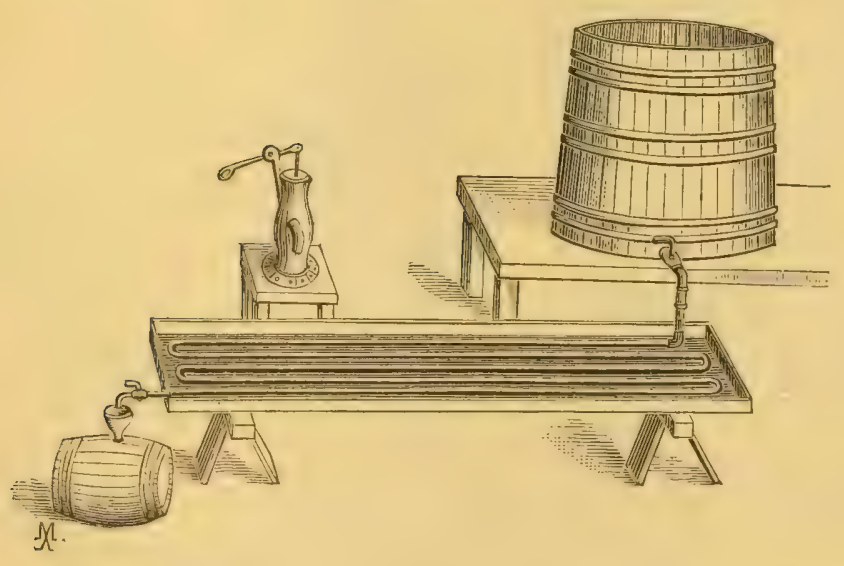

COOLING PAN.

The hot sirup passes through the iron pipe immersed in cold water. 



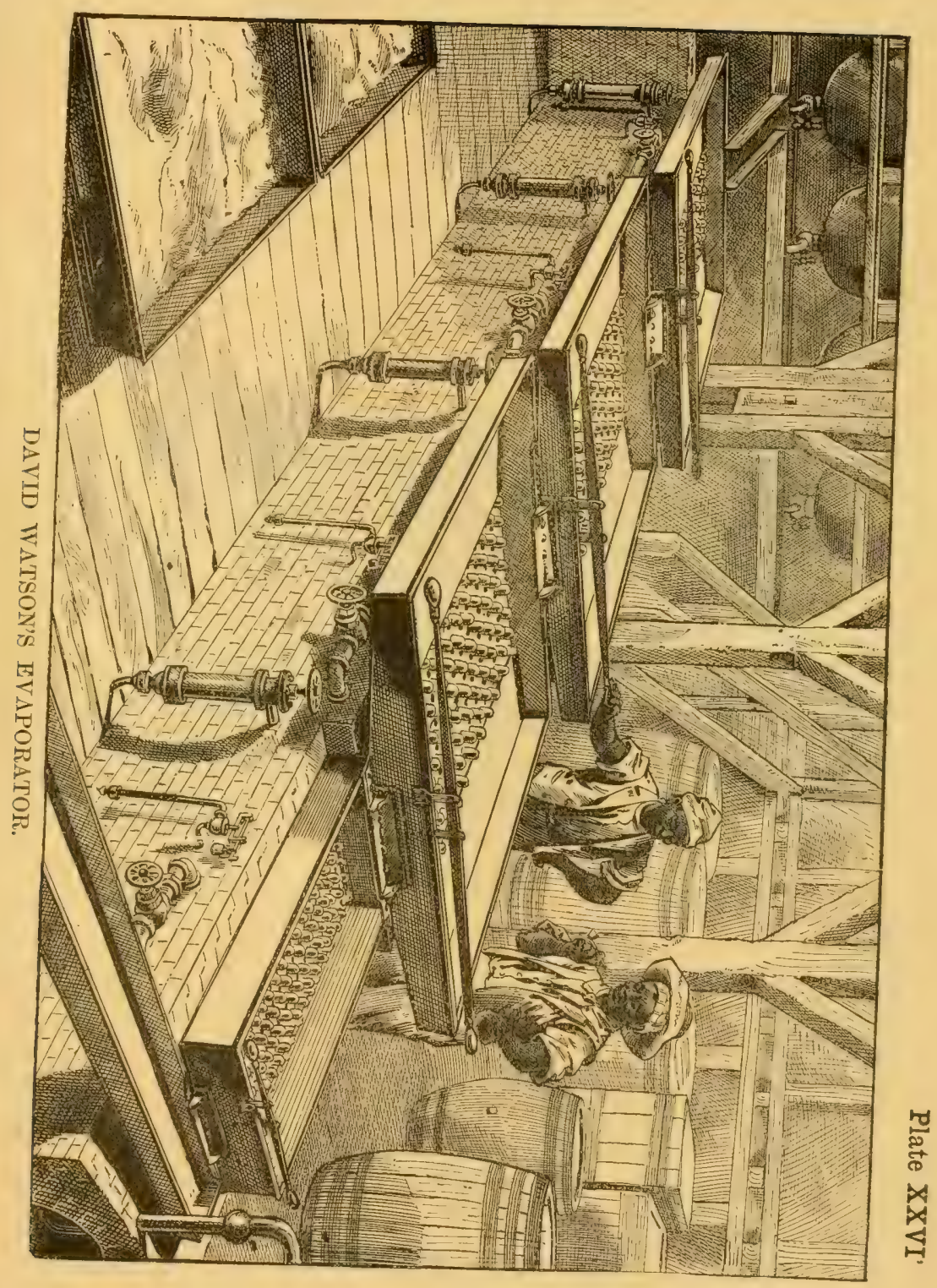





\section{Plate XXVII.}

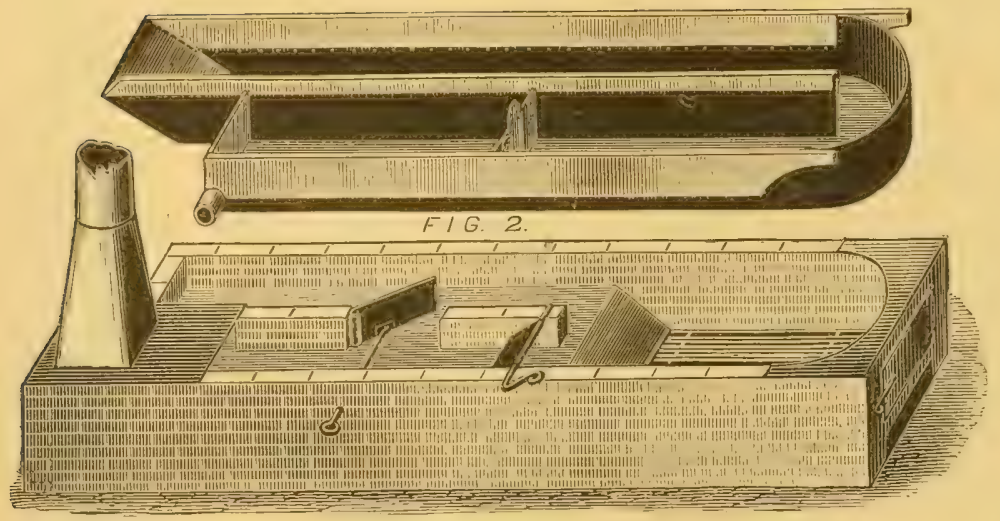

STUBB'S EVAPORATOR. 



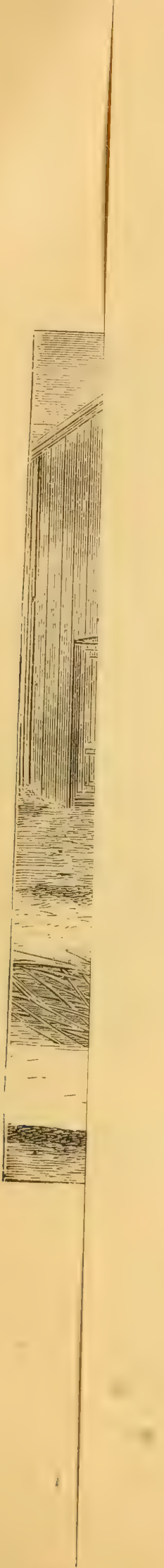





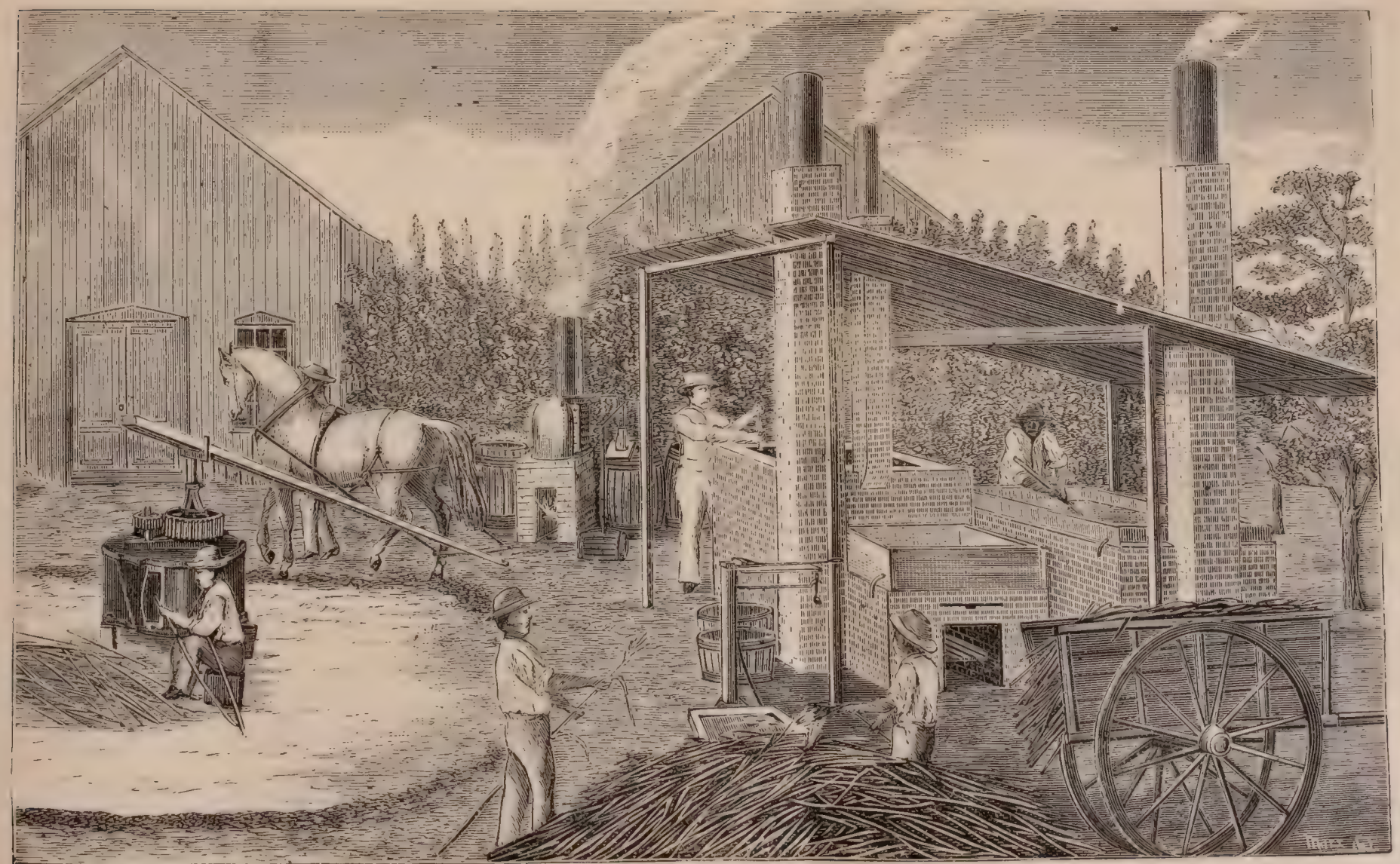

SIGAR MACHINERY OF THE DEPARTMENT OF AGRICULTURL:

[Unitel States Sugar Mill. Experiments for two years on grounds of Department of Agriculture. Description in the Chemist's Iecport.] 

PlateXXIX.

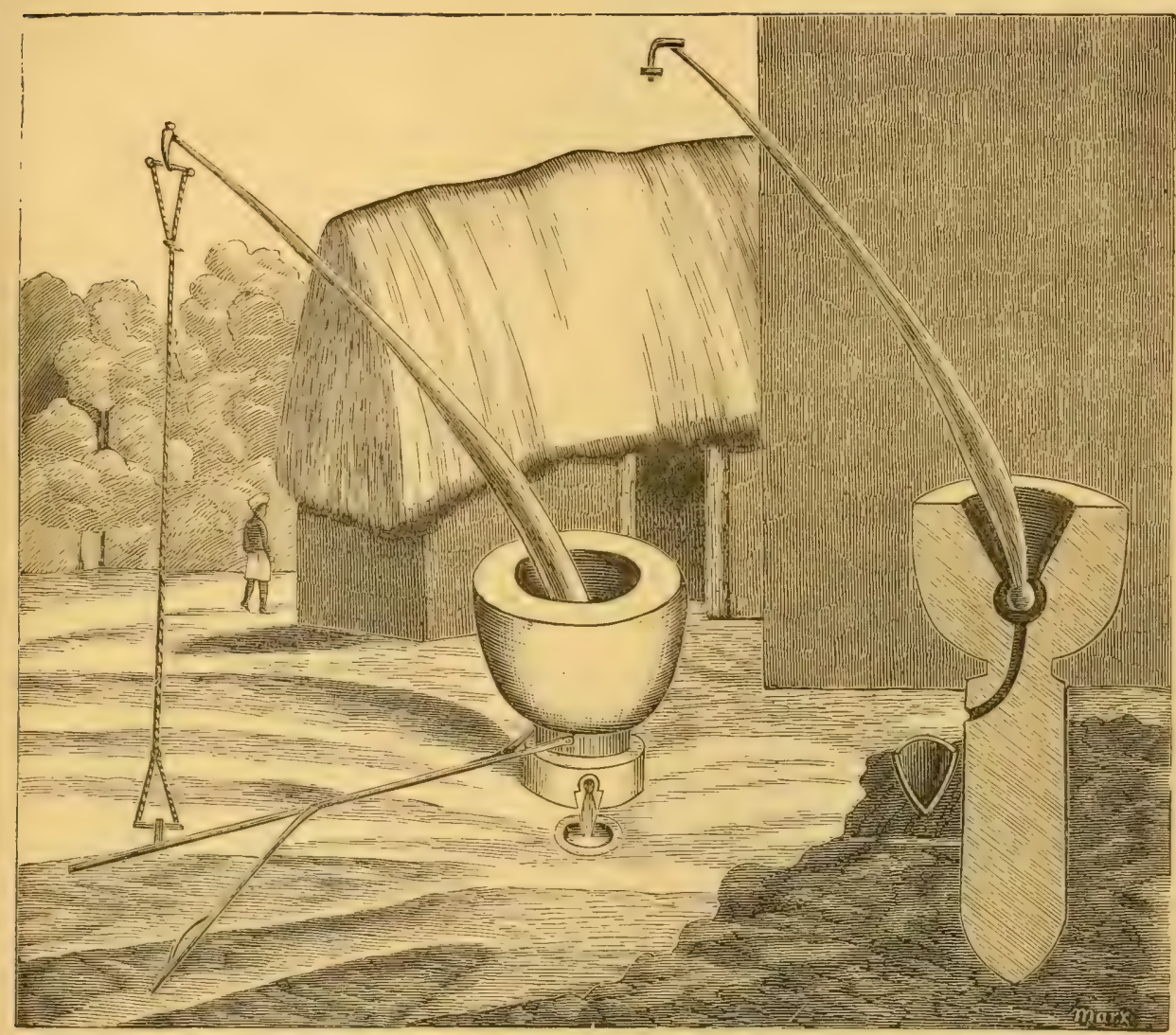

SUGAR MILL IN HINDOOSTAN IN 1800. 



\section{Plate XXX.}

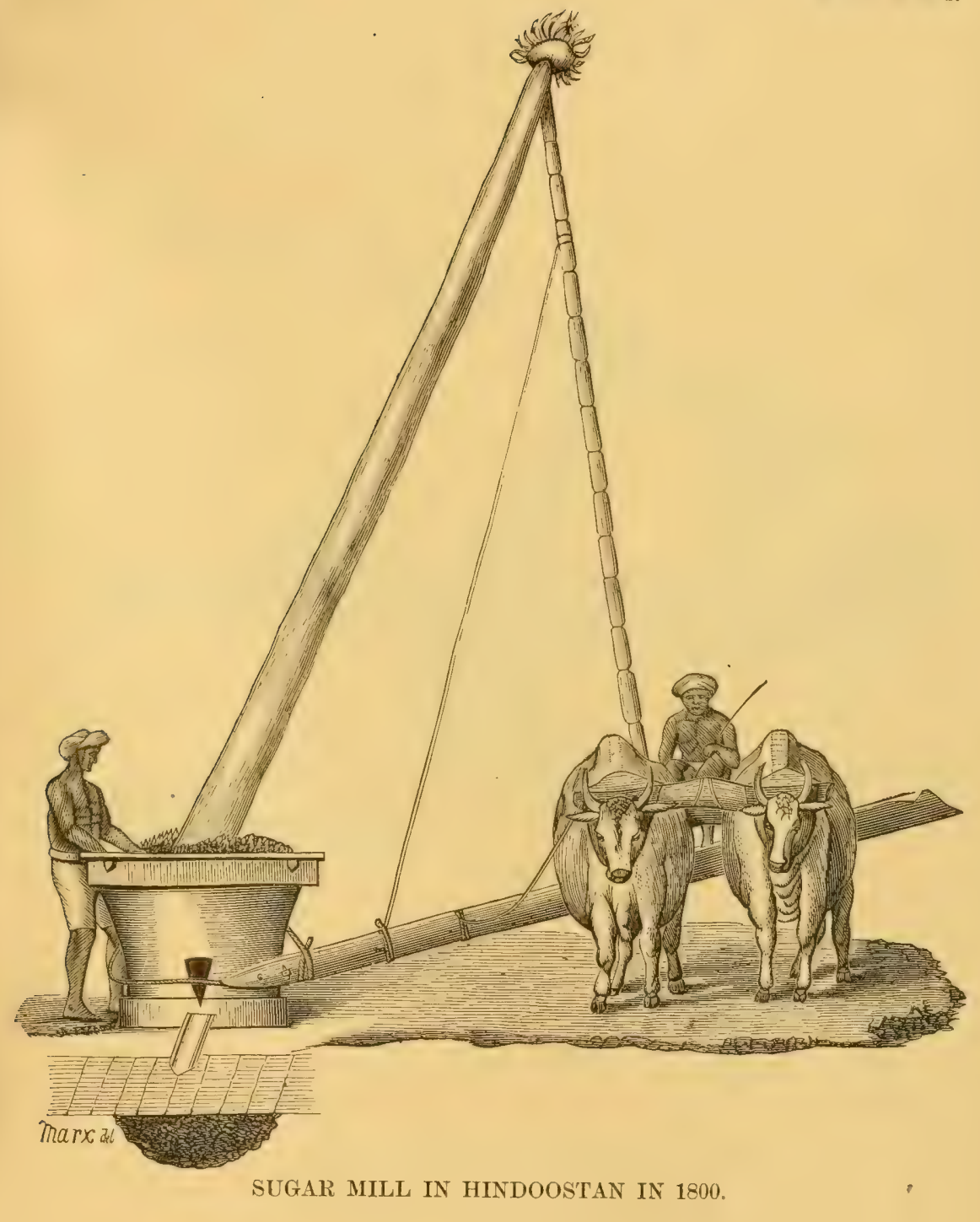





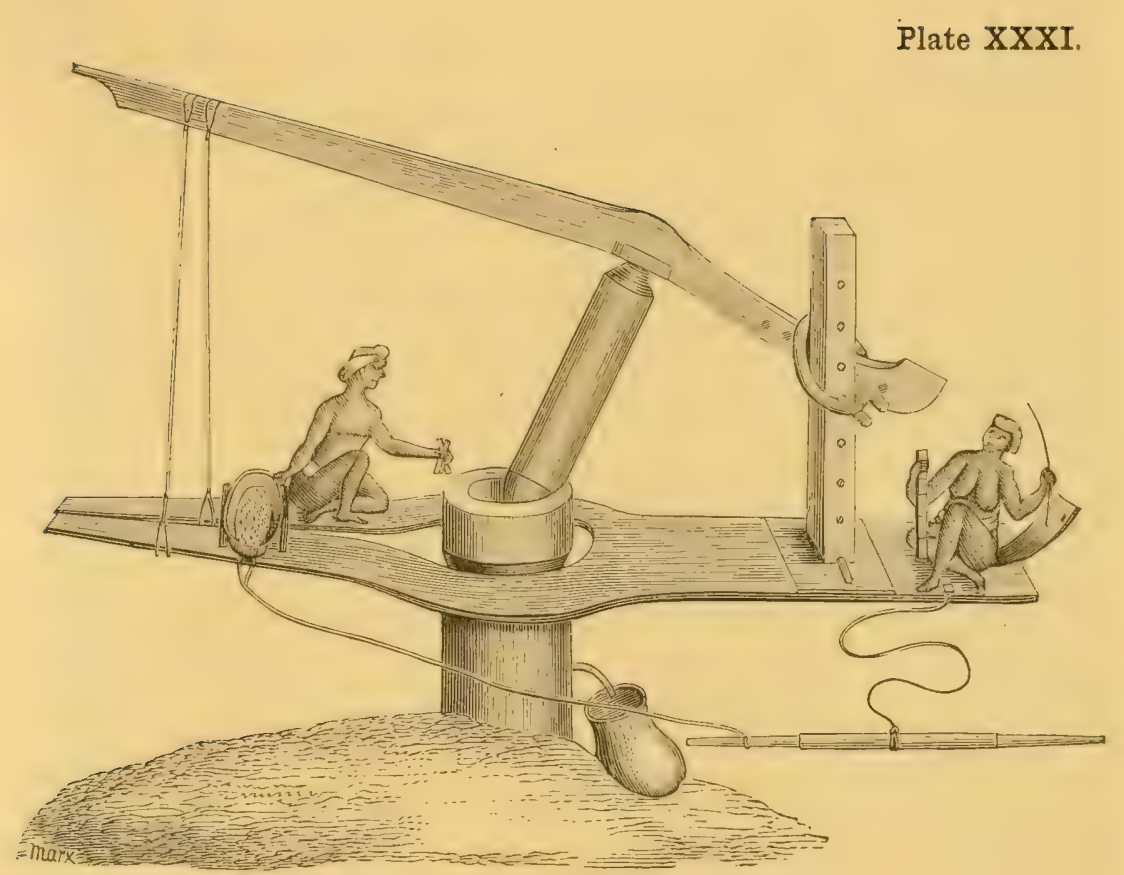

SUGAR MILL IN HINDOOSTAN IN 1800 . 



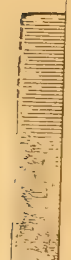

$=$ 



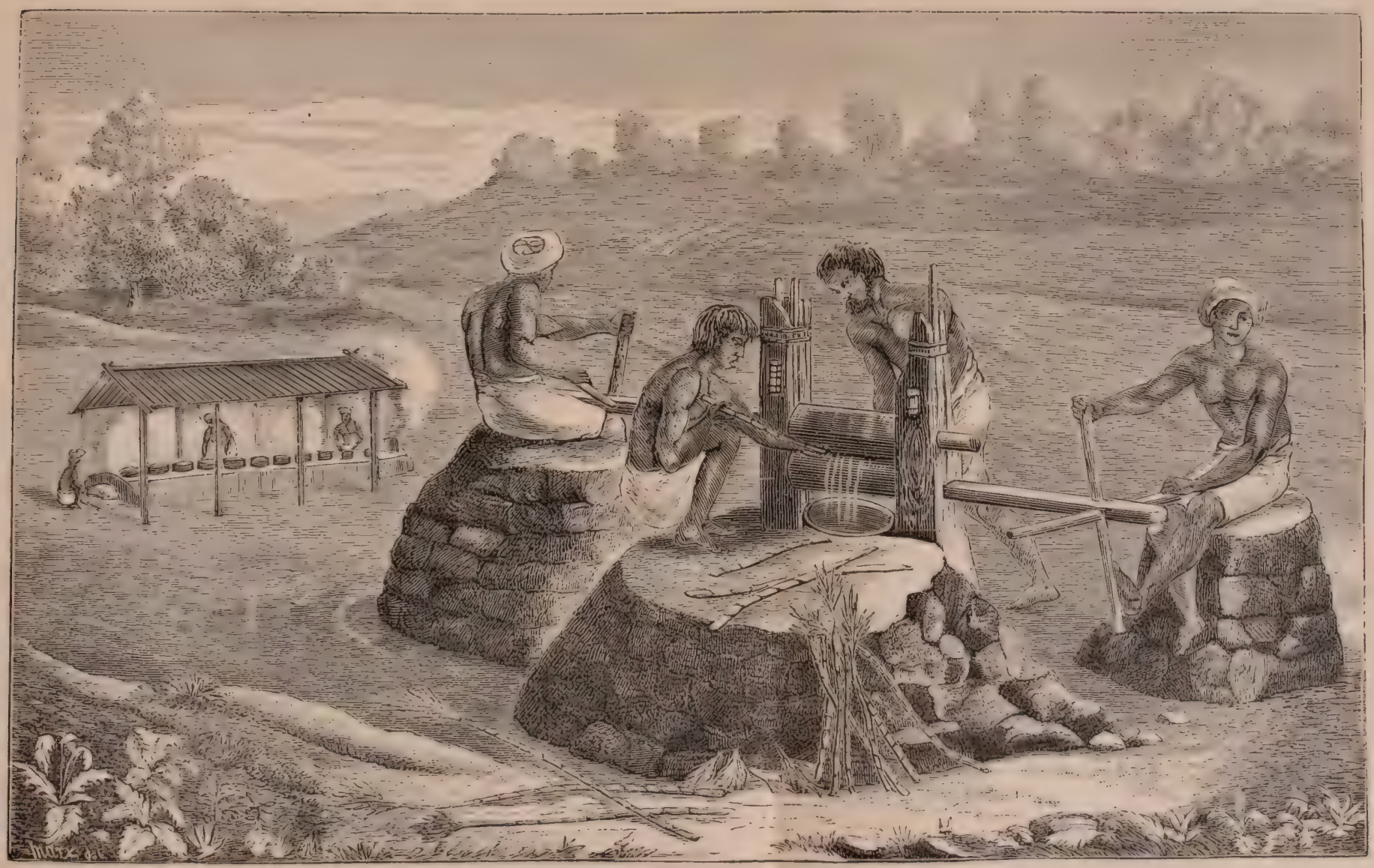




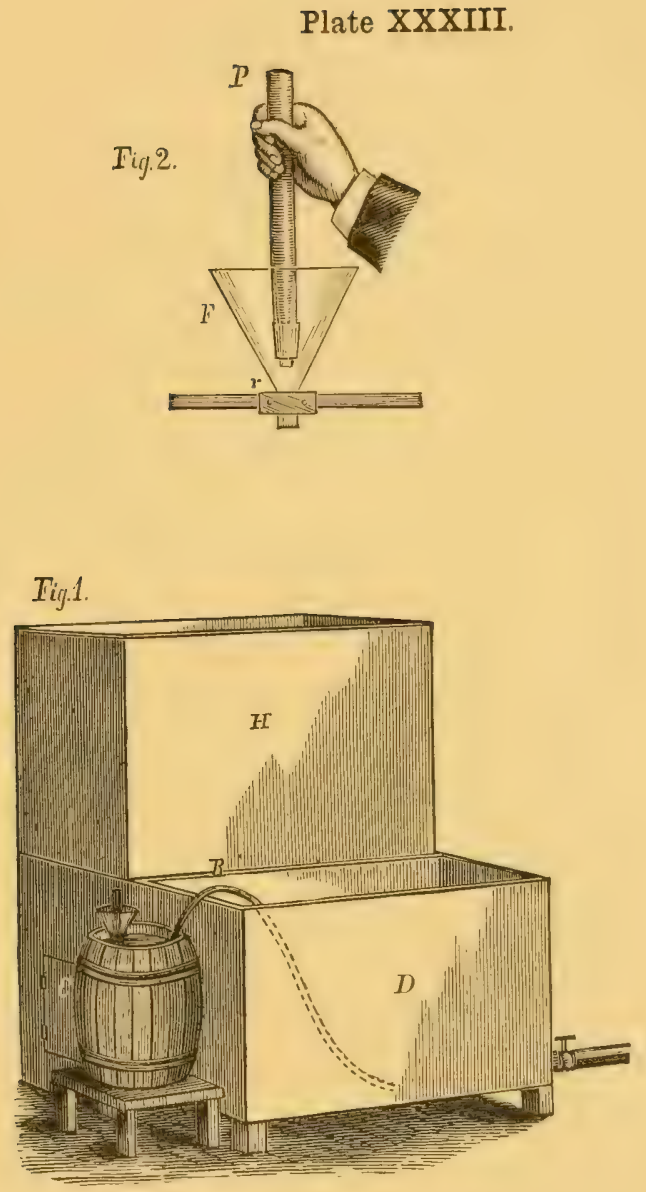

MACHINERY USED IN STEWAR'T'S PROCESS. 





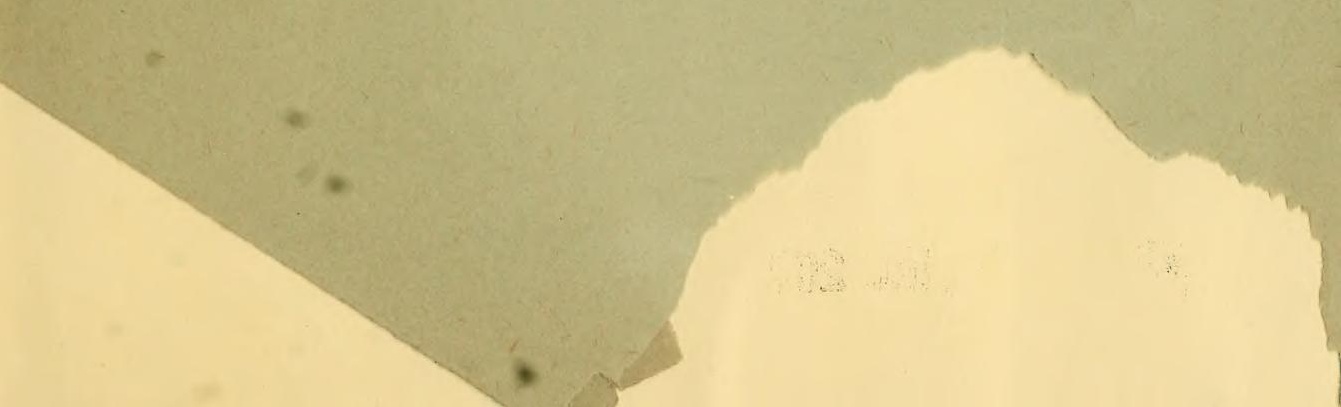




\section{LIBRARY OF CONGRESS}

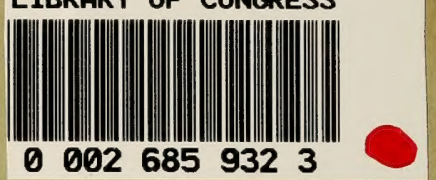

